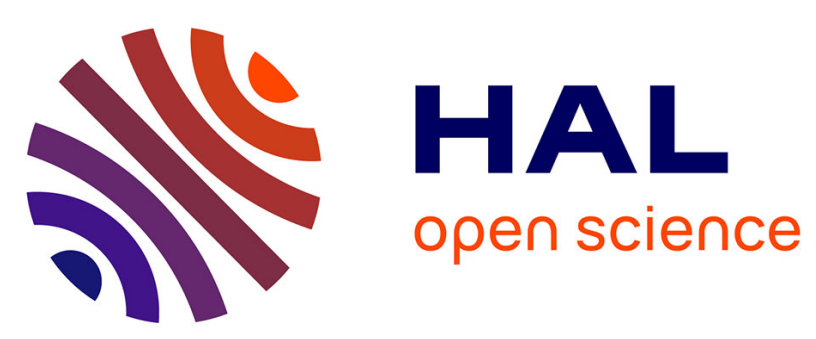

\title{
Room Temperature Self- and H 2 -Broadened Line Parameters of Carbon Monoxide in the First Overtone Band: Theoretical and Revised Experimental Results
} Koorosh Esteki, Adriana Predoi-Cross, Chad Povey, Sergey Ivanov, Aziz Ghoufi, Franck Thibault, Mary Ann H. Smith

\section{To cite this version:}

Koorosh Esteki, Adriana Predoi-Cross, Chad Povey, Sergey Ivanov, Aziz Ghoufi, et al.. Room Temperature Self- and H 2 -Broadened Line Parameters of Carbon Monoxide in the First Overtone Band: Theoretical and Revised Experimental Results. Journal of Quantitative Spectroscopy and Radiative Transfer, 2017, 203, pp.309-324. 10.1016/j.jqsrt.2017.04.008 . hal-01533342

\section{HAL Id: hal-01533342 \\ https://hal.science/hal-01533342}

Submitted on 7 Jun 2018

HAL is a multi-disciplinary open access archive for the deposit and dissemination of scientific research documents, whether they are published or not. The documents may come from teaching and research institutions in France or abroad, or from public or private research centers.
L'archive ouverte pluridisciplinaire $\mathbf{H A L}$, est destinée au dépôt et à la diffusion de documents scientifiques de niveau recherche, publiés ou non, émanant des établissements d'enseignement et de recherche français ou étrangers, des laboratoires publics ou privés. 


\title{
Room Temperature Self- and $\mathrm{H}_{2}$-Broadened Line Parameters of Carbon Monoxide in the First Overtone Band: Theoretical and Revised Experimental Results
}

\author{
Koorosh Esteki ${ }^{1,2}$, Adriana Predoi-Cross ${ }^{1^{*}}$, Chad Povey ${ }^{1}$, Sergey Ivanov $^{3}$, Aziz Ghoufi , \\ Franck Thibault ${ }^{4}$, Mary Ann H. Smith ${ }^{5}$ \\ 1 \\ Department of Physics and Astronomy, University of Lethbridge, Lethbridge, AB, Canada \\ 2 \\ Present address: Mechanical and Manufacturing Engineering, Schulich School of Engineering, \\ University of Calgary, Calgary, AB, Canada \\ 3 Federal Scientific Research Centre "Crystallography and Photonics" of Russian Academy of \\ Sciences (FSRC “Crystallography and Photonics” RAS), Leninsky pr. 59, Moscow, 119333, \\ Russia \\ Institut de Physique de Rennes, UMR CNRS 6251, Université de Rennes 1, Campus de \\ Beaulieu, F-35042 Rennes, France \\ 5 \\ Science Directorate, NASA Langley Research Center, Hampton, VA, USA
}

*Corresponding author. Department of Physics and Astronomy, University of Lethbridge, Lethbridge, AB, T1K 3M4 Canada, Tel: 403-329-2697 Fax: 403-329-2057, E-mail:

adriana.predoicross@uleth.ca

\begin{abstract}
Lorentz self- and $\mathrm{H}_{2}$-broadened half-width and pressure-induced shift coefficients, line mixing coefficients as well as line center positions and intensities were obtained using a nonlinear least square fitting technique for $48(\mathrm{P}(24)$ to $\mathrm{R}(23))$ ro-vibrational transitions belonging to the first overtone $(2 \leftarrow 0)$ band of ${ }^{12} \mathrm{C}^{16} \mathrm{O}$ at room temperature. All spectra in the 4146 to $4332 \mathrm{~cm}^{-1}$ spectral interval were fitted simultaneously employing four line shape functions: the Voigt, Speed Dependent Voigt, Rautian and Speed Dependent Rautian profiles. The collisional line mixing effect has been observed and investigated as an asymmetry in the analyzed line profiles. A semi-empirical Exponential Power Gap Law method was used to estimate the self- and $\mathrm{H}_{2}$-broadening coefficients and the collisional line mixing parameters. Additionally, a classical approach was applied to calculate the half-width coefficients of
\end{abstract}


transitions in the $2 \leftarrow 0$ band for carbon monoxide broadened by $\mathrm{H}_{2}$ and for pure $\mathrm{CO}$. The classical approach based on a simple computational method, ensures the molecular motion is correctly characterized in 3 dimensions. The calculations used vibrationally independent intermolecular interaction potentials. The variation of $\mathrm{CO}$ half-width coefficients with rotational quantum number $\mathrm{J} \leq 24$ was computed and compared with measurements. The agreement between the theoretical broadening coefficients is better for pure $\mathrm{CO}$ rather than for the $\mathrm{CO}-\mathrm{H}_{2}$ system.

Keywords:

carbon monoxide, $\mathrm{CO}$ widths, $\mathrm{CO}$ shifts, $\mathrm{H}_{2}$, hydrogen, infrared spectra, line mixing, spectral line shapes, speed dependence

\section{Introduction}

Carbon monoxide $(\mathrm{CO})$ has been the subject of numerous investigations in recent decades due to its ability to offer insight into the evolution of galactic and extragalactic astrophysical entities [1]. The presence of CO in Jupiter's atmosphere was first reported in 1975 [2] and CO was later found in the atmospheres of the other giant planets, Saturn [3], Neptune [4, 5], and Uranus [6] and in the atmosphere of Saturn's moon, Titan [7]. The infrared lines of CO corresponding to the first overtone band were discovered in spectra of the predominantly $\mathrm{CO}_{2}$ rich atmospheres of Venus and Mars [8,9]. Moreover, CO is an attractive candidate for scientists to perform high signal-to-noise laboratory measurements (see, e.g. [10]).

The upcoming missions such as the GEO stationary Coastal and Air Pollution Events (GEO-CAPE), Global Atmospheric Composition Mission (GACM) and Active Sensing of $\mathrm{CO}_{2}$ absorption over Nights, Days and Seasons (ASCENDS) will map the spectral radiances located in the $2.3 \mu \mathrm{m}$ region to obtain distributions of concentrations for terrestrial atmospheric CO [11]. Accurate retrievals of atmospheric composition from spectra recorded by remote sensing techniques rely on having access to highly accurate line parameters for both self- and foreign-gas broadening. While considerable progress has been made in improving self- and air-broadened 
line parameters in the $2 \leftarrow 0$ band of CO (see Ref. [11]), our present study focuses on self- and $\mathrm{H}_{2}$-broadening in the same band, and in the following paragraphs we briefly review the previously available measurements.

Self-broadening parameters in the first overtone band of $\mathrm{CO}$ have been reported in numerous studies, while $\mathrm{H}_{2}$-broadened line shapes have been studied less often. The half-width coefficients of self-broadened transitions in the $2 \leftarrow 0$ and the $3 \leftarrow 0$ bands of $\mathrm{CO}$ have been measured by Plyler et al. [12] using a high resolution grating spectrometer for 21 lines in the Rbranch over a range of pressures between 1.5 to 4 atm. James et al. [13] have published measurements of pressure-broadened widths for 20 transitions in the $2 \leftarrow 0$ band of $\mathrm{CO}$ by hydrogen and nitrogen at $295 \mathrm{~K}$ for several pressures in the range of 10 to 35 Torr using a $1-\mathrm{m}$ long gas cell attached to a Jarrel-Ash Ebert spectrometer. Hunt et al. [14] have reported the room temperature half width coefficients of 31 self-broadened lines in the first overtone band of CO in the pressure range of 1 to 2 atm with an estimated accuracy of $\pm 3.0 \%$ employing a highresolution Littrow type grating spectrometer at a resolution of $0.045 \mathrm{~cm}^{-1}$.

Bouanich et al. [15] have studied the self- and foreign-broadened widths of 22 transitions belonging to the first overtone band of $\mathrm{CO}$ perturbed by $\mathrm{N}_{2}, \mathrm{H}_{2}, \mathrm{O}_{2}, \mathrm{NO}, \mathrm{HCl}$, and $\mathrm{CO}_{2}$ at $299 \mathrm{~K}$ and pressures ranging from 1 to $5 \mathrm{~atm}$. Bouanich et al. [16] also determined the self-broadened half-width coefficients of 22 lines in the P- and R-branches of CO at 298, 198, 131, and $85 \mathrm{~K}$ along with their temperature dependences.

Bouanich et al. [17] have used a tunable difference frequency laser spectrometer to measure the broadening and shift parameters in the $2 \leftarrow 0$ band of CO. They measured self-, He-, $\mathrm{Kr}-, \mathrm{O}_{2^{-}}$, and $\mathrm{N}_{2}$-broadened coefficients for several lines, and compared them with theoretical estimations based upon the semi-classical model by Robert-Bonamy and different interaction potentials.

Pressure broadening, pressure shift, and line mixing parameters of 42 lines of the first overtone band of pure $\mathrm{CO}$ and $\mathrm{CO}$ broadened by $\mathrm{N}_{2}$ have been investigated by Predoi-Cross $e t$ al. [18] using spectra recorded with a Bomem DA8.003 Fourier transform spectrometer at $303 \mathrm{~K}$ at various gas sample pressures. The authors have used the Lorentz profile to retrieve spectral line parameters for pure carbon monoxide as well as a Voigt and an empirical line shape model $\left(\mathrm{HC}_{\mathrm{v}}\right)$ which combines hard collision and speed-dependent Lorentz models to retrieve line parameters. They also compared the line broadening and pressure-shift coefficients with semi- 
classical computations. The measured line mixing parameters were compared with line mixing computations based upon an empirical energy corrected sudden scaling law.

Zou and Varanasi [19] have published self- and air-broadening coefficients, self- and airinduced shift parameters of the $1 \leftarrow 0$ and $2 \leftarrow 0$ bands of carbon monoxide for transitions between the $\mathrm{P}(24)$ and $\mathrm{R}(26)$ lines. The spectra were recorded at several temperatures ranging from $174 \mathrm{~K}$ to room temperature using a Bruker IFS-120HR Fourier transform spectrometer. In addition, they reported line positions and intensities, as well as the temperature dependences of the broadening and shift coefficients for each studied transition.

The line positions, intensities, broadening and pressure-induced shift parameters for pure $\mathrm{CO}$ and $\mathrm{CO}$ diluted in $\mathrm{H}_{2}$ belonging to the first overtone band were reported by Devi et al. [20] at $297 \mathrm{~K}$ for pressures between 3 and 507 Torr using the former Fourier transform spectrometer at the McMath-Pierce Solar Telescope, Kitt Peak National Observatory, AZ. Their measurements cover the 4130 to $4345 \mathrm{~cm}^{-1}$ region corresponding to transitions between $\mathrm{P}(27)$ and $\mathrm{R}(27)$. The authors have studied the vibrational dependence of the self-shift parameters by comparing them with coefficients published in previous spectroscopic works on the fundamental band. Line mixing effects could not be quantified in their data analysis.

Brault et al. [21] studied line positions and intensities, self-broadened widths, pressureinduced shifts and line mixing parameters in the $(2 \leftarrow 0)$ band of $\mathrm{CO}$ for the $\mathrm{P}(23)$ to $\mathrm{R}(23)$ transitions at temperatures between 297.8 to $301.6 \mathrm{~K}$ and pressures from 200 to 600 Torr applying the Voigt and Speed Dependent Voigt (SDV) models. The authors have also calculated the transition dipole moments using the intensity information and compared them with the Herman-Wallis parameters for transitions in this band.

Using a Bruker IFS-120HR Fourier transform spectrometer Sung et al. [22] have measured $\mathrm{H}_{2}$-broadened half-widths and $\mathrm{H}_{2}$-induced pressure-shift coefficients and determined the temperature dependences for the fundamental $(1 \leftarrow 0)$, first overtone $(2 \leftarrow 0)$ and second overtone $(3 \leftarrow 0)$ bands over a temperature range between 83 and $302 \mathrm{~K}$ and pressures from 101.11 to 539.74 Torr.

Since there was considerable disagreement between the $\mathrm{H}_{2}$-broadened results of Devi et al. [20] and those of Ref. [22], pressure-induced shift and half-width coefficients of pure CO and $\mathrm{CO}-\mathrm{H}_{2}$ mixtures were re-measured by Devi et al. [23] employing the multispectrum nonlinear least squares method [24] with a new set of $\mathrm{H}_{2}$-broadened spectra. The authors have analyzed 48 
transitions between $\mathrm{P}(24)$ and $\mathrm{R}(24)$ in the $2 \leftarrow 0$ band of $\mathrm{CO}$ at room temperature and pressure range from 3 to 643 Torr using a Voigt profile.

Regalia-Jarlot et al. [25] have studied the broadening and pressure-induced shift coefficients of $\mathrm{CO}$ diluted by air and $\mathrm{H}_{2}$ in the $1 \leftarrow 0$ band as well as self- and $\mathrm{H}_{2}$-broadened line widths and shifts in the $2 \leftarrow 0$ band, analysing spectra recorded with a Fourier transform spectrometer operating in stepping mode.

Devi et al. [11] have determined self- and air-broadened Lorentz half-width and pressureinduced shift coefficients and their temperature dependences of $\mathrm{CO}$ in the first overtone band using spectra recorded over the temperature and pressure ranges of 151.15 to $298 \mathrm{~K}$ and pressures of 5.11 to 699.14 Torr, respectively. Retrieving precise line positions and intensities enabled them to determine rovibrational constants $(G, B, D$ etc.) employing a multispectrum nonlinear least squares spectrum fitting technique. The authors have reported the speeddependent line shape parameters along with collisional line mixing coefficients obtained by applying the off-diagonal relaxation matrix element (ORME) formalism to obtain best fit residuals.

Our review of the literature indicates that no studies have been reported for the spectral line parameters of carbon monoxide perturbed by hydrogen in the second overtone band since 2005 . In this study, we have re-analyzed the high-resolution spectra of self-broadened $\mathrm{CO}$ and $\mathrm{CO}$ broadened by hydrogen $[20,23]$ recorded in the first overtone band. We have used four different line shapes in the multispectrum analysis (Voigt, speed dependent Voigt, Rautian, and Rautian with speed dependence) and compared the resulting line shape parameters with results available in the literature. These four models allowed us to investigate the contributions of Dicke narrowing and speed-dependence to the measured line shapes.

Line mixing coefficients have been calculated using the Exponential Power Gap (EPG) law. A classical approach was applied to calculate $\mathrm{CO}$ line widths for collisions of pure carbon monoxide and of mixtures of carbon monoxide and hydrogen, both performed using simple interaction potentials.

\section{Experimental description}

Absorption spectra of high purity research-grade (99.999\%) carbon monoxide $\left({ }^{12} \mathrm{C}^{16} \mathrm{O}\right)$ purchased from Matheson Inc. and samples of the same high-purity carbon monoxide mixed with 
dry, research grade hydrogen in the $(2 \leftarrow 0)$ band of $\mathrm{CO}$ were recorded at high resolution $(0.0052$

- $0.0055 \mathrm{~cm}^{-1}$ ) using the former Fourier transform spectrometer situated on Kitt Peak, AZ. Details regarding the spectra and the data acquisition procedure are given in Refs. [20, 23].

For the convenience of the reader, a brief summary of the experimental details is provided here. Ten pure $\mathrm{CO}$ and eight $\mathrm{H}_{2}$-broadened $\mathrm{CO}\left(\mathrm{CO}+\mathrm{H}_{2}\right)$ spectra with different mixing ratios were recorded at room ( 297.90-298.20 K) temperature. The experimental setup consisted of a Globar light source at $12 \mathrm{~V}$ and $\mathrm{CaF}_{2}$ beam splitter. The experimental conditions of all the spectra analyzed in this work are given in Table 1 . A $\mathrm{LN}_{2}$-cooled InSb detector was employed in recording the spectra. The signal to noise ratio $(\mathrm{S} / \mathrm{N})$ was estimated to be in the 200 to 500 range. The entire spectral region extends between 4146 and $4332 \mathrm{~cm}^{-1}$. Overlaid CO spectra used in the present study are shown in panel (B) of Figure 1. The top panel presents the differences between observed and calculated spectra. The concentrations of the spectra studied in Ref. 20 have been re-calculated using the present line intensities for pure $\mathrm{CO}$ and we have entered the revised volume mixing ratios in Table 1.

\section{Spectroscopic analysis}

For remote sensing applications, the Voigt line shape model (VP) (see Eqs. (2-5) of Ref. [26]) has been used for several decades. The line shape function known as the Speed Dependant Voigt profile (SDV) (see Eq. (11) of Ref. [26]) introduced first by Berman et al. [27] and later expanded by Pickett [28] is a weighted summation of Lorentzian profiles according to different absorber speeds and incorporates the dependence of relaxation rates term on the speed of the absorber. The analysis software employed in this study uses the implementation of speeddependence introduced by Rohart et al. (see Eqs. (10) Ref. [26] and references therein).

The Voigt or speed dependent Voigt line shape functions is only satisfactory when it is assumed that the mean-free path of the molecule is much larger than the wavelength of the incident radiation. So, if this condition is not met, and if the memory about coherence with the radiation is preserved after collision, smaller broadening parameters would be expected. This phenomenon is known as the Dicke narrowing effect [29] and has to be taken into account by adopting appropriate model.

The Galatry profile (GP) [29] is used when the molecular collisions are assumed to be soft (i.e., a great number of collisions are needed to yield a noticeable change in velocity, meaning 
the effect of only one collision is small and can be ignored). The Rautian and Sobel'man line shape formulation (RP) ( [30] or Eqs. (5-6) of Ref. [26]) and the one of Nelkin-Ghatak [31] have been introduced to account for hard collisions (i.e., for molecular systems where each collision randomizes the velocity, based upon a Maxwellian distribution [32], and thus the velocity memory is lost [33]). Collisional narrowing was implemented assuming that it can be related to the molecular diffusion.

Practically, the speed dependence of the velocity changing collisions and relaxation rates turn up simultaneously. Ciurylo and Szudy [34] described the collisional broadening applying the classical shift theory by Anderson [35] and the thermal motion of absorbing molecules by the Galatry model and introduced the speed dependent Galatry (SDG) line shape profile. By integrating the speed dependence relaxation rate in Rohart's approximation (see Eqs. (10) Ref. [26] and references therein) in the Rautian and Sobel'man formulation [33], we can obtain the speed dependent Rautian (SDR) profile.

To obtain the self- and air-broadened half-width and pressure-induced shift parameters, the following two equations are needed:

$$
\begin{gathered}
\gamma(p, T)=p\left[\gamma_{H_{2}}^{0}\left(p_{0}, T_{0}\right)(1-\chi)\left[\frac{T_{0}}{T}\right]^{n_{1}}+\gamma_{\text {self }}^{0}\left(p_{0}, T_{0}\right) \chi\left[\frac{T_{0}}{T}\right]^{n_{2}}\right] \\
v(T)=v_{0}+p\left[\delta_{H_{2}}^{0}(T)(1-\chi)+\delta_{\text {self }}^{0}(T) \chi\right]
\end{gathered}
$$

where $\delta^{0}$ and $\gamma_{\mathrm{H}_{2}}^{0}$ represent the retrieved pressure-shift and Lorentzian half-width coefficients (in $\left.\mathrm{cm}^{-1} \mathrm{~atm}^{-1}\right)$ at the reference pressure $\left(p_{0}=1 \mathrm{~atm}\right)$ and temperature $\left(T_{0}=296 \mathrm{~K}\right)$, respectively. $\gamma(p, T)$ expressed in $\mathrm{cm}^{-1}$ is the Lorentzian half-width of the line at the pressure $p\left(p=p_{C O}+\right.$ $p_{\mathrm{H}_{2}}$ ) and temperature $T$. $n_{1}$ and $n_{2}$ are the temperature dependence exponents of half-width coefficients and $\chi$ is the volume mixing ratio of $\mathrm{CO}$ in the pressure-broadened spectra.

The transition intensity between each two rovibrational states of any molecule possessing electrical dipole moment for a pure gas can be described by the following expression [36]:

$$
S_{i j}=\frac{I_{a} A_{i j}}{8 \pi c v_{i j}^{2}} \frac{g^{\prime} e^{-h c E^{\prime \prime} /\left(k_{B} T\right)}\left(1-e^{-h c v_{i j} /\left(k_{B} T\right)}\right)}{Q(T)}
$$

In the equation above, $S_{i j}$ is the weighted spectral line intensity based upon the natural terrestrial isotopologue abundances, $I_{a}$ (for ${ }^{12} \mathrm{C}^{16} \mathrm{O}$ is equal to 0.986544$)$, introduced with the unit of $\left(\mathrm{cm}^{-1} /\right.$ (molecule. $\left.\mathrm{cm}^{-2}\right)$ ) to describe it as the wavenumber per column density. $h$ is Planck's constant, $c$ is the speed of light, $T$ is the temperature $(\mathrm{K})$ and $v_{i j}$ is the transition wavenumber $\left(\mathrm{cm}^{-1}\right) . A_{i j}$ is 
the Einstein coefficient in $\mathrm{s}^{-1}, E^{\prime \prime}$ is the lower state energy $\left(\mathrm{cm}^{-1}\right)$ and $g^{\prime}$ is the is the upper state statistical weight which can be estimated by $g=g_{\varepsilon} g_{r o t}=(2 J+1) g_{s} g_{i}\left(g_{\varepsilon}\right.$ stands for total degeneracy yielding from the product of vibrational and electronic statistical weight, and $g_{i}$ and $g_{s}$ are the state-independent and state-dependent nuclear spin statistical weights, respectively (in the case of carbon monoxide, $g_{i}=g_{s}=1$ ). Double prime and prime (" and ') correspond as usual to the lower and upper states, respectively. $Q(T)$ is the total internal partition function and $k_{B}$ is the Boltzman constant. Note that equation (3) can only be applied for those molecules that have electrical transition dipole moments.

A dispersion parameter is required to be implemented in the line shape function of interest when a weak asymmetry is observed in the spectral lines that is characteristic to line mixing effects [37]. We least squared fitted the spectral interval $\left(4146-4332 \mathrm{~cm}^{-1}\right)$ corresponding to the entire band, all at once, rather than analyze the transitions one by one, and we used the ORME formalism [38]. The pressure broadening and the pressure shift coefficients come from the real and imaginary parts of the diagonal relaxation matrix elements, as shown in the following expression:

$$
W_{k k}^{0}=\gamma_{k}+i \delta_{k}
$$

The off-diagonal elements of the relaxation matrix are labeled $W_{l k}^{0}$. These elements cause mixing of the lines $l$ and $k$. For a given line interacting with all the other lines, the coefficient which realizes that effect can be represented as follows [37]:

$$
Y_{k}^{0}(T)=2 \sum_{l \neq k} \frac{d_{l}}{d_{k}} \frac{W_{l k}^{0}}{v_{k}-v_{l}} .
$$

$Y_{k}^{0}(T)$ are the first order, Rosenkranz [37], line mixing coefficients, and this theory works well if the spectral lines are separated well enough. In Eq. (5) $d_{l}$ and $d_{k}$ are the dipole moments of the optical transitions, $v_{l}$ and $v_{k}$ are the line centers of the transitions at zero pressure. Finally, the off-diagonal matrix elements are approximated by (minus) state-to-state rotational transfer rates (see [33,38] for a review). With the help of the Rosenkranz [37] line profile, the expression for the collisional absorption coefficient is given by:

$$
\alpha(v)=\frac{1}{\pi} \sum_{l} S_{l} \frac{p \gamma_{l}^{0}+p Y_{l}^{0}\left(v-v_{0}^{l}-p \delta_{l}^{0}\right)}{\left(v-v_{0}^{l}-p \delta_{l}^{0}\right)^{2}+\left(p \gamma_{l}^{0}\right)^{2}}
$$


where " $l$ " designates a rovibrational line $v_{i} j_{i} \rightarrow v_{f} j_{f}$. In Eq. (6) $p$ is the total pressure, $v_{0}^{l}$ is the line position of the spectral line $l, Y_{l}^{0}, \gamma_{l}^{0}$ and $\delta_{l}^{0}$ are the line mixing coefficients, half-width at half maximum and pressure induced shift coefficients per atm, respectively.

There are several semi-empirical scaling laws such as the Energy Corrected Sudden (ECS), Exponential Power Gap (EPG) and Modified Exponential Gap Law (MEGL) that can be used to predict the values of the relaxation matrix elements $[33,38]$.

The EPG scaling law makes use of standard collisional transfer rates, $k\left(v_{i} j_{i} \rightarrow v_{i} j_{i}^{\prime}, T\right)$, between the rotational levels $j_{i}$ and $j_{i}$ ' belonging to the same vibrational state $v_{\mathrm{i}}$. The expression for the collisional transfer rate from lower to a higher rotational level, exploiting the EPG law is given by the following equation $[33,38]$ :

$$
k\left(v_{i} j_{i} \rightarrow v_{i} j_{i}^{\prime}, T\right)=a\left[\frac{\left|\Delta E_{j_{i} j_{i}^{\prime}}\right|}{B_{0}}\right]^{-b} \exp \left(\frac{-c\left|\Delta E_{j_{i} j_{i}^{\prime}}\right|}{B_{0}}\right)
$$

Here, $\Delta E_{j_{i} j_{i}^{\prime}}$ is the energy difference (in $\mathrm{cm}^{-1}$ ) between each two rotational levels, $B_{0}$ is the

rotational constant (in $\mathrm{cm}^{-1}$ ) corresponding to the ground vibrational state, $a, b$ and $c$ are the adjustable parameters that need to be optimized applying nonlinear least squares technique. The real part of the diagonal element of the relaxation matrix can be approximated as follows (the so called random phase approximation):

$$
R e\left(W_{k k}\right)=\frac{1}{2}\left\{\sum_{j_{i}^{\prime} \neq j_{i}} k\left(v_{i} j_{i} \rightarrow v_{i} j_{i}^{\prime}, T\right)+\sum_{j_{f}^{\prime} \neq j_{f}} k\left(v_{f} j_{f} \rightarrow v_{f} j_{f}^{\prime}, T\right)\right\}
$$

In our approach we have ignored the vibrational dependence of the collisional rates.

\section{Theoretical calculations of $\mathrm{CO}$ - and $\mathrm{H}_{2}$-broadening coefficients}

In this section, we present the first results of classical trajectory calculations of $\mathrm{CO}$ pressure-broadening coefficients for pure $\mathrm{CO}-\mathrm{CO}$ and mixtures of $\mathrm{CO}$ and $\mathrm{H}_{2}$. A classical trajectory approach to compute the impact line broadening, shift and line mixing coefficients was proposed by R.G. Gordon [39,40] in 1966. The classical approach enables an exact threedimensional (3D) self-consistent characterization of translational and rotational motion of molecules without fitting for any parameters. This method is simple, visual, and computationally efficient. This classical approach, with applications to a variety of molecular systems [41-53], has been shown to be efficient and constitutes an accurate tool that provides theoretical results that are in much better agreement with benchmark quantum and/or experimental data, when 
compared with the results of semi-classical formalisms in cases where an accurate and robust $a b$ initio based potential energy surface (PES) is used.

In the framework of the classical impact theory, the collisional half-width, $\gamma$, and pressure shift, $\delta$, of electric dipole vibration-rotational spectral line are given by $[39,40]$ :

$$
\gamma=\frac{n_{b} \bar{v}}{2 \pi c} \operatorname{Re} \sigma \quad \delta=-\frac{n_{b} \bar{v}}{2 \pi c} \operatorname{Im} \sigma \quad \bar{v}=\sqrt{8 k_{B} T / \pi \mu}
$$

where the cross sections, $\sigma$ are as follows

$$
\begin{aligned}
\text { for } P \text { - lines } \sigma & =\left\langle v\left\{1-P_{e l} \exp \left[-i\left(\eta_{v i b}+\eta\right)\right] \cos ^{2} \frac{\beta}{2}\right\}\right\rangle_{b, V, O} \cdot \bar{v}^{-1} \\
\text { for } R \text { - lines } \quad \sigma & =\left\langle v\left\{1-P_{e l} \exp \left[-i\left(\eta_{v i b}-\eta\right)\right] \cos ^{2} \frac{\beta}{2}\right\}\right\rangle_{b, V, O} \cdot \bar{v}^{-1} .
\end{aligned}
$$

Here, $n_{b}$ is number density of perturbing particles; $c$ is the speed of light; $\mu$ is the reduced mass of the colliding pair; $T$ is the temperature and $k_{B}$ is the Boltzmann constant. $P_{e l}$ is the probability of a given collision to be elastic ( $P_{e l}$ is calculated using box-quantization [44]). The average $\langle\ldots\rangle$ is calculated over the impact parameter $b$, at relative speed $v$ and using the initial orientations (denoted here by $O$ ) of the axes $\vec{r}_{1}$ and $\vec{r}_{2}$ of both interacting molecules and the directions of their angular velocities, $\vec{\omega}_{1}$ and $\vec{\omega}_{2}$. The variable $\eta$ characterizes the "rotational dephasing" due to collisions and ?? is the angle between the before and after collision orientations of the active molecule's angular momentum ("rotational reorientation"). The values of $P_{e l}, \eta$ and ?? are calculated from the dynamics of each particular collision by the modified method described in [41,50].

The vibrational phase shift, $\eta_{v i b}$, is defined by $[39,40]$

$$
\eta_{v i b}=\hbar^{-1} \int_{\text {coll }}\left(V_{u}-V_{l}\right) d t
$$

where, $V_{l}$ and $V_{u}$ are the full intermolecular potential energies in the lower and upper vibrational states of the optical transition under consideration and the integral is taken over the collision trajectory. In our present calculations, we neglect this vibrational phase shift since molecules are treated as rigid rotors and we use the simple vibrationally independent PES. Line shift calculations are not performed since line shift is much more sensitive to vibrational dephasing than line width.

All calculations of half-widths of ${ }^{12} \mathrm{C}^{16} \mathrm{O}$ electric dipole transitions perturbed by $\mathrm{H}_{2}$ and $\mathrm{CO}$ were made for the room temperature $(T=296 \mathrm{~K})$. The classical 3D dynamics (C3D) for collision of two rigid diatomic molecules is characterized by applying 17 first-order Hamilton differential 
equations within body-fixed frames [44]. Broadening coefficients of CO molecule were calculated by considering perturbing molecules located in the ground vibrational state with $J_{2}$ values up to 10 for $\mathrm{H}_{2}$ and up to 57 for $\mathrm{CO}$, weighted by the nuclear spin ( 1 for collisions with $\mathrm{CO}$ and $(-1)^{J_{2}+1}+2$ for collisions with $\mathrm{H}_{2}$ ) and Boltzmann factors. The initial intermolecular distance was set as $R_{\max }=15 \AA$ for $\mathrm{CO}$ and $\mathrm{H}_{2}$ mixtures and $R_{\max }=20 \AA$ for pure $\mathrm{CO}$, to ensure that there will be no interaction between molecules. Other collision parameters (initial relative speed $\mathrm{v}$, impact parameter $b$, initial orientations of molecular axes and vectors of angular momentum) were selected via a Monte Carlo procedure. The sample relative velocities were set to follow a Maxwell distribution with temperature, $T$. Uniform sampling was used to select $b^{2}$, the orientations of both molecules in 3D space, and the directions of angular momenta. In order to decrease the computation time in the present Monte Carlo calculations we have implemented an efficient algorithm of $b$-sampling developed by Chapman and Green [54]. The parameters impact parameter of collisions were set to: $(0-13) \AA$ for $\mathrm{CO}-\mathrm{H}_{2}$ and $(0-19) \AA$ for pure carbon monoxide; and the relative velocities were set to $(0.01-3) \mathrm{v}_{\mathrm{p}}$, where $\mathrm{v}_{\mathrm{p}}$ is the most probable relative speed of a given colliding pair.

The bond lengths, $r$, of the molecules and their rotational constants, $B$, were fixed to their values in the ground vibrational level (see Table 2, all parameters are taken from Ref. [55]). The initial rotation frequency $\omega_{1}$ of $\mathrm{CO}$ molecule was determined via its rotational quantum number $J=J_{1}$ by the rigid rotor formulae based on the so called Langer prescription $[39,40,54,56]$ : $\omega_{1}=\frac{2 B}{\hbar} J$ for $P$-lines and $\omega_{1}=\frac{2 B}{\hbar}(J+1)$ for $R$-lines.

Hamilton equations of motion were integrated numerically by employing the Gear method [57] (recommended as a method to solve "stiff" problems) using standard IMSL Math Library routine IVPAG. All numerical calculations were performed within fixed time-grid intervals 1 fs using double precision, $10^{-8}$ tolerance parameter and a variable step of integration. The RMS error of Monte Carlo averaging was below $1 \%$ for calculated line widths at different $T_{s}$ and $J_{s}$.

In our classical calculations for pure carbon monoxide and for mixtures of carbon monoxide and hydrogen, a simple expression of the PES was used for both systems, namely, the sum of the Tipping-Herman (TH) potential, $V_{T H}[58]$ and electrostatic interactions, $V_{e l}$

$$
V=V_{T H}+V_{e l}
$$


The Tipping-Herman potential is defined by a three-term expansion in Legendre polynomials as follows:

$$
\begin{gathered}
V_{T H}=V_{T H}\left(R, \theta_{1}\right)=V_{R_{0}}(R)+V_{R_{1}}(R) P_{1}\left(\cos \theta_{1}\right)+V_{R_{2}}(R) P_{2}\left(\cos \theta_{1}\right) \\
V_{R_{0}}(R)=4 \varepsilon\left[\left(\frac{\sigma}{R}\right)^{12}-\left(\frac{\sigma}{R}\right)^{6}\right] ; V_{R_{1}}(R)=4 \varepsilon\left[R_{1}\left(\frac{\sigma}{R}\right)^{13}-A_{1}\left(\frac{\sigma}{R}\right)^{7}\right] ; V_{R_{2}}(R)=4 \varepsilon\left[R_{2}\left(\frac{\sigma}{R}\right)^{12}-A_{2}\left(\frac{\sigma}{R}\right)^{6}\right] .
\end{gathered}
$$

Here $\theta_{1}$ is the angle between the axis of $\mathrm{CO}$ molecule and the vector of intermolecular center-ofmass separation, $\vec{R} ; P_{1}\left(\cos \theta_{1}\right)$ and $P_{2}\left(\cos \theta_{1}\right)$ are the Legendre polynomials; $\varepsilon$ and $\sigma$ are the Lennard-Jones (LJ) potential parameters. Electrostatic interactions include dipole-dipole, dipolequadrupole and quadrupole-quadrupole interactions (see, e.g., [59]):

$$
\begin{gathered}
V_{e l}=V_{e l}\left(R, \theta_{1}, \theta_{2}, \varphi_{1}, \varphi_{2}\right)=V_{\mu_{1} \mu_{2}}+V_{\mu_{1} Q_{2}}+V_{\mu_{2} Q_{1}}+V_{Q_{1} Q_{2}}, \\
V_{\mu_{1} \mu_{2}}=-\frac{\mu_{1} \mu_{2}}{R^{3}} f_{\mu_{1} \mu_{2}}\left(\theta_{1}, \theta_{2}, \varphi_{1}, \varphi_{2}\right) ; \quad V_{\mu_{1} Q_{2}}=\frac{3}{2} \frac{\mu_{1} Q_{2}}{R^{4}} f_{\mu_{1} Q_{2}}\left(\theta_{1}, \theta_{2}, \varphi_{1}, \varphi_{2}\right) ; \\
V_{\mu_{2} Q_{1}}=\frac{3}{2} \frac{\mu_{2} Q_{1}}{R^{4}} f_{\mu_{2} Q_{1}}\left(\theta_{1}, \theta_{2}, \varphi_{1}, \varphi_{2}\right) ; \quad V_{Q_{1} Q_{2}}=\frac{3}{4} \frac{Q_{1} Q_{2}}{R^{5}} f_{Q_{1} Q_{2}}\left(\theta_{1}, \theta_{2}, \varphi_{1}, \varphi_{2}\right) .
\end{gathered}
$$

Here $\mu_{1}, \mu_{2}$ are the dipole moments and $Q_{1}, Q_{2}$ are the quadrupole moments of the interacting molecules; $\theta_{1}, \theta_{2}$ and $\varphi_{1}, \varphi_{2}$ are usual polar and azimuth angles of molecular axes in the bodyfixed coordinate system (note that its $z$-axis is always directed along the $\vec{R}$ vector). Note also that for $\mathrm{CO}-\mathrm{H}_{2}$ interaction $V_{\mu_{1} \mu_{2}}=0$ since $\mathrm{H}_{2}$ molecule has no dipole moment. Angular functions for electrostatic interactions are given by [59]:

$$
\begin{gathered}
f_{\mu 1 \mu 2}\left(\theta_{1}, \theta_{2}, \varphi_{1}, \varphi_{2}\right)=2 \cos \theta_{1} \cos \theta_{2}-\sin \theta_{1} \sin \theta_{2} \cos \left(\varphi_{1}-\varphi_{2}\right) \\
f_{\mu_{1} Q_{2}}\left(\theta_{1}, \theta_{2}, \varphi_{1}, \varphi_{2}\right)=\cos \theta_{1}\left(3 \cos ^{2} \theta_{2}-1\right)-2 \sin \theta_{1} \sin \theta_{2} \cos \theta_{2} \cos \left(\varphi_{1}-\varphi_{2}\right) \\
f_{\mu_{2} Q_{1}}\left(\theta_{1}, \theta_{2}, \varphi_{1}, \varphi_{2}\right)=\cos \theta_{2}\left(3 \cos ^{2} \theta_{1}-1\right)-2 \sin \theta_{2} \sin \theta_{1} \cos \theta_{1} \cos \left(\varphi_{2}-\varphi_{1}\right) \\
f_{Q_{1} Q_{2}}\left(\theta_{1}, \theta_{2}, \varphi_{1}, \varphi_{2}\right) \\
=1 \\
-5\left(\cos ^{2} \theta_{1}\right. \\
\left.+\cos ^{2} \theta_{2}+3 \cos ^{2} \theta_{1} \cos ^{2} \theta_{2}\right)+2\left[\sin \theta_{1} \sin \theta_{2} \cos \left(\varphi_{1}-\varphi_{2}\right)-4 \cos \theta_{1} \cos \theta_{2}\right]^{2}
\end{gathered}
$$

In above equations we set $R_{1}=2 A_{1}=12 d_{m c} / \sigma, R_{2}=A_{2}=\rho$, where $d_{m c}$ is the separation of the CO center-of-mass and the center-of-charge and $\rho$ is the reduced polarizability anisotropy of CO molecule.

The values of dipole and quadrupole moments of $\mathrm{CO}$ and $\mathrm{H}_{2}$ molecules used in the calculations are given in Table 2. In the present classical calculations we did not fit the parameters of the Tipping-Herman interaction potential to experimental data (as was done in 
previous papers [18,55] using the semi-classical Robert-Bonamy method) but tried to use unadjusted (theoretical or measured) ones. We used three different sources for LJ interaction parameters, $\varepsilon$ and $\sigma$, (see Table 3 ). For reduced polarizability anisotropy of $\mathrm{CO}$ molecule, $\rho=\left(\alpha_{\|}-\alpha_{\perp}\right) /\left(\alpha_{\|}+2 \alpha_{\perp}\right)$, where $\alpha_{\|}$and $\alpha_{\perp}$ are the polarizabilities of CO molecule along the bond and perpendicular to the bond, respectively,, we used two very different data: $\rho=0.16667$ [59] and $\rho=0.089[55,60,61]$.

For the separation of the CO center-of-mass and center-of-charge, we used fixed value $d_{m c}$ $=0.21 \AA$ [62]. Then $R_{1}=12 d_{m c} / \sigma, A_{1}=R_{1} / 2, R_{1}=A_{2} \approx \rho \equiv\left(\alpha_{\|}-\alpha_{\perp}\right) /\left(\alpha_{\|}+2 \alpha_{\perp}\right)$. As for LJ interaction parameters, $\varepsilon$ and $\sigma$, we took their values from the books [59] and [63] and from the article [55] (see Table 3).

\section{Results and data analysis}

\subsection{Narrowing coefficients}

In order to account for the narrowing effects for both hard and soft collisional cases we have first determined the dynamical friction parameter $\left(\beta_{\text {diff }}\right.$ in $\left.\mathrm{cm}^{-1} / \mathrm{atm}\right)$ which is given by the following equation for the frequency of elastic velocity-changing collisions:

$$
\beta_{\text {diff }}=\frac{k_{B} T}{2 \pi c M D} \text {. }
$$

Here, $k_{B}$ is the Boltzmann constant, $T$ is the temperature $(\mathrm{K}), D$ is the mass diffusion constant $\left(\mathrm{m}^{2} / \mathrm{s}\right), M$ is the mass of the absorber $(\mathrm{kg})$ and $c$ is the speed of light $(\mathrm{cm} / \mathrm{s})$.

The $\mathrm{H}_{2}$ molecule was modeled by means of a single united atom force field [64] while CO was described as a three electrostatic sites model [65]. Intermolecular interactions were described by combining electrostatic and van der Waals interactions. For both interactions, a cutoff of $12 \AA$ was used. Electrostatic contribution was computed by using the Ewald sum with a convergence parameter of $0.36 \AA^{-1}$ while the van der Waals interactions were modeled from Lennard-Jones (LJ) potential. Crossed LJs interactions were evaluated from the LorentzBerthelot mixing rule. For $\mathrm{CO}-\mathrm{H}_{2}$ mixtures, eight volume fractions, corresponding to the experimental spectra, were investigated (Table 4). Lengths of box are $\mathrm{L}_{z}=\mathrm{L}_{\mathrm{y}}=\mathrm{L}_{\mathrm{x}}=344 \AA$. Molecular dynamics (MD) simulations were carried out from DLPOLY software [66]. Time-step of $1 \mathrm{fs}$ was used. The acquisition phase corresponds to $10 \mathrm{~ns}$ after an equilibration period of $5 \mathrm{~ns}$. MD runs were performed in the NVT statistical ensemble where $\mathrm{N}$ is the number of particles, $\mathrm{T}$ 
the temperature, $\mathrm{V}$ the volume of the simulation box. Temperature and pressure are $300 \mathrm{~K}$ and 1 bar respectively. In canonical ensemble temperature was kept constant by means of Nosé-Hoover algorithm [67] such that the relaxation time of the thermostat was $0.5 \mathrm{fs}$. Integration of the motion equations was performed by using the velocity Verlet algorithm [68]. Mean Square Displacement (MSD) was computed by using the following correlation expression:

$$
M S D(t)=\left\langle\frac{1}{N} \sum_{i=1}^{N}\left(\left(\vec{r}_{l}(t)-\vec{r}_{l}(0)\right)^{2}\right\rangle\right.
$$

where $\vec{r}_{i}(t)$ denotes the position of a particle $i$ at time $t$ and $\mathrm{N}$ the number of particles. In an isotropic medium, self-diffusion coefficient $\left(D_{s}\right)$ in an isotropic phase was computed from MSD

$$
D_{S}=\frac{1}{6} \lim _{t \rightarrow \infty} \frac{M S D}{t} .
$$

The Maxwell-Stephan diffusion was managed by means of the model of Darken [69]:

$$
D_{12}=x_{1} D_{1}+x_{2} D_{2}
$$

where $x_{1}$ and $x_{2}$ are the molar fraction of both 1 and 2 components and $D_{1}$ and $D_{2}$ are the selfdiffusion constants of 1 and 2. Indeed, it has been shown that the model of Darken is in quantitative agreement with the expression for the binary Maxwell-Stefan diffusion coefficient [70,71]. Calculated self and binary diffusion coefficients as well as related dynamical friction coefficients are gathered in Table 4. Ultimately, the latter coefficients were directly used in our line shape analysis to account for the Dicke narrowing regime in RP and SDR models.

\subsection{Fits of the experimental spectra}

The pressure broadening, pressure shift and line mixing parameters as well as the line positions and intensities for both pure carbon monoxide and carbon monoxide perturbed by hydrogen were determined applying the nonlinear least square multispectrum nonlinear least squares technique described in Ref. [24] to fit all the spectra simultaneously to noise level. Four line shape models as defined in Section 3 were employed to retrieve the required sets of line parameters. All initial values for line parameters for the pure gas were taken from the HITRAN2012 database [72]. In the case of $\mathrm{CO}-\mathrm{H}_{2}$, all values of $\mathrm{H}_{2}$ broadened widths and line shifts were taken from the GEISA database [73]. We did not use the values from the study in Ref. [11] as initial guesses because we did not want to bias the fit towards those results.

The multispectrum software [24] allows users to fit all the spectra simultaneously to the noise level. In retrieving the line broadening coefficients, we tried to float all the experimental 
values reported in this work. A list of all adjustable parameters for the EPG scaling law is given in the Table 5. These coefficients have been computed based upon the retrieved Voigt profile results. Since the line mixing coefficients should not depend of the line shape model used, we calculated them only using the line parameters retrieved with the Voigt profile.

All line parameters retrieved experimentally using the VP, SDV, RP and SDR line shape functions are listed in Tables 6-10. The errors listed in parentheses correspond to one standard deviation of the fit. The intensities and line positions of present work were used to obtain Einstein A coefficients applying Eq. (3). Comparisons of retrieved and calculated broadening at half-width at half-maximum (HWHM), collisional pressure shift as well as line mixing values are plotted in Figures 2 to 8.

Fig. 2(A) shows a nearly the same average difference of $0.000785 \mathrm{~cm}^{-1}$ between the newly retrieved line positions and those stored in the HITRAN or GEISA databases. Fig. 2(B) shows that our retrieved line intensities match better the ones in HITRAN, with average ratios of 1.009 (Voigt) and 1.010 (SD-Voigt). The agreement with the intensities available in the GEISA database is worse with average values of 0.972 (Voigt) and 0.974 (SD-Voigt). The plots for uncertainties in line positions (Fig. 2 (C)) and in line intensities (Fig. 2 (D)) show that the parameters are determined with lower uncertainties when we use the SD-Voigt profile.

Panel (A) of Figure 3 shows that our pure carbon monoxide line broadening coefficients retrieved with the SD-Voigt model are in better with the results from Refs. [11], as compared with the results from Ref. [21]. For the results obtained using the Voigt profile, we have very good agreement with the results in Ref. [18]. Our measured shifts plotted in Figure 3 (A) determined using the Voigt or SD-Voigt models with inclusion of line mixing agree very well with the results obtained through the same type of fit, i.e. Ref. [18] for Voigt results and both Refs. [11,21] for SD-Voigt results, respectively. Panel (B) of Figure 3 shows that the speeddependent profiles provide slightly higher broadening coefficients than the Voigt or Rautian profiles. The differences between the sets of broadening coefficients obtained with the four profiles are small, but noticeable and are fairly consistent over the range of $m$ values.

The results presented in Fig. 5 for $\mathrm{H}_{2}$-broadening show a good agreement for $|\mathrm{m}|<14$ with both sets of previous results. The scatter in our results for values $|\mathrm{m}|>14$ and the departures from the two previous sets [22,23] are attributed to the fact that our set of spectra was not optimal for retrievals of $\mathrm{H}_{2}$-broadening coefficients at high $|\mathrm{m}|$ values. Also, the fact that unlike done in Ref. 
[23], we have not used a constrained analysis method which is known to remove the scatter in broadening coefficients. The $\mathrm{H}_{2}$-pressure induced line shifts presented in Figure 6 do not agree very well with previous studies which is not surprising since we have retrieved also $\mathrm{H}_{2}$-line mixing parameters and the two sets of parameters are known to be highly correlated.

The line mixing coefficients are difficult to retrieve accurately from experimental spectra. Our retrieved values for CO-broadened line mixing coefficients presented in Fig. 7 (A) agree well at medium $|\mathrm{m}|$ values with previous measurements and show more scatter at both low and high $|\mathrm{m}|$ values where the transitions are weaker. Dicke narrowing, speed-dependence and line mixing, all lead to an effective line narrowing, so these three parameters are all correlated. It is possible that our method of introducing the narrowing parameter based on calculated diffusion constants leads to a underestimation of this parameter. Hence, the experimental values obtained by us for the line mixing coefficients are a bit overestimated. For both $\mathrm{CO}$ - and $\mathrm{H}_{2}$-broadened line mixing coefficients, the best agreement is observed with the semi-empirical results calculated with the Exponential Power Gap law.

In Fig. 8 we present our measured results for speed dependence parameters obtained for pure $\mathrm{CO}$ (panel (A)) and for the $\mathrm{CO}-\mathrm{H}_{2}$ system (panel (B)). One striking observation that has to be verified experimentally using new spectra is the very small size of speed-dependence parameters for the $\mathrm{CO}-\mathrm{H}_{2}$ system. As discussed by Kochanov [74], the speed-dependence coefficients are not expected to have a visible J-dependence. The strong J-dependence observed both in the speed-dependence results of Devi et al. [11] and in our retrieved speed dependence coefficients is due to the fact that both Dicke narrowing and the speed-dependence effect introduce a narrowing of the lines [74,75], hence making the narrowing and speed-dependence coefficients to be highly correlated. Since in our study we have fixed the narrowing parameter, its $\mathrm{J}$-dependence is neglected and it may have resurfaced in the retrieved speed-dependence coefficients. We have calculated the speed-dependence parameters according to the expressions of Kochanov [75] and we have obtained best agreement with our experimental values for a value of $\mathrm{q}=5$ in the expression of effective potential $\mathrm{V} \sim \mathrm{r}^{-\mathrm{q}}$, a fact that can be attributed to the contributions from the Van der Waals and quadrupole-quadrupole terms in the interaction potentials.

\subsection{Classical calculations of widths and comparisons with experimental data}


The results of classical calculations of $\mathrm{CO}$ line broadening coefficients are shown in Figures 9-14. First of all, we have ascertained that the values of $b_{\max }$ (maximum impact parameter) which we used are sufficiently large to provide converged results for the line widths. Fig. 9 and Table 11 represent the broadening convergence with increasing $b_{\max }$. We have checked the validity of the approximation by performing calculations only at the mean thermal velocity (MThV), thus avoiding a thermal average over speeds. This assumption is widely used in line broadening and shift calculations since it greatly reduces CPU time. In this approximation, the initial relative speed, $v$, in all collisions is fixed to its mean arithmetic speed (see Eq. (9)). The results are presented in Fig. 10 and gathered in Table 12. It is seen that for pure $\mathrm{CO}$ this assumption works quite well but for mixtures of $\mathrm{CO}$ and $\mathrm{H}_{2}$ there are some small problems (non-physical behavior of $J$-dependence). So, in all our further calculations we decided (for reliability) to refuse MThV approximation and use Maxwell-Boltzmann speed averaging.

It is known that in molecular collisions sometimes the so called quasi-bound complexes (see, e.g. [53]) arise which may influence the spectral line shape. Special additional calculations showed, however, that their influence on CO line broadening in our cases is negligible. At least, it is so when the Tipping-Herman + electrostatic PES is used.

The comparison of theoretical results with experimental data for self-perturbed $\mathrm{CO}$ and $\mathrm{CO}$ perturbed by $\mathrm{H}_{2}$ is shown respectively in Fig. 11 and Fig. 12. Note that calculated pressure broadening coefficients in P- and R-branches are identical for the same $|\mathrm{m}|$ values. For selfperturbed $\mathrm{CO}$, the theoretical broadening coefficients were calculated using three different sets of potential parameters (see curves 1-3 in Fig. 11). Classical results for both systems and different potentials used are gathered in Table 13. As one can see there is practically no difference between theoretical results obtained with these different potential parameters. The theoretical and experimental results for the self- and $\mathrm{H}_{2}$-broadened $\mathrm{CO}$ systems were in satisfactory agreement. The magnitudes of maximum and mean relative errors are $16 \%$ and $8 \%$ for pure $\mathrm{CO}$ and $31 \%$ and $15 \%$ for mixtures of $\mathrm{CO}$ and $\mathrm{H}_{2}$. Note that these values of errors are derived from the comparison of data for R- lines. In this estimation, we used theoretical data with the set of potential parameters designated in Fig. 9.

In Fig. 13 and Fig. 14 we analyzed the contributions of different parts of the interaction potential into the $\mathrm{CO}$ pressure broadening coefficients. It is clear from these figures that in both the self- and the $\mathrm{H}_{2}$-perturbed carbon monoxide cases, the main contributions come, firstly, from 
the Tipping-Herman (TH) part of the potential and, secondly, from the quadrupole-quadrupole interactions. As for dipole-dipole (dd) and dipole-quadrupole (dQ) interactions, they are very weak and may be neglected and this corroborates the results of Ref. [60]. Table 14 summarizes these results.

The main problem in present classical trajectory calculations relates to the line shifts, more precisely, with accounting for vibrational dephasing, $\eta_{v i b}$ arising from the variation of the PES with the vibrational quantum numbers relevant to the optical transition. In a previous article [55] this variation was taken into account somewhat crudely using fitting parameters for long-range interactions. It was the necessity of that time. Meanwhile, line shift is very sensitive to vibrational dephasing and more delicate methods and PESs should be applied.

There is no such problems with CO line broadening since line-widths only slightly depend on band (they are nearly the same for $1 \leftarrow 0,2 \leftarrow 0$ and $3 \leftarrow 0$ bands, see Fig. 2 and 3 of Ref. [55]). So, in this work, both molecules were treated as rigid rotors in calculations of widths (namely, widths are the same for all vibrational bands involving quite low vibrational numbers owing to the CO triple bound).

\section{Conclusion and directions for future work}

We have reported experimentally measured and theoretical line parameters for transitions in the first overtone $(2 \leftarrow 0)$ band of ${ }^{12} \mathrm{C}^{16} \mathrm{O}$ at the ambient temperature $(\sim 298 \mathrm{~K})$ to determine the pressure broadening coefficients for $48(\mathrm{P}(24)$ to $\mathrm{R}(23))$ rovibrational transitions. Applying a nonlinear least square technique (Labfit software, [24]), all the analyzed spectra were fitted simultaneously to the noise level. Our results agreed well with previous results as mentioned before. Note that there are many experimental studies of carbon monoxide in the first overtone band, and for this reason only a few selected studies have been plotted and compared in the present work. Pressure-broadened half-width coefficients of CO self-perturbed and perturbed by $\mathrm{H}_{2}$ and collisional line mixing coefficients generated using the EPG scaling law are in good agreement with the experimental values.

Additionally, we present the first results of calculations of self- and $\mathrm{H}_{2}$-broadened width coefficients of $\mathrm{CO}$ using classical impact theory. For a start, we applied very simple interaction PESs which were used in previous works on these molecular systems using the semi-classical Robert and Bonamy approach. However, in our present calculations we did not adjust potential 
energy parameters but used theoretical (or measured) ones. In spite of the simplicity of the PESs, we obtained quite good results for half-widths, especially for pure CO. It is important to include vibrational state dependence into intermolecular interaction surfaces. It would be the best of all to have robust and up-to-date PESs decomposed into series of bi-spherical harmonics separately for different vibrational states of the $\mathrm{CO}$ molecule. After this a reliable classical calculations of line broadening, shift and kinetic parameters (Dicke narrowing, etc.) are straightforward. This study is a step forward towards obtaining information on the narrowing, speed dependence and line mixing parameters that may be needed in the future if databases implement the HartmannTran model recommended by IUPAC [76].

In the future we intend to extend our study using spectra recorded over a large range of pressures and temperatures, to enable us to determine the temperature dependence of line parameters for the $\mathrm{CO}-\mathrm{CO}$ and $\mathrm{CO}-\mathrm{H}_{2}$ systems. If possible, we would like to test line shape models such as the ones given in Refs. [77-82] that can be used over a range of pressures and include speed dependent effects and line narrowing or line mixing.

\section{Acknowledgments}

This work was carried out at the University of Lethbridge funded through the Natural Sciences and Engineering Research Council of Canada and supported by the Discovery and CREATE grant programs. The research performed at the College of William and Mary, Connecticut College and NASA Langley Research Center was supported under contracts and cooperative agreements with the National Aeronautics and Space Administration. We are thankful to Dr. D. Chris Benner at the College of William and Mary for his permission of using multispectrum fitting software, LABFIT, to carry out the data analysis. We thank Mr. Hossein Naseri for his contributions to the early stage of the analysis.

\section{References}

[1] Dickman RL, Snell RL, Schloerb FP. Carbon monoxide as an extragalactic mass tracer. APJ 1986;309(1):326-0. doi:10.1086/164604. 
[2] Beer R. Detection of carbon monoxide in Jupiter. APJ 1975;200(3):L167-9. doi:10.1086/181923.

[3] Noll KS, Knacke RF, Geballe TR, Tokunaga AT. Detection of carbon monoxide in Saturn. APJ 1986;309(2):L91-4. doi:10.1086/184768.

[4] Rosenqvist J, Lellouch E, Romani PN, Paubert G, Encrenaz T. Millimeter-wave observations of Saturn, Uranus, and Neptune - CO and HCN on Neptune. APJ 1992;392(2):L99-2. doi:10.1086/186435.

[5] Marten A, Gautier D, Owen T, Sanders DB, Matthews HE, Atreya SK, Tilanus RPJ, Deane JR. First observations of CO and HCN on Neptune and Uranus at millimeter wavelengths and the implications for atmospheric chemistry. APJ 1993;406(1):285-97. doi:10.1086/172440.

[6] Encrenaz T, Lellouch E, Art PD, Feuchtgruber H, Orton GS, Atreya SK. First detection of CO in Uranus. A\&A, 2004;413(2):L5-9. doi: 10.1051/0004-6361:20034637.

[7] Lutz BL, De Bergh C, Owen T. Titan: Discovery of carbon monoxide in its atmosphere. Science 1983:220(4604)1374-5. doi:10.1126/science.220.4604.1374.

[8] Gray Young LD, Young AT. Interpretation of high-resolution spectra of Mars: IV. New calculations of the CO abundance. Icarus 1977:30(1):75-9. doi:10.1016/0019-1035(77)90122-1.

[9] Connes P, Connes J, Kaplan L D, Benedict WS. Carbon monoxide in the Venus atmosphere APJ, 1968;152(3P1):731-4. doi:10.1086/149590.

[10] Seleznev AF, Fedoseev GV, Koshelev MA, Tretyakov MY. Shape of collision-broadened lines of carbon monoxide, J. Quant. Spectrosc. Radiat. Transfer 2015;161:171-9. doi:10.1016/j.jqsrt.2015.04.011.

[11] Devi VM, Benner DC, Smith MAH, Mantz AW, Sung K, Brown LR, Predoi-Cross A. Spectral line parameters including temperature dependences of self- and air-broadening in the $2 \leftarrow 0$ band of $\mathrm{CO}$ at $2.3 \mu \mathrm{m}$. J. Quant. Spectrosc. Radiat. Transfer 2012;113:1013-33. doi:10.1016/j.jqsrt.2012.02.010.

[12] Plyler EK, Thibault RJ. Self-broadening of carbon monoxide in the $2 v$ and $3 v$ bands. J. Re. Natl. Stand. Sec. A 1963;67A(3):229-1. doi:10.6028/jres.067A.022

[13] James TC, Plyler EK. Linewidths in the 2-0 band of carbon monoxide broadened by nitrogen and hydrogen. J. Chem. Phys. 1964;40:221-3. doi:10.1063/1.1724866.

[14] Hunt RH, Toth RA, Plyler EK. High-resolution determination of the widths of selfbroadened lines of carbon monoxide. J. Chem. Phys. 1968 ;49 :3909-2. doi:10.1063/1.1670699. 
[15] Bouanich JP, Brodbeck C. Mesure des largeurs et des deplacements des raies de la bande 0 $\rightarrow 2$ de $\mathrm{CO}$ autoperturbé et perturbé par $\mathrm{N}_{2}, \mathrm{O}_{2}, \mathrm{H}_{2}, \mathrm{HCl}$, $\mathrm{NO}$ et $\mathrm{CO}_{2}$. J. Quant. Spectrosc. Radiat. Transfer 1973;13(1):1-7. doi:10.1016/0022-4073(73)90095-2.

[16] Bouanich J-P. On the temperature dependence of self-broadening in the first overtone band of CO. J. Quant. Spectrosc. Radiat. Transfer 1984;31 (6):561-7. doi: 10.1016/00224073(84)90061-X.

[17] Bouanich J-P, Bermejo D, Domenech JL, Martinez RZ, Santos J. Pressure-induced lineshifts in the $2 \leftarrow 0$ band of $\mathrm{CO}$ self-perturbed and perturbed by $\mathrm{He}, \mathrm{Kr}, \mathrm{O}_{2}$, and $\mathrm{N}_{2}$. J. Mol. Spectrosc. 1996;179(1):22-1. doi:10.1006/jmsp.1996.0180.

[18] Predoi-Cross A, Bouanich J-P, Benner DC, May AD, Drummond JR. Broadening, shifting, and line asymmetries in the $2 \leftarrow 0$ band of $\mathrm{CO}$ and $\mathrm{CO}-\mathrm{N}_{2}$ : experimental results and theoretical calculations. J. Chem. Phys. 2000;113(1):158-68. doi: http://dx.doi.org/10.1063/1.481783.

[19] Zou Q, Varanasi P. New laboratory data on the spectral line parameters in the 1-0 and 2-0 bands of ${ }^{12} \mathrm{C}^{16} \mathrm{O}$ relevant to atmospheric remote sensing. J. Quant. Spectrosc. Radiat. Transfer 2002;75(1):63-92. doi:10.1016/S0022-4073(02)00007-9.

[20] Devi VM, Benner DC, Smith MAH, Rinsland CP, Mantz AW. Determination of self- and $\mathrm{H}_{2}$-broadening and shift coefficients in the $2-0$ band of ${ }^{12} \mathrm{C}^{16} \mathrm{O}$ using a multispectrum fitting procedure. J. Quant. Spectrosc. Radiat. Transfer 2002;75(4):455-71. doi:10.1016/S00224073(02)00023-7.

[21] Brault JW, Brown LR, Chackerian CJr, Freedman R, Predoi-Cross A, Pine AS. Selfbroadened ${ }^{12} \mathrm{C}^{16} \mathrm{O}$ line shapes in the $v=2 \leftarrow 0$ band. J. Mol. Spectrosc., 2003:222(2):220-39. doi:10.1016/j.jms.2003.07.002.

[22] Sung K, Varanasi P. Hydrogen-broadened half-widths and hydrogen-induced line shifts of ${ }^{12} \mathrm{C}^{16} \mathrm{O}$ relevant to the Jovian atmospheric spectra. J. Quant. Spectrosc. Radiat. Transfer 2004;85 (2):165-82. doi:10.1016/S0022-4073(03)00202-4.

[23] Devi VM, Predoi-Cross A, Benner DC, Smith MAH, Rinsland CP, Mantz AW, Self- and $\mathrm{H}_{2}$-broadened width and shift coefficients in the $2 \leftarrow 0$ band of ${ }^{12} \mathrm{C}^{16} \mathrm{O}$ : revisited. J. Mol. Spectrosc. 2004;228(2):580-92. doi:10.1016/j.jms.2004.05.006.

[24] Benner DC, Rinsland CP, Devi VM, Smith MAH, Atkins D. A multispectrum nonlinear least squares fitting technique. J. Quant. Spectrosc. Radiat. Transfer 1995;53(6):705-21. doi:10.1016/0022-4073(95)00015-D. 
[25] Régalia-Jarlot L, Thomas X, Von der Heyden P, Barbe A. Pressure-broadened line widths and pressure-induced line shifts coefficients of the (1-0) and (2-0) bands of ${ }^{12} \mathrm{C}^{16} \mathrm{O}$, J. Quant. Spectrosc. Radiat. Transfer 2005;91(2):121-31. doi:10.1016/j.jqsrt.2004.05.042.

[26] Hashemi R, Rozario H, Povey, Predoi-Cross A. Line-shape models testing on six acetylene transitions in the $v_{1}+v_{3}$ band broadened by $\mathrm{N}_{2}$. J Quant Spectrosc Radiat Transfer 2014;140:5866. doi: 10.1016/j.jqsrt.2014.02.013.

[27] Berman PR. Speed-dependent collisional width and shift parameters in spectral line profiles. J Quant Spectrosc Radiat Transfer 1972;12(9):1331-42. doi:10.1016/00224073(72)90189-6.

[28] Pickett HM. Effects of velocity averaging on the shapes of absorption lines. J. Chem. Phys. 1980;73(12):6090-4. doi: http://dx.doi.org/10.1063/1.440145.

[29] Galatry L. Simultaneous effect of Doppler and foreign gas broadening on spectral lines. Phys. Rev. 1961;122(4):1218-23. doi:10.1103/PhysRev.122.1218.

[30] Rautian SG, Sobel'man II. The effect of collisions on the Doppler broadening of spectral lines. Sov. Phys. Uspekhi 1967;9(5):701-16. doi:10.1070/pu1967v009n05abeh003212.

[31] Nelkin M, Ghatak A. Simple binary collision model for Van Hove's $G_{s}(r, t)$. Phys. Rev. 1964;135(1A):A4-9. doi:10.1103/PhysRev.135.A4.

[32] De Vizia MD, Rohart F, Castrillo A, Fasci E, Moretti L, Gianfrani L. Speed-dependent effects in the near-infrared spectrum of self-colliding $\mathrm{H}_{2}{ }^{18} \mathrm{O}$ molecules. Phys. Rev. A 2011;83(5):052506-1-8. doi: https://doi.org/10.1103/PhysRevA.83.052506.

[33] Hartmann JM, Boulet C, Robert D. Collisional Effects on Molecular Spectra. Elsevier Science, United Kingdom, 2008. doi: 454000054,12,1.

[34] Ciuryło R, Szudy J. Speed-dependent pressure broadening and shift in the soft collision approximation. J. Quant. Spectrosc. Radiat. Transfer 1997;57(3):411-23. doi:10.1016/S00224073(96)00078-7.

[35] Anderson PW. A method of synthesis of the statistical and impact theories of pressure broadening. Phys. Rev. 1952;86 (5) 809-9. doi:10.1103/PhysRev.86.809.

[36] Šimečková M, Jacquemart D, Rothman LS, Gamache RR, Goldman A. Einstein Acoefficients and statistical weights for molecular absorption transitions in the HITRAN database. J. Quant. Spectrosc. Radiat. Transfer 2006;98(1)130-55. doi:10.1016/j.jqsrt.2005.07.003. 
[37] Rosenkranz P. Shape of the $5 \mathrm{~mm}$ oxygen band in the atmosphere. IEEE Trans. Antennas. Propag. 1975;AP23(4)498-6. doi:10.1109/TAP.1975.1141119.

[38] Levy A, Lacome N, Chackerian CJr. Spectroscopy of the Earth's atmosphere and of the interstellar medium. In: Rao KN, editor, New York: Academic Press; 1992.

[39] Gordon RG. Theory of the width and shift of molecular spectral lines in gases. J. Chem. Phys. 1966; 44(8):3083-9. doi:10.1063/1.1727183.

[40] Gordon RG. Semiclassical theory of spectra and relaxation in molecular gases. J. Chem. Phys. 1966;45(5):1649-5. doi:10.1063/1.1727808.

[41] Buldyreva J, Ivanov SV, Nguyen L. Collisional line broadening in the atmosphere of light particles: problems and solutions in the framework of semiclassical treatment. J. Raman Spectrosc. 2005;36(2):148-2. doi:10.1002/jrs.1283.

[42] Ivanov SV, Nguyen L, Buldyreva J. Comparative analysis of purely classical and semiclassical approaches to collision line broadening of polyatomic molecules: $\mathrm{I}_{2} \mathrm{C}_{2} \mathrm{H}_{2}-\mathrm{Ar}$ case. J. Mol. Spectrosc. 2005;233(1):60-7. doi:10.1016/j.jms.2005.05.014.

[43] Nguyen L, Ivanov SV, Buzykin OG, Buldyreva J. Comparative analysis of purely classical and semiclassical approaches to collision line broadening of polyatomic molecules: $\mathrm{II} . \mathrm{C}_{2} \mathrm{H}_{2}-\mathrm{He}$ case. J. Mol. Spectrosc. 2006;239(1):101-7. doi: 10.1016/j.jms.2006.05.020.

[44] Ivanov SV, Buzykin OG. Classical calculation of self-broadening in $\mathrm{N}_{2}$ Raman spectra. Mol. Phys. 2008;106(9-10):1291-02. doi: http://dx.doi.org/10.1080/00268970802270034.

[45] Ivanov SV, Buzykin OG. On the accuracy of classical, semiclassical and quantum methods in collision line broadening calculations: comparative analysis for $\mathrm{C}_{2} \mathrm{H}_{2}-\mathrm{Ar}$, He systems. J. Quant. Spectrosc. Radiat. Transfer 2010;111(15) 2341-53. doi: 10.1016/j.jqsrt.2010.04.031. [46] Thibault F, Ivanov SV, Buzykin OG, Gomez L, Dhyne M, Joubert P, Lepere M. Comparison of classical, semiclassical and quantum methods in hydrogen broadening of acetylene lines. J. Quant. Spectrosc. Radiat. Transfer 2011;112(9)1429-37. doi:10.1016/j.jqsrt.2011.02.011.

[47] Gomez L, Ivanov SV, Buzykin OG, Thibault F. Comparison of quantum, semiclassical and classical methods in hydrogen broadening of nitrogen lines. J. Quant. Spectrosc. Radiat. Transfer 2011;112(12):1942-9. doi: 10.1016/j.jqsrt.2011.04.005. 
[48] Thibault F, Gomez L, Ivanov SV, Buzykin OG, Boulet C. Comparison of quantum, semiclassical and classical methods in the calculation of nitrogen self-broadened linewidths. J. Quant. Spectrosc. Radiat. Transfer 2012;113(15):1887-97. doi:10.1016/j.jqsrt.2012.06.003.

[49] Povey C, Guillorel-Obregon M, Predoi-Cross A, Ivanov SV, Buzykin OG, Thibault F. Low pressure line shape study of nitrogen-perturbed acetylene transitions in the $v_{1}+v_{3}$ band over a range of temperatures. Can. J. Phys. 2013;91(11):896-5. doi:10.1139/cjp-2013-0031.

[50] Ivanov SV, Buzykin OG. Precision considerations of classical and semiclassical methods used in collision line broadening calculations: different linear molecules perturbed by argon. J. Quant. Spectrosc. Radiat. Transfer 2013;119:84-94. doi:10.1016/j.jqsrt.2012.12.021.

[51] Thibault F, Martínez RZ, Bermejo D, Ivanov SV, Buzykin OG, Ma Q. An experimental and theoretical study of nitrogen-broadened acetylene lines. J. Quant. Spectrosc. Radiat. Transfer 2014;142:17-4. doi: http://dx.doi.org/10.1016/j.jqsrt.2014.03.009.

[52] Ivanov SV, Boulet C, Buzykin OG, Thibault F. Line mixing effects in isotropic Raman spectra of pure $\mathrm{N}_{2}$ : a classical trajectory study. J. Chem. Phys., 2014;141(18):184306. doi: 10.1063/1.4901084.

[53] Ivanov SV. Quasi-bound complexes in collisions of different linear molecules: Classical trajectory study of their manifestations in rotational relaxation and spectral line broadening. J. Quant. Spectrosc. Radiat. Transfer 2016;177:269-82. doi: 10.1016/j.jqstr.2016.01.034.

[54] Chapman S, Green S. Rotational excitation of linear molecules by collisions with atoms: Comparison of classical and quantum methods. J. Chem. Phys. 1977;67(5):2317-31. doi: 10.1063/1.435067.

[55] Bouanich J-P, Predoi-Cross A. Theoretical calculations for line-broadening and pressureshifting in the fundamental and first two overtone bands of $\mathrm{CO}-\mathrm{H}_{2}$. J. Mol. Spectrosc. 2005;742 (1-3):183-0. doi:10.1016/j.molstruc.2005.01.004.

[56] Langer RE. On the connection formulas and the solutions of the wave equation. Phys. Rev. 1937;51(8):669-6. doi: 10.1103/PhysRev.51.669.

[57] Gear CW. Numerical initial value problems in ordinary differential equations. New Jersey: Prentice Hall ; 1971.

[58] Tipping RH, Herman RM. Impact theory for the noble gas pressure-induced $\mathrm{HCl}$ vibrationrotation and pure rotation line widths - I. J. Quant. Spectrosc. Radiat. Transfer 1970;10(8):88196. doi: http://dx.doi.org/10.1016/0022-4073(70):90031-2. 
[59] Hirschfelder JO, Curtiss CF, Bird RB. Molecular theory of gases and liquids. New York: Wiley and Sons; 1954.

[60] Predoi-Cross A, Bouanich JP, Benner DC, May AD, Drummond JR. Broadening, shifting, and line asymmetries in the $2 \leftarrow 0$ band of $\mathrm{CO}$ and $\mathrm{CO}-\mathrm{N}_{2}$ : Experimental results and theoretical calculations. J. Chem. Phys. 2000;113(1):158-68. doi: 10.1063/1.1738101.

[61] Gray CG, Gubbins KE. Theory of molecular fluids. New York: Oxford University Press: 1984.

[62] Friedmann $\mathrm{H}$. The quantum mechanical distribution function of molecular systems: translational and rotational motions. In: Adv. Chem. Phys. John: Wiley \& Sons Inc.; 2007, pp. 225-302.

[63] Poling BE, Prausnitz JM, O'Connell JP. The properties of gases and liquids. In: $5^{\text {th }}$ ed., New York: McGraw-Hill; 2001. doi: 10.1039/b517931a

[64] Frost H, Düren T, Snurr RQ. Effects of surface area, free volume, and heat of adsorption on hydrogen uptake in metal-organic frameworks. J. Phys. Chem. B 2006;110(19):9565-0. doi: 10.1021/jp060433 .

[65] Martín-Calvo A, Lahoz-Martín FD, Calero S. Understanding carbon monoxide capture using metal-organic frameworks. J. Phys. Chem. C, 2012;116(11):6655-3. doi: 10.1021/jp211563e.

[66] Todorov IT, Smith W, Trachenko K, Dove MT. DL_POLY_3: new dimensions in molecular dynamics simulations via massive parallelism. J. Mater. Chem. 2006; 16(20) 1911-8 (2006).

[67] Nosé S. A unified formulation of the constant temperature molecular dynamics methods. J. Chem. Phys. 1984;81(1):511-9. doi: 10.1063/1.447334

[68] Allen MP, Tildesley DJ. Computer Simulation of Liquids. United States: Oxford University Press; 1987.

[69] Darken L. Diffusion, mobility and their interrelation through free energy in binary metallic systems. Trans. AIME, 1948;175:184-01. doi:

[70] Fernández GA, Vrabec J, Hasse H. Self diffusion and binary Maxwell-Stefan diffusion in simple fluids with the Green-Kubo method. Int. J. Thermophys. 2004;25(1):175-86. doi: 10.1023/B:IJOT.0000022333.07168.c4. 
[71] Van de Ven-Lucassen IMJJ, Vlugt TJH, Van der Zenden AJJ, Kerkhof PJAM. Using molecular dynamics to obtain Maxwell-Stefan diffusion coefficients in liquid systems. Mol. Phys. 1998;94(3):495-3. doi: 10.1080/002689798168006.

[72] Rothman LS, Gordon IE, Babikov Y, Barbe A, Benner D.C, Bernath PF et al. The HITRAN2012 molecular spectroscopic database. J. Quant. Spectrosc. Radiat. Transfer, 2013;130:4-50. doi: 10.1016/j.jqsrt.2013.07.002.

[73] Jacquinet-Husson N, Armante R, Scott NA, Chédin A, Crépeau L, Boutammine C et al. The 2015 edition of the GEISA spectroscopic database. J. Mol. Spectrosc. 2016; 327:31-72. doi: 10.1016/j.jms.2016.06.007.

[74] Kochanov VP. Manifestations of small-angle molecular scattering in spectral line profiles, J. Exp. Theor. Phys. 2014, ; 118(3): 335-50. doi: 10.1134/S1063776114020125.

[75] Kochanov VP. On parameterization of spectral line profiles including the speed-dependence in the case of gas mixtures. J Quant Spectrosc Radiat Transfer 2017; 189: 18-23. doi: 10.1016/j.jqsrt.2016.11.007.

[76] Tennyson J, Bernath PF, Campargue A, Császár AG, Daumont L, Gamache RR et al. Recommended isolated-line profile for representing high-resolution spectroscopic transitions (IUPAC Technical Report). Pure Appl. Chem. 2014; 86(12): 1931-43. doi: 10.1515/pac-20140208.

[77] Pine AS. $\mathrm{N}_{2}$ and Ar broadening and line mixing in the $\mathrm{P}$ and $\mathrm{R}$ branches of the $v_{3}$ band of CH4. J Quant Spectrosc Radiat Transfer 1997; 57: 157-76. doi: 10.1016/S0022-4073(96)001306.

[78] Kochanov VP. Collision line narrowing and mixing of multiplet spectra. J Quant Spectrosc Radiat Transfer 2000; 66: 313-25. doi: 10.1016/S0022-4073(99)00116-8.

[79] Ciurylo R, Pine AS. Speed-dependent line mixing profiles. J Quant Spectrosc Radiat Transfer 2000; 67: 375-93. doi: .1016/S0022-4073(00)00030-3.

[80] Kochanov VP. Line profiles for the description of line mixing, narrowing, and dependence of relaxation constants on speed. J Quant Spectrosc Radiat Transfer 2011; 112: 1931-41. doi: 10.1016/j.jqsrt.2011.04.009.

[81] Kochanov VP. Speed-dependent spectral line profile including line narrowing and mixing. J Quant Spectrosc Radiat Transfer 2016; 177: 261-8. doi: 10.1016/j.jqsrt.2016.02.014. 
[82] Cherkasov M.R. Theory of relaxation parameters of the spectrum shape in the impact approximation-I: General consideration. J Quant Spectrosc Radiat Transfer. 2014; 141. P.73-88. doi: 10.1016/j.jqsrt.2013.11.013.

\section{List of Figures}

Fig. 1. Multispectrum fits of 10 spectra of CO using the (A) Voigt, (B) Speed-Dependent Voigt, (C) Rautian, (D) Speed-Dependent Rautian profiles, all with weak line mixing, covering the region 4149.5 and $4170.5 \mathrm{~cm}^{-1}$ belonging to the $\mathrm{P}(20)$ to $\mathrm{R}(24)$ transition in the $2 \leftarrow 0$ band of $\mathrm{CO}$.

Fig 2 Ratios of line positions (panel (A)) and line intensities (panel (B)) between our measured results and the corresponding values in the HITRAN [72] and GEISA [73] databases. Panels (C) and (D) present the measured uncertainties obtained for line positions $\left(\times 10^{5} \mathrm{~cm}^{-1}\right)$ and intensities $\left(\times 10^{25} \mathrm{~cm}^{-1} /\left(\right.\right.$ molecule $\left.\left.\cdot \mathrm{cm}^{-2}\right)\right)$, respectively.

Fig. 3. (A) Measured Lorentz self-broadened half-width coefficients of CO using the Voigt and speed-dependent Voigt (SD-Voigt) models and comparison with published results. The line shape model used is mentioned in the figure legend. (B) Sample of broadening coefficients obtained using the speed-dependent Voigt, Voigt, Rautian and speed-dependent Rautian line shape models. (C) Measured Lorentz self-broadened half-width coefficients of CO in the present study using Voigt, speed-dependent Voigt (SD-Voigt), Rautian and speed-dependent Rautian models.

Fig. 4. (A) Measured room temperature pressure-induced shift coefficients of pure $\mathrm{CO}$ from present study using the Voigt and speed-dependent Voigt (SD-Voigt) models and their comparisons with the literature values. (B) Room temperature self-induced pressure-shift coefficients retrieved with four different line shape models.

Fig. 5. Measured Lorentz half-width coefficient of $\mathrm{H}_{2}$-broadened $\mathrm{CO}$ from the present study using the Voigt and speed-dependent Voigt models and comparisons with published results obtained using the Voigt model. 
Fig. 6. Measured pressure-induced shift coefficients of $\mathrm{H}_{2}$-broadened $\mathrm{CO}$ from present study using Voigt and speed-dependent Voigt models and their comparisons with published measurements obtained using the Voigt model.

Fig. 7. (A) Measured collisional line mixing parameter of pure $\mathrm{CO}$ using the Voigt and speeddependent Voigt models compared with other published and calculated results obtained using the exponential power gap (EPG) law. (B) Measured collisional line mixing of $\mathrm{CO}-\mathrm{H}_{2}$ obtained using the Voigt and speed-dependent Voigt models.

Fig. 8. Speed dependence parameters for pure $\mathrm{CO}$ (a), and $\mathrm{CO}$ and $\mathrm{H}_{2}$ mixtures (b) obtained using the speed-dependent Voigt profile.

Fig. 9. Test of convergence of thermally averaged theoretical line broadening coefficients for pure $\mathrm{CO}$ (panel (A)) and $\mathrm{CO}$ broadened by $\mathrm{H}_{2}$ (panel (B)) with $b_{\max }$ (in $\AA$ ) increasing. $J$ dependences of $\mathrm{CO}$ half-widths calculated using a different parameter $b_{\max }$ in the calculation. Interaction PES parameters for pure CO are $\varepsilon=110 \mathrm{~K}, \sigma=3.59 \AA$ [59], $\rho=0.089$ [60, 61]. Interaction parameters for $\mathrm{CO}$ broadened by $\mathrm{H}_{2}$ are $\varepsilon=48.8787 \mathrm{~K}, \sigma=3.3872 \AA$ [55], $\rho=$ 0.16667 [59].

Fig. 10. Test of the MThV approximation. Parameters of interaction PESs are the same as in Fig. 9.

Fig. 11. Comparison of theoretical with experimental results for the pure CO system. Theoretical broadening at half width half maximum coefficients was calculated using three different sets of potential energy parameters (curves 1-3). The parameters of PESs are as follows: (1) $\varepsilon=110 \mathrm{~K}, \sigma$ $=3.59 \AA$ [59], $\rho=0.089$ [60, 61]; (2) $\varepsilon=91.7 \mathrm{~K}, \sigma=3.690 \AA$ [63], $\rho=0.089$ [61]; (3) $\varepsilon=91.7 \mathrm{~K}, \sigma$ $=3.690 \AA[63], \rho=0.089[60,61] . \mathrm{R}_{\max }=20 \AA, \mathrm{b}_{\max }=19 \AA$.

Fig. 12. Comparison of theoretical and experimental results for $\mathrm{CO}$ and $\mathrm{H}_{2}$ mixtures. The theoretical $\mathrm{H}_{2}$-broadening coefficients were calculated using two different sets of parameters for PESs (curves 1 and 2). The parameters of the interaction PES are as follows: (1) $\varepsilon=48.8787 \mathrm{~K}, \sigma$ $=3.3872 \AA$ [53], $\rho=0.16667$ [57]; (2) $\varepsilon=91.7 \mathrm{~K}, \sigma=3.690 \AA$ ([61] + Berthelot rules), $\rho=0.089$ [59]. $R_{\max }=15 \AA, b_{\max }=13 \AA$. 
Fig. 13. Contributions of different parts of the interaction PES into CO pressure broadening coefficients for pure CO. The parameters of interaction PES correspond to Fig. 9.

Fig. 14. Contributions of different parts of interaction PES into $\mathrm{CO}$ pressure broadening coefficients for $\mathrm{CO}$ broadened by $\mathrm{H}_{2}$. The parameters of interaction PES correspond to Fig. 9.

Table 1. Summary of experimental conditions of the measured spectra of pure $\mathrm{CO}$ and $\mathrm{CO}-\mathrm{H}_{2}$ mixtures used in this study.

\begin{tabular}{ccccc}
\hline \hline $\begin{array}{c}\text { Gas } \\
\text { Sample }\end{array}$ & $\begin{array}{c}\text { Temperature } \\
(\mathbf{K})\end{array}$ & $\begin{array}{c}\text { Total Pressure } \\
\text { (Torr) }\end{array}$ & $\begin{array}{c}\text { Volume Gas } \\
\text { Mixture Ratio }\end{array}$ & $\begin{array}{c}\text { Path Length } \\
(\mathbf{m})\end{array}$ \\
\hline \hline Pure CO & 298.05 & 97.26 & 1.0 & 0.0205 \\
Pure CO & 298.05 & 148.30 & 1.0 & 0.0205 \\
Pure CO & 298.05 & 329.50 & 1.0 & 0.0205 \\
Pure CO & 298.30 & 3.15 & 1.0 & 0.1 \\
Pure CO & 297.90 & 4.47 & 1.0 & 0.1 \\
Pure CO & 298.20 & 9.40 & 1.0 & 0.1 \\
Pure CO & 298.15 & 123.85 & 1.0 & 0.1 \\
Pure CO & 279.90 & 279.90 & 1.0 & 0.1 \\
Pure CO & 298.20 & 507.00 & 1.0 & 0.1 \\
Pure CO & 298.15 & 1.36 & 1.0 & 1.5 \\
$\mathrm{CO}-\mathrm{H}_{2}$ & 298.20 & 155.15 & 0.1696 & 0.1 \\
$\mathrm{CO}-\mathrm{H}_{2}$ & 298.05 & 315.65 & 0.1899 & 0.1 \\
$\mathrm{CO}-\mathrm{H}_{2}$ & 297.85 & 474.65 & 0.2297 & 0.1 \\
$\mathrm{CO}-\mathrm{H}_{2}$ & 275.95 & 94.33 & 0.0487 & 1.5 \\
$\mathrm{CO}-\mathrm{H}_{2}$ & 275.65 & 174.12 & 0.0509 & 1.5 \\
$\mathrm{CO}-\mathrm{H}_{2}$ & 275.75 & 332.34 & 0.0496 & 1.5 \\
$\mathrm{CO}-\mathrm{H}_{2}$ & 296.20 & 574.70 & 0.0120 & 1.5 \\
$\mathrm{CO}-\mathrm{H}_{2}$ & 296.35 & 643.11 & 0.0474 & 1.5 \\
\hline \hline
\end{tabular}


Table 2. Molecular parameters for $\mathrm{CO}$ and $\mathrm{H}_{2}$ used in the theoretical calculations of $\mathrm{CO}$ line broadening coefficients.

\begin{tabular}{|c|c|c|c|c|}
\hline Molecule & $r(\AA)$ & $B\left(\mathrm{~cm}^{-1}\right)$ & $\mu(\mathrm{D})$ & $Q(\mathrm{D} \cdot \AA)$ \\
\hline${ }^{12} \mathrm{C}^{16} \mathrm{O}$ & 1.1309 & 1.9225 & 0.11 & -2.0 \\
\hline $\mathbf{H}_{2}$ & 0.7508 & 59.3345 & 0 & 0.6522 \\
\hline
\end{tabular}

Table 3. CO-CO, $\mathrm{H}_{2}-\mathrm{H}_{2}$ and $\mathrm{CO}-\mathrm{H}_{2}$ Lennard-Jones interaction parameters, $\varepsilon, \sigma$, used in present calculations.

\begin{tabular}{|c|c|c|c|}
\hline Type of Interaction & $\varepsilon(\mathbf{K})$ & $\sigma(\AA)$ & Reference \\
\hline \multirow{2}{*}{$\mathrm{CO}-\mathrm{CO}$} & 110 & 3.59 & {$[58]$} \\
\hline & 91.7 & 3.69 & {$[62]$} \\
\hline $\mathbf{H}_{2}-\mathbf{H}_{2}$ & 59.7 & 2.827 & {$[62]$} \\
\hline \multirow{2}{*}{$\mathrm{CO}-\mathrm{H}_{2}$} & 48.8787 & 3.3872 & [54] \\
\hline & 73.9898 & 3.2585 & {$[62]^{\mathrm{a}}$} \\
\hline
\end{tabular}

${ }^{\text {a }}$ Calculated from data of Ref. [62] using Lorentz-Berthelot combination rules.

Table 4. Calculated diffusion constants $\left(\mathrm{cm}^{2} / \mathrm{s}\right)$ and friction parameter $\left(\mathrm{cm}^{-1} \mathrm{~atm}^{-1}\right)$ for pure $\mathrm{CO}$ and $\mathrm{H}_{2}$ as well as for $\mathrm{CO}-\mathrm{H}_{2}$ mixtures with different molar fractions calculated at $\mathrm{T}=298 \mathrm{~K}$ and pressure of $1 \mathrm{~atm}$.

\begin{tabular}{|c|c|c|c|c|}
\hline $\begin{array}{c}\text { Diffusion } \\
\text { Constant for } \\
\text { Pure CO } \\
\end{array}$ & $\begin{array}{c}\text { Diffusion } \\
\text { Constant for } \\
\text { Pure } \mathrm{H}_{2} \\
\end{array}$ & $\begin{array}{c}\text { Volume Mixing } \\
\text { Ratio of CO-H} \\
\text { Spectra } \\
\end{array}$ & $\begin{array}{c}\text { Diffusion } \\
\text { Constant for gas } \\
\text { mixture }\left(\mathrm{D}_{12}\right) \\
\end{array}$ & $\begin{array}{l}\text { Friction Parameter } \\
\qquad\left(\beta_{\text {diff }}\right) \times 10^{4}\end{array}$ \\
\hline \multirow[t]{8}{*}{0.194} & 1.420 & 1 (pure CO) & 0.19 & 242.299 \\
\hline & & 0.0120 & 1.41 & 33.424 \\
\hline & & 0.0474 & 1.36 & 34.479 \\
\hline & & 0.0487 & 1.36 & 34.530 \\
\hline & & 0.0496 & 1.36 & 34.555 \\
\hline & & 0.0509 & 1.36 & 34.581 \\
\hline & & 0.1696 & 1.21 & 38.747 \\
\hline & & 0.1899 & 1.19 & 39.563 \\
\hline
\end{tabular}


Table 5. Optimized adjustable parameters for semi-empirical calculations using the Exponential Power Gap (EPG) method.

\begin{tabular}{cccc}
\hline \multirow{2}{*}{ Constants $^{*}$} & CO-CO & CO-H & CO-H \\
\cline { 2 - 4 } & P and R & P & R \\
\hline \hline $\boldsymbol{a}\left(\mathrm{cm}^{-1} \boldsymbol{a t m}^{-1}\right)$ & 0.04555 & 0.0152 & 0.0181 \\
$\boldsymbol{b}$ & 0.41980 & 0.1280 & 0.1910 \\
$\boldsymbol{c}$ & 1.10630 & 1.2000 & 1.1000 \\
\hline \hline
\end{tabular}

*See text for details.

Table 6. Line positions, intensities and Einstein A coefficients obtained using the SpeedDependent Voigt line shape model.

\begin{tabular}{|c|c|c|c|}
\hline $\mathbf{m}$ & $\begin{array}{l}\text { Line Positions } \\
\quad\left(\mathrm{cm}^{-1}\right)\end{array}$ & $\begin{array}{c}\text { Line Intensity } \times 10^{22} \\
\left(\mathrm{~cm}^{-1} /\left(\text { molecule } \mathrm{cm}^{-2}\right)\right) \text { at } 296 \mathrm{~K}\end{array}$ & $\begin{array}{l}\text { Einstein A coefficient } \\
\qquad\left(s^{-1}\right)\end{array}$ \\
\hline-24 & $4148.797708(99)$ & $0.559(5)$ & 0.4246 \\
\hline-23 & $4154.212260(93)$ & $0.840(5)$ & 0.4291 \\
\hline-22 & $4159.560420(64)$ & $1.231(5)$ & 0.4371 \\
\hline-21 & $4164.841602(45)$ & $1.770(5)$ & 0.4434 \\
\hline-20 & $4170.055891(33)$ & $2.504(6)$ & 0.4464 \\
\hline-19 & $4175.203163(24)$ & $3.487(7)$ & 0.4495 \\
\hline-18 & $4180.283295(18)$ & $4.747(7)$ & 0.4518 \\
\hline-17 & $4185.296052(15)$ & $6.272(7)$ & 0.4588 \\
\hline-16 & $4190.241224(12)$ & $8.123(8)$ & 0.4647 \\
\hline-15 & $4195.118736(10)$ & $10.310(8)$ & 0.4697 \\
\hline-14 & $4199.928509(8)$ & $12.694(9)$ & 0.4800 \\
\hline-13 & $4204.670277(7)$ & $15.588(10)$ & 0.4790 \\
\hline-12 & $4209.343958(7)$ & $18.369(10)$ & 0.4858 \\
\hline-11 & $4213.949410(6)$ & 21.171(11) & 0.4921 \\
\hline-10 & $4218.486447(6)$ & $23.804(11)$ & 0.4961 \\
\hline
\end{tabular}




\begin{tabular}{|c|c|c|c|}
\hline-9 & $44222.954945(6)$ & $25.852(12)$ & 0.5063 \\
\hline-8 & $4227.354766(5)$ & $27.329(12)$ & 0.5148 \\
\hline-7 & $4231.685733(5)$ & $27.873(12)$ & 0.5248 \\
\hline-6 & $4235.947753(5)$ & $27.350(12)$ & 0.5362 \\
\hline-5 & $4240.140651(6)$ & $25.635(12)$ & 0.5506 \\
\hline-4 & $4244.264227(6)$ & $22.662(12)$ & 0.5699 \\
\hline-3 & $4248.318396(7)$ & $18.433(11)$ & 0.6038 \\
\hline-2 & $4252.303025(8)$ & $13.111(10)$ & 0.6718 \\
\hline-1 & $4256.217943(14)$ & $6.848(9)$ & 1.0184 \\
\hline 1 & $4263.837930(14)$ & $7.038(9)$ & 0.3458 \\
\hline 2 & $4267.542864(8)$ & $13.901(10)$ & 0.4193 \\
\hline 3 & $4271.177403(6)$ & $20.192(11)$ & 0.4528 \\
\hline 4 & $4274.741533(6)$ & $25.585(12)$ & 0.4734 \\
\hline 5 & $4278.235058(5)$ & $29.853(13)$ & 0.4866 \\
\hline 6 & $4281.657825(5)$ & $32.875(13)$ & 0.4978 \\
\hline 7 & $4285.009711(5)$ & $34.537(14)$ & 0.5064 \\
\hline 8 & $4288.290573(5)$ & $34.895(14)$ & 0.5137 \\
\hline 9 & $4291.500221(5)$ & $34.018(13)$ & 0.5222 \\
\hline 10 & $4294.638584(5)$ & $32.210(13)$ & 0.5274 \\
\hline 11 & $4297.705411(5)$ & $29.600(13)$ & 0.5336 \\
\hline 12 & $4300.700661(5)$ & $26.496(12)$ & 0.5393 \\
\hline 13 & $4303.624136(6)$ & $23.135(11)$ & 0.5435 \\
\hline 14 & $4306.475699(6)$ & $19.687(11)$ & 0.5496 \\
\hline 15 & $4309.255182(7)$ & $16.334(10)$ & 0.5558 \\
\hline 16 & $4311.962464(8)$ & $13.275(9)$ & 0.5581 \\
\hline 17 & $4314.597391(9)$ & $10.552(9)$ & 0.5632 \\
\hline 18 & $4317.159814(11)$ & $8.208(8)$ & 0.5667 \\
\hline 19 & $4319.649574(14)$ & $6.244(8)$ & 0.5711 \\
\hline 20 & $4322.066549(18)$ & $4.616(7)$ & 0.5797 \\
\hline 21 & $4324.410613(24)$ & $3.374(7)$ & 0.5824 \\
\hline 22 & $4326.681506(33)$ & $2.401(6)$ & 0.5869 \\
\hline 23 & $4328.879349(46)$ & $1.691(6)$ & 0.5874 \\
\hline
\end{tabular}

Table 7. Line broadening coefficients $\left(\mathrm{cm}^{-1} \mathrm{~atm}^{-1}\right)$ for pure $\mathrm{CO}$ (Fig. 3, panel (C)) and CO-H (Fig.5, panel (B)) for transitions in the first overtone band obtained using the Voigt, SpeedDependent Voigt, Rautian and Speed-Dependent Rautian line shape models. Calculated values obtained using the EPG method are also included.

\begin{tabular}{|c|c|c|c|c|c|c|c|c|c|c|}
\hline \multirow{2}{*}{$\mathbf{m}$} & \multicolumn{5}{|c|}{$\mathrm{CO}-\mathrm{CO}$} & \multicolumn{5}{|c|}{$\mathrm{CO}-\mathrm{H}_{2}$} \\
\hline & Voigt & Rautian & SD- & SD- & EPG & Voigt & Rautian & SD- & SD- & EPG \\
\hline
\end{tabular}




\begin{tabular}{|c|c|c|c|c|c|c|c|c|c|c|}
\hline & & & Voigt & Rautian & & & & Voigt & Rautian & \\
\hline-24 & $\begin{array}{c}0.04935 \\
(65)\end{array}$ & $\begin{array}{c}0.04994( \\
73)\end{array}$ & $\begin{array}{c}0.05008( \\
74)\end{array}$ & $\begin{array}{c}0.05043( \\
74)\end{array}$ & 0.04537 & $\begin{array}{c}0.0588(3 \\
7)\end{array}$ & $\begin{array}{c}0.0673(2 \\
4)\end{array}$ & $\begin{array}{c}0.05789( \\
193)\end{array}$ & $\begin{array}{c}0.05771( \\
195)\end{array}$ & 0.05972 \\
\hline-23 & $\begin{array}{c}0.05128 \\
(47)\end{array}$ & $\begin{array}{c}0.05150( \\
52)\end{array}$ & $\begin{array}{c}0.05154( \\
52)\end{array}$ & $\begin{array}{c}0.05189( \\
52)\end{array}$ & 0.05053 & $\begin{array}{c}0.0624(2 \\
5)\end{array}$ & $\begin{array}{c}0.0708(1 \\
6)\end{array}$ & $\begin{array}{c}0.06254( \\
133)\end{array}$ & $\begin{array}{c}0.06231( \\
135)\end{array}$ & 0.06296 \\
\hline-22 & $\begin{array}{c}0.05155 \\
(33)\end{array}$ & $\begin{array}{c}0.05196( \\
37)\end{array}$ & $\begin{array}{c}0.05193( \\
37)\end{array}$ & $\begin{array}{c}0.05232( \\
37)\end{array}$ & 0.05309 & $\begin{array}{c}0.0679(1 \\
8)\end{array}$ & $\begin{array}{c}0.0744(1 \\
1)\end{array}$ & $\begin{array}{c}0.06823( \\
101)\end{array}$ & $\begin{array}{c}0.06799( \\
102)\end{array}$ & 0.06499 \\
\hline-21 & $\begin{array}{c}0.05228 \\
(25)\end{array}$ & $\begin{array}{c}0.05277( \\
27)\end{array}$ & $\begin{array}{c}0.05284( \\
27)\end{array}$ & $\begin{array}{c}0.05319( \\
27)\end{array}$ & 0.05464 & $\begin{array}{c}0.0671(1 \\
3)\end{array}$ & $0.0742(8)$ & $\begin{array}{c}0.06790( \\
69)\end{array}$ & $\begin{array}{c}0.06769( \\
70)\end{array}$ & 0.06634 \\
\hline-20 & $\begin{array}{c}0.05406 \\
(19)\end{array}$ & $\begin{array}{c}0.05424( \\
21)\end{array}$ & $\begin{array}{c}0.05424( \\
21)\end{array}$ & $\begin{array}{c}0.05461( \\
21)\end{array}$ & 0.05572 & $0.0653(9)$ & $0.0720(6)$ & $\begin{array}{c}0.06585( \\
49)\end{array}$ & $\begin{array}{c}0.06564( \\
50)\end{array}$ & 0.06726 \\
\hline-19 & $\begin{array}{c}0.05532 \\
(15)\end{array}$ & $\begin{array}{c}0.05530( \\
16)\end{array}$ & $\begin{array}{l}0.05542( \\
32)\end{array}$ & $\begin{array}{c}0.05498( \\
33)\end{array}$ & 0.05656 & $0.0645(7)$ & $0.0718(4)$ & $\begin{array}{c}0.06441( \\
36)\end{array}$ & $\begin{array}{c}0.06419( \\
37)\end{array}$ & 0.06791 \\
\hline-18 & $\begin{array}{c}0.05654 \\
(13)\end{array}$ & $\begin{array}{c}0.05644( \\
13)\end{array}$ & $\begin{array}{c}0.05753( \\
28)\end{array}$ & $\begin{array}{c}0.05716( \\
32)\end{array}$ & 0.05729 & $0.0674(5)$ & $0.0729(3)$ & $\begin{array}{c}0.06790( \\
30)\end{array}$ & $\begin{array}{c}0.06779( \\
30)\end{array}$ & 0.06835 \\
\hline-17 & $\begin{array}{c}0.05718 \\
(11)\end{array}$ & $\begin{array}{c}0.05743( \\
11)\end{array}$ & $\begin{array}{c}0.05718( \\
19)\end{array}$ & $\begin{array}{c}0.05650( \\
19)\end{array}$ & 0.05797 & $0.0658(4)$ & $0.0722(3)$ & $\begin{array}{c}0.06604( \\
22)\end{array}$ & $\begin{array}{c}0.06583( \\
23)\end{array}$ & 0.06862 \\
\hline-16 & $\begin{array}{c}0.0581( \\
10)\end{array}$ & $\begin{array}{c}0.05834( \\
9)\end{array}$ & $\begin{array}{c}0.05821( \\
16)\end{array}$ & $\begin{array}{c}0.05763( \\
16)\end{array}$ & 0.05865 & $0.0662(3)$ & $0.0719(2)$ & $\begin{array}{c}0.06651( \\
18)\end{array}$ & $\begin{array}{c}0.06631( \\
19)\end{array}$ & 0.06876 \\
\hline-15 & $\begin{array}{c}0.05925 \\
(9)\end{array}$ & $\begin{array}{c}0.05937( \\
8)\end{array}$ & $\begin{array}{c}0.05917( \\
13)\end{array}$ & $\begin{array}{c}0.05864( \\
14)\end{array}$ & 0.05934 & $0.0674(3)$ & $0.0718(2)$ & $\begin{array}{c}0.06747( \\
15)\end{array}$ & $\begin{array}{c}0.06731( \\
16)\end{array}$ & 0.06878 \\
\hline-14 & $\begin{array}{c}0.06004 \\
(8)\end{array}$ & $\begin{array}{c}0.06009( \\
7)\end{array}$ & $\begin{array}{c}0.06023( \\
12)\end{array}$ & $\begin{array}{c}0.05975( \\
13)\end{array}$ & 0.06008 & $0.0690(2)$ & $0.0727(2)$ & $\begin{array}{c}0.06888( \\
13)\end{array}$ & $\begin{array}{c}0.06872( \\
14)\end{array}$ & 0.06870 \\
\hline-13 & $\begin{array}{c}0.06157 \\
(8)\end{array}$ & $\begin{array}{c}0.06183( \\
6)\end{array}$ & $\begin{array}{c}0.06246( \\
12)\end{array}$ & $\begin{array}{c}0.06201( \\
13)\end{array}$ & 0.06088 & $0.0685(2)$ & $0.0716(1)$ & $\begin{array}{c}0.06865( \\
12)\end{array}$ & $\begin{array}{c}0.06852( \\
12)\end{array}$ & 0.06853 \\
\hline-12 & $\begin{array}{c}0.06242 \\
(8)\end{array}$ & $\begin{array}{c}0.06242( \\
6)\end{array}$ & $\begin{array}{c}0.06293( \\
10)\end{array}$ & $\begin{array}{c}0.06246( \\
11)\end{array}$ & 0.06177 & $0.0667(2)$ & $0.0698(1)$ & $\begin{array}{c}0.06726( \\
11)\end{array}$ & $\begin{array}{c}0.06713( \\
11)\end{array}$ & 0.06831 \\
\hline-11 & $\begin{array}{c}0.06348 \\
(7)\end{array}$ & $\begin{array}{c}0.06321( \\
5)\end{array}$ & $\begin{array}{c}0.06387( \\
10)\end{array}$ & $\begin{array}{c}0.06347( \\
10)\end{array}$ & 276 & $90(2)$ & $0.0712(1)$ & $\begin{array}{c}0.06899( \\
10)\end{array}$ & $\begin{array}{c}0.06887( \\
10)\end{array}$ & 0.06804 \\
\hline-10 & $\begin{array}{c}0.06432 \\
(7)\end{array}$ & $\begin{array}{c}0.06417( \\
5)\end{array}$ & $\begin{array}{l}0.06511( \\
9)\end{array}$ & $\begin{array}{c}0.06478( \\
10)\end{array}$ & 0.06389 & $0.0695(2)$ & $0.0710(1)$ & $\begin{array}{c}0.06960( \\
9)\end{array}$ & $\begin{array}{c}0.06951( \\
10)\end{array}$ & 0.06778 \\
\hline-9 & $\begin{array}{c}0.06525 \\
(7)\end{array}$ & $\begin{array}{c}0.06505( \\
5)\end{array}$ & $\begin{array}{l}0.06565( \\
9)\end{array}$ & $\begin{array}{l}0.06516( \\
9)\end{array}$ & 0.06519 & $0.0694(2)$ & $0.0708(1)$ & $\begin{array}{c}0.06952( \\
9)\end{array}$ & $\begin{array}{c}0.06943( \\
9)\end{array}$ & 0.06755 \\
\hline-8 & $\begin{array}{c}0.06617 \\
(7)\end{array}$ & $\begin{array}{c}0.06603( \\
5)\end{array}$ & $\begin{array}{l}0.06665( \\
8)\end{array}$ & $\begin{array}{l}0.06624( \\
9)\end{array}$ & 0.06670 & $0.0695(2)$ & $0.0709(1)$ & $\begin{array}{c}0.06966( \\
9)\end{array}$ & $\begin{array}{c}0.06956( \\
9)\end{array}$ & 0.06742 \\
\hline-7 & $\begin{array}{c}0.06751 \\
\text { (7) }\end{array}$ & $\begin{array}{c}0.06719( \\
5)\end{array}$ & $\begin{array}{l}0.06807( \\
9)\end{array}$ & $\begin{array}{l}0.06771( \\
9)\end{array}$ & 0.06847 & $0.0692(2)$ & $0.0708(1)$ & $\begin{array}{c}0.06934( \\
9)\end{array}$ & $\begin{array}{c}0.06925( \\
9)\end{array}$ & 0.06744 \\
\hline-6 & $\begin{array}{c}0.06995 \\
(8)\end{array}$ & $\begin{array}{c}0.06894( \\
5)\end{array}$ & $\begin{array}{l}0.06963( \\
9)\end{array}$ & $\begin{array}{l}0.06926( \\
10)\end{array}$ & 0.07057 & $0.0697(2)$ & $0.0712(1)$ & $\begin{array}{c}0.06987( \\
9)\end{array}$ & $\begin{array}{c}0.06977( \\
9)\end{array}$ & 0.06770 \\
\hline-5 & $\begin{array}{c}0.07153 \\
(8)\end{array}$ & $\begin{array}{c}0.07125( \\
5)\end{array}$ & $\begin{array}{c}0.07226( \\
10)\end{array}$ & $\begin{array}{c}0.07196( \\
11)\end{array}$ & 0.07306 & $0.0697(2)$ & $0.0717(1)$ & $\begin{array}{c}0.06985( \\
9)\end{array}$ & $\begin{array}{c}0.06974( \\
10)\end{array}$ & 0.06831 \\
\hline-4 & $\begin{array}{c}0.07416 \\
(9)\end{array}$ & $\begin{array}{c}0.07401( \\
6)\end{array}$ & $\begin{array}{c}0.07492( \\
11)\end{array}$ & $\begin{array}{c}0.07465( \\
13)\end{array}$ & 0.07603 & $0.0701(2)$ & $0.0725(1)$ & $\begin{array}{c}0.07018( \\
10)\end{array}$ & $\begin{array}{c}0.07007( \\
10)\end{array}$ & 0.06940 \\
\hline-3 & $\begin{array}{c}0.07736 \\
(10)\end{array}$ & $\begin{array}{c}0.07755( \\
7)\end{array}$ & $\begin{array}{c}0.07866( \\
14)\end{array}$ & $\begin{array}{c}0.07842( \\
16)\end{array}$ & 0.07946 & $0.0702(2)$ & $0.0737(1)$ & $\begin{array}{c}0.07034( \\
12)\end{array}$ & $\begin{array}{c}0.07021( \\
12)\end{array}$ & 0.07113 \\
\hline-2 & $\begin{array}{c}0.08100 \\
(12)\end{array}$ & $\begin{array}{c}0.08136( \\
10)\end{array}$ & $\begin{array}{c}0.08294( \\
20)\end{array}$ & $\begin{array}{c}0.08278( \\
23)\end{array}$ & 0.08296 & $0.0701(3)$ & $0.0749(2)$ & $\begin{array}{c}0.07017( \\
15)\end{array}$ & $\begin{array}{c}0.07001( \\
15)\end{array}$ & 0.07363 \\
\hline-1 & $\begin{array}{c}0.08674 \\
(19)\end{array}$ & 0.08696( & $\begin{array}{c}0.08776( \\
36)\end{array}$ & $\begin{array}{c}0.08756( \\
40)\end{array}$ & 0.08710 & $0.0742(5)$ & $0.0808(3)$ & $\begin{array}{c}0.07460( \\
28)\end{array}$ & $\begin{array}{c}0.07441( \\
28)\end{array}$ & 0.07636 \\
\hline
\end{tabular}


17)

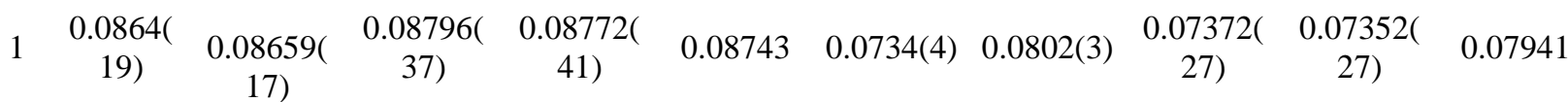

$2 \begin{array}{ccccccccc}0.08171 & 0.08174( & 0.08287( & 0.08265( & 0.08367 & 0.0704(3) & 0.0749(2) & 0.07050( & 0.07034( \\ 0.07646\end{array}$

$3 \quad 0.07754 \quad 0.07749\left(\begin{array}{llllllll}0.07852( & 0.07822( & 0.07859 & 0.0706(2) & 0.0736(1) & 0.07063( & 0.07050(\end{array}\right.$

$\begin{array}{ccccccccc}(10) & 7) & 13) & 15) & & & & & \end{array}$

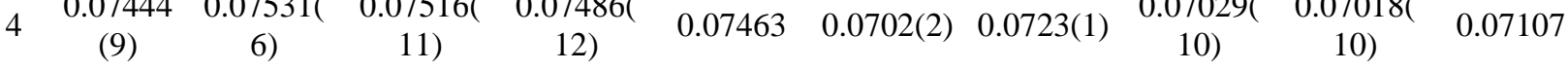

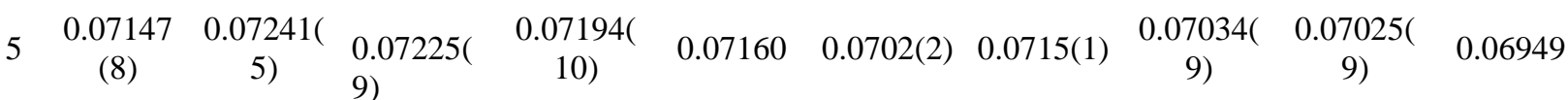

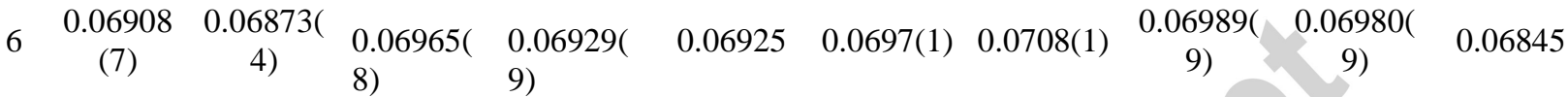

$\begin{array}{ccclllllll}0.06718 & 0.06706( & 0.06772( & 0.06732( & 0.06739 & 0.0698(1) & 0.0706(1) & 0.06994( & 0.06987( & 0.06781\end{array}$

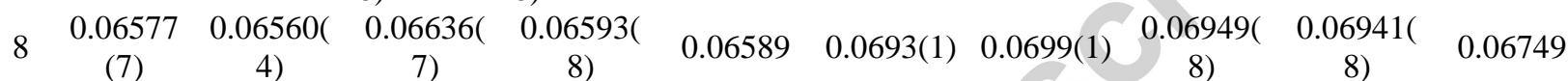

$\begin{array}{cccccccccc}0 & 0.06473 & 0.06453( & 0.06515( & 0.06469( & 0.06467 & 0.0692(1) & 0.0698(1) & 0.06939( & 0.06931( \\ 0 & (7) & 4) & 7) & 8) & & 0.06739\end{array}$

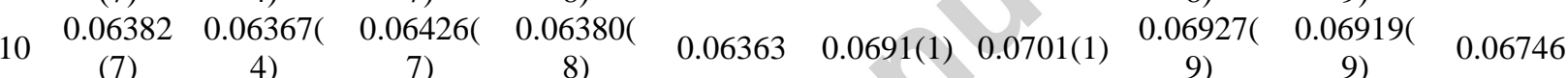

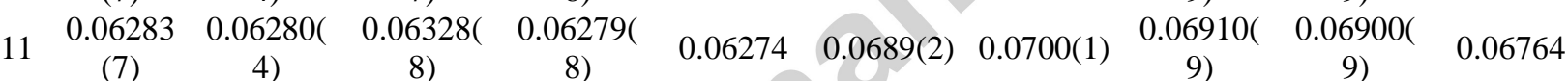

$12 \begin{array}{ccccccccc}0.06185 & 0.06189( & 0.06229( & 0.06178( & 0.06194 & 0.0690(2) & 0.0702(1) & 0.06899( & 0.06890( \\ (7) & 5) & 8) & 8) & 0.06791\end{array}$

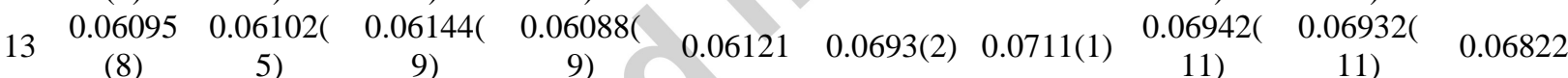

$14 \begin{array}{ccccccccc}0.06007 & 0.06019( & 0.06051( & 0.05995( & 0.06052 & 0.0687(2) & 0.0710(1) & 0.06883( & 0.06870( \\ (8) & 5) & 10) & 10) & 0.06855 & 12) & 12) & \end{array}$

$15 \begin{array}{ccccccccc}0.05882 & 0.05904( & 0.05924( & 0.05861( & 0.05984 & 0.0684(2) & 0.0713(1) & 0.06861( & 0.06848( \\ (9) & 6) & 11) & 11) & & & 0.06888\end{array}$

$16 \begin{array}{ccccccccc}0.05767 & 0.05802( & 0.05804( & 0.05745( & 0.05916 & 0.0677(2) & 0.0718(2) & 0.06778( & 0.06763( \\ (9) & 7) & 12) & 12) & 0.06918\end{array}$

$17 \begin{array}{cccccccccc}0.05681 & 0.05697( & 0.05704( & 0.05644( & 0.05844 & 0.0670(3) & 0.0716(2) & 0.06732( & 0.06714( & 0.06943\end{array}$

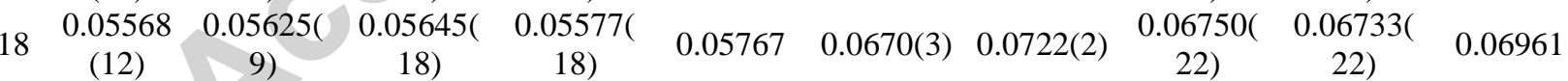

$19 \begin{array}{ccccccccc}0.05481 & 0.05501( & 0.05525( & 0.05458( & 0.05680 & 0.0674(4) & 0.0729(3) & 0.06792( & 0.06774( \\ 28) & 22) & 0.06969 & 28) & \end{array}$

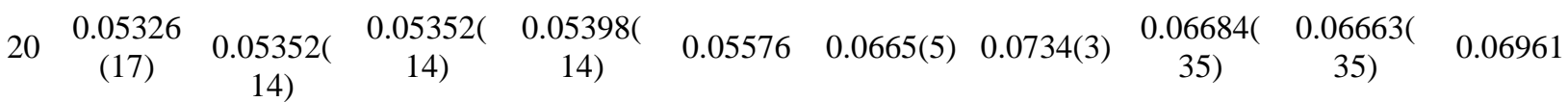

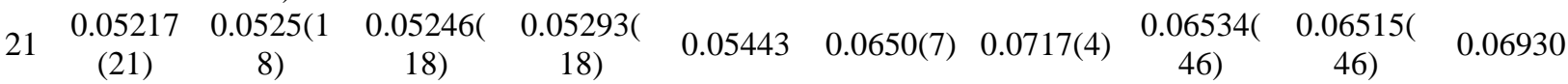

$22 \begin{array}{ccccccccc}0.05092 & 0.05191( & 0.05143( & 0.05191( & 0.05256 & 0.0645(9) & 0.0724(6) & 0.06477( & 0.06459( \\ (26) & 24) & 24) & 24) & & & 62) & 62) & 0.06861\end{array}$

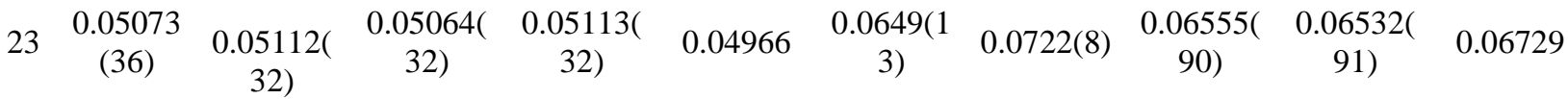




\begin{tabular}{llccccc}
\hline \hline \multirow{2}{*}{24} & \multirow{2}{*}{0.04432} & $0.0666(2$ & $0.0731(1$ & 0.06855( & 0.06813( & 0.06483 \\
& & 0 & $3)$ & $148)$ & $144)$ & 0.068 \\
\hline \hline
\end{tabular}

Table 8. Pressure-induced line shift coefficients $\left(\mathrm{cm}^{-1} \mathrm{~atm}^{-1}\right)$ for $\mathrm{CO}-\mathrm{CO}$ and $\mathrm{CO}-\mathrm{H}_{2}$ for transitions in the first overtone band obtained using the Voigt, Speed-Dependent Voigt, Rautian and Speed-Dependent Rautian line shape models.

\begin{tabular}{|c|c|c|c|c|c|c|c|c|}
\hline \multirow[b]{2}{*}{$\mathbf{m}$} & \multicolumn{4}{|c|}{ CO-CO } & \multicolumn{4}{|c|}{$\mathrm{CO}-\mathrm{H}_{2}$} \\
\hline & Voigt & Rautian & SD-Voigt & $\begin{array}{c}\text { SD- } \\
\text { Rautian }\end{array}$ & Voigt & Rautian & SD-Voigt & $\begin{array}{c}\text { SD- } \\
\text { Rautian }\end{array}$ \\
\hline- & $\begin{array}{c}0.00652(7 \\
0)\end{array}$ & $\begin{array}{c}- \\
0.00669(6 \\
5)\end{array}$ & $\begin{array}{c}- \\
0.00668(6 \\
4)\end{array}$ & $\begin{array}{c}- \\
0.00670(6 \\
5)\end{array}$ & $\begin{array}{c}0.0006(2 \\
9)\end{array}$ & $\begin{array}{c}0.0004(3 \\
3)\end{array}$ & $\begin{array}{c}0.0024(1 \\
7)\end{array}$ & $\begin{array}{c}0.0025(1 \\
7)\end{array}$ \\
\hline- & $\begin{array}{c}- \\
0.00677(5 \\
2)\end{array}$ & $\begin{array}{c}- \\
0.00668(4 \\
6)\end{array}$ & $\begin{array}{c}- \\
0.00668(4 \\
5)\end{array}$ & $\begin{array}{c}- \\
0.00667(4 \\
6)\end{array}$ & $\begin{array}{c}- \\
0.0040(2 \\
0)\end{array}$ & $\begin{array}{c}0.0043(2 \\
2)\end{array}$ & $\begin{array}{c}- \\
0.0051(1 \\
2)\end{array}$ & $\begin{array}{c}- \\
0.0051(1 \\
2)\end{array}$ \\
\hline- & $\begin{array}{c}- \\
0.00502(3 \\
6)\end{array}$ & $\begin{array}{c}- \\
0.00640(3 \\
2)\end{array}$ & $\begin{array}{c}- \\
0.00640(3 \\
2)\end{array}$ & $\begin{array}{c}- \\
0.00640(3 \\
2)\end{array}$ & $\begin{array}{c}0.0115(1 \\
5)\end{array}$ & $\begin{array}{c}- \\
0.0121(1 \\
6)\end{array}$ & $\begin{array}{c}- \\
0.0110(9)\end{array}$ & $\begin{array}{c}- \\
0.0110(9)\end{array}$ \\
\hline $\begin{array}{c}- \\
21\end{array}$ & $\begin{array}{c}- \\
0.00619(2 \\
7)\end{array}$ & $\begin{array}{c}- \\
0.00610(2 \\
4)\end{array}$ & $\begin{array}{c}- \\
0.00609(2 \\
4)\end{array}$ & $0.00609(2$ & $0.008(10)$ & $\begin{array}{c}- \\
0.0082(1 \\
1)\end{array}$ & $0.0076(6)$ & $\begin{array}{c}- \\
0.0076(6)\end{array}$ \\
\hline $\begin{array}{c}- \\
20\end{array}$ & $\begin{array}{c}- \\
0.00541(2 \\
1)\end{array}$ & $\begin{array}{c}- \\
0.00561(1 \\
8)\end{array}$ & $\begin{array}{c}- \\
0.00561(1 \\
8)\end{array}$ & $\begin{array}{c}- \\
0.00561(1 \\
8)\end{array}$ & $\begin{array}{c}- \\
0.0075(7)\end{array}$ & $\begin{array}{c}- \\
0.0077(8)\end{array}$ & $\begin{array}{c}- \\
0.0077(4)\end{array}$ & $\begin{array}{c}- \\
0.0077(4)\end{array}$ \\
\hline $\begin{array}{c}- \\
19\end{array}$ & $\begin{array}{c}- \\
0.00531(1 \\
6)\end{array}$ & $\begin{array}{c}- \\
0.00546(1 \\
4)\end{array}$ & $\begin{array}{c}0.00547(1 \\
4)\end{array}$ & $\begin{array}{c}- \\
0.00547(1 \\
4)\end{array}$ & $\begin{array}{c}- \\
0.0070(6)\end{array}$ & $\begin{array}{c}- \\
0.0073(6)\end{array}$ & $\begin{array}{c}- \\
0.0075(3)\end{array}$ & $\begin{array}{c}- \\
0.0074(3)\end{array}$ \\
\hline- & $\begin{array}{c}- \\
0.00511(1 \\
6)\end{array}$ & $\begin{array}{c}- \\
0.00536(1 \\
4)\end{array}$ & $\begin{array}{c}- \\
0.00550(1 \\
1)\end{array}$ & $\begin{array}{c}- \\
0.00552(1 \\
1)\end{array}$ & $\begin{array}{c}- \\
0.0062(5)\end{array}$ & $\begin{array}{c}- \\
0.0064(6)\end{array}$ & $\begin{array}{c}- \\
0.0068(3)\end{array}$ & $\begin{array}{c}- \\
0.0068(3)\end{array}$ \\
\hline- & $\begin{array}{c}- \\
0.00508(1 \\
3)\end{array}$ & $\begin{array}{c}0.00560(1 \\
1)\end{array}$ & $\begin{array}{c}- \\
0.00546(9 \\
)\end{array}$ & $\begin{array}{c}- \\
0.00548(9 \\
)\end{array}$ & $\begin{array}{c}- \\
0.0065(4)\end{array}$ & $\begin{array}{c}- \\
0.0066(4)\end{array}$ & $\begin{array}{c}- \\
0.0064(2)\end{array}$ & $\begin{array}{c}- \\
0.0064(2)\end{array}$ \\
\hline $\begin{array}{c}- \\
16\end{array}$ & $\begin{array}{c}- \\
0.00513(1 \\
2)\end{array}$ & $\begin{array}{c}- \\
0.00549(9)\end{array}$ & $\begin{array}{c}- \\
0.00553(8 \\
)\end{array}$ & $\begin{array}{c}- \\
0.00554(8 \\
)\end{array}$ & $\begin{array}{c}- \\
0.0053(3)\end{array}$ & $\begin{array}{c}- \\
0.0054(3)\end{array}$ & $\begin{array}{c}- \\
0.0053(2)\end{array}$ & $\begin{array}{c}- \\
0.0053(2)\end{array}$ \\
\hline $\begin{array}{c}- \\
15\end{array}$ & $\begin{array}{c}- \\
0.00525(1 \\
0)\end{array}$ & $\begin{array}{c}- \\
0.00549(8)\end{array}$ & $\begin{array}{c}- \\
0.00553(7 \\
)\end{array}$ & $\begin{array}{c}- \\
0.00554(7 \\
)\end{array}$ & $\begin{array}{c}- \\
0.0062(3)\end{array}$ & $\begin{array}{c}- \\
0.0063(3)\end{array}$ & $\begin{array}{c}- \\
0.0062(2)\end{array}$ & $\begin{array}{c}- \\
0.0062(2)\end{array}$ \\
\hline $\begin{array}{c}- \\
14\end{array}$ & $\begin{array}{c}- \\
0.00508(1 \\
0)\end{array}$ & $\begin{array}{c}- \\
0.00574(7)\end{array}$ & $\begin{array}{c}- \\
0.00573(6 \\
)\end{array}$ & $\begin{array}{c}- \\
0.00573(6 \\
)\end{array}$ & $\begin{array}{c}- \\
0.0055(2)\end{array}$ & $\begin{array}{c}- \\
0.0056(2)\end{array}$ & $\begin{array}{c}- \\
0.0056(1)\end{array}$ & $\begin{array}{c}- \\
0.0056(1)\end{array}$ \\
\hline $\begin{array}{c}- \\
13\end{array}$ & $\begin{array}{c}- \\
0.00499(9 \\
)\end{array}$ & $\begin{array}{c}- \\
0.00534(5)\end{array}$ & $\begin{array}{c}- \\
0.00534(5 \\
)\end{array}$ & $\begin{array}{c}- \\
0.00534(5 \\
)\end{array}$ & $\begin{array}{c}- \\
0.0051(2)\end{array}$ & $\begin{array}{c}- \\
0.0052(2)\end{array}$ & $\begin{array}{c}- \\
0.0052(1)\end{array}$ & $\begin{array}{c}- \\
0.0052(1)\end{array}$ \\
\hline
\end{tabular}




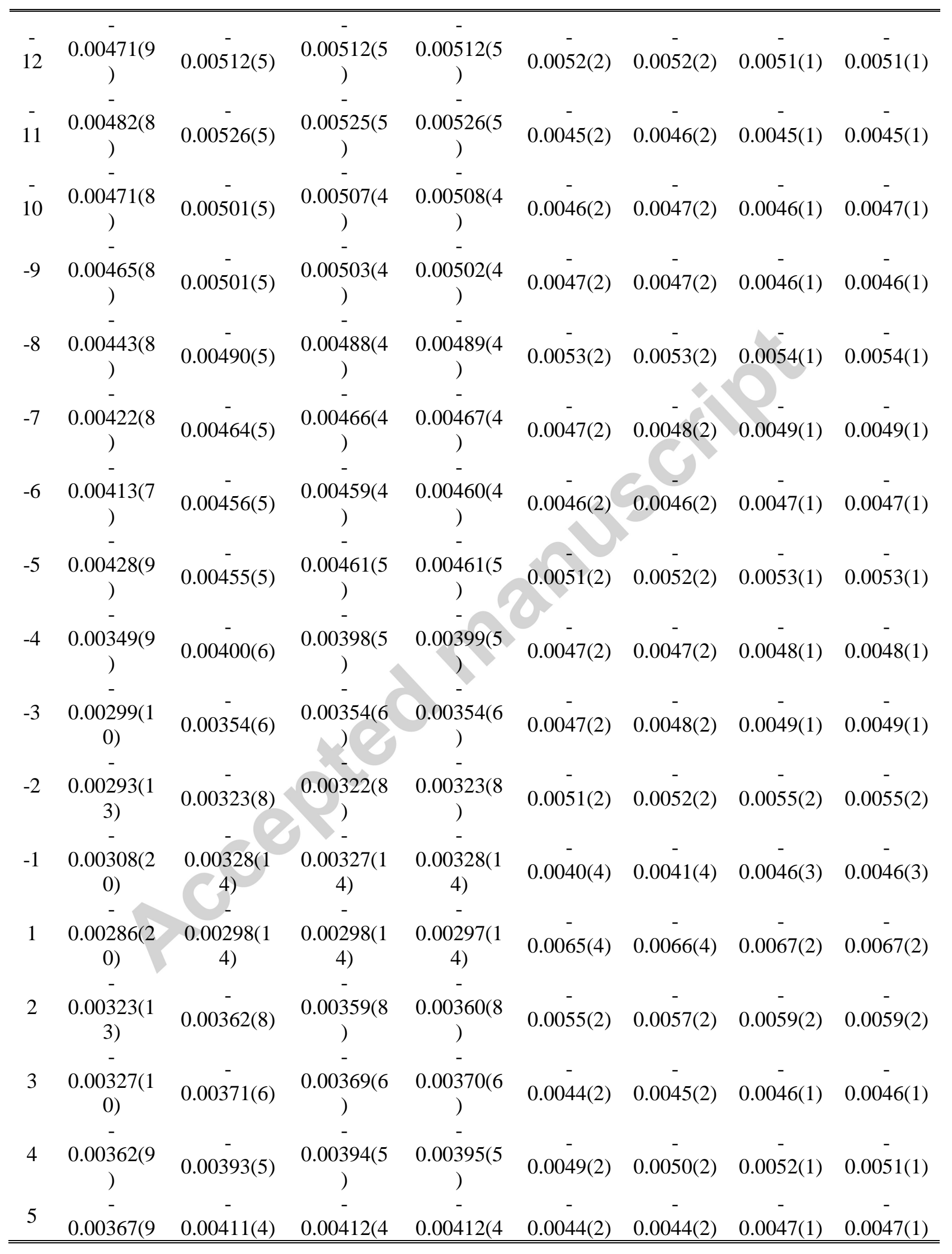




\begin{tabular}{|c|c|c|c|c|c|c|c|c|}
\hline & ） & & ） & ） & & & & \\
\hline & - & & - & - & & & & \\
\hline 6 & $\begin{array}{c}0.00381(8 \\
)\end{array}$ & $0.00423(4)$ & $\begin{array}{c}0.00422(4 \\
)\end{array}$ & $\begin{array}{c}0.00422(4 \\
)\end{array}$ & $0.0044(2)$ & $0.0045(2)$ & $0.0047(1)$ & $0.0048(1)$ \\
\hline & - & & - & - & & & & \\
\hline 7 & $\begin{array}{c}0.00394(8 \\
)\end{array}$ & $\stackrel{-}{0.00433(4)}$ & $\begin{array}{c}0.00433(4 \\
)\end{array}$ & $\begin{array}{c}0.00434(4 \\
)\end{array}$ & $\begin{array}{c}- \\
0.0043(2)\end{array}$ & $0.0043(2)$ & $0.0046(1)$ & $0.0046(1)$ \\
\hline 8 & $\begin{array}{c}- \\
0.00396(8 \\
)\end{array}$ & $\begin{array}{c}- \\
0.00439(4)\end{array}$ & $\begin{array}{c}- \\
0.00438(4 \\
)\end{array}$ & $\begin{array}{c}- \\
0.00438(4 \\
)\end{array}$ & $0.0042(2)$ & $\begin{array}{c}- \\
0.0042(2)\end{array}$ & $\begin{array}{c}- \\
0.0043(1)\end{array}$ & $0.0043(1)$ \\
\hline 9 & $\begin{array}{c}- \\
0.00385(8 \\
)\end{array}$ & $\begin{array}{c}- \\
0.00429(4)\end{array}$ & $\begin{array}{c}- \\
0.00428(4 \\
)\end{array}$ & $\begin{array}{c}- \\
0.00428(4 \\
)\end{array}$ & $\begin{array}{c}- \\
0.0042(2)\end{array}$ & $\begin{array}{c}- \\
0.0042(2)\end{array}$ & $\begin{array}{c}- \\
0.0044(1)\end{array}$ & $\begin{array}{c}- \\
0.0044(1)\end{array}$ \\
\hline 10 & $\begin{array}{c}- \\
0.00403(8 \\
)\end{array}$ & $\begin{array}{c}- \\
0.00444(4)\end{array}$ & $\begin{array}{c}- \\
0.00443(4 \\
)\end{array}$ & $\begin{array}{c}- \\
0.00444(4 \\
)\end{array}$ & $\begin{array}{c}- \\
0.0037(2)\end{array}$ & $\begin{array}{c}- \\
0.0037(2)\end{array}$ & $0.0038(1)$ & $\begin{array}{c}- \\
0.0038(1)\end{array}$ \\
\hline 11 & $\begin{array}{c}- \\
0.00394(8 \\
)\end{array}$ & $\begin{array}{c}- \\
0.00434(4)\end{array}$ & $\begin{array}{c}- \\
0.00434(4 \\
)\end{array}$ & $\begin{array}{c}- \\
0.00434(4 \\
)\end{array}$ & $0.0035(2)$ & $0.0036(2)$ & $0.0037(1)$ & $\begin{array}{c}- \\
0.0037(1)\end{array}$ \\
\hline 12 & $\begin{array}{c}- \\
0.00413(8 \\
)\end{array}$ & $\begin{array}{c}- \\
0.00445(4)\end{array}$ & $\begin{array}{c}- \\
0.00445(4 \\
)\end{array}$ & $\begin{array}{c}- \\
0.00445(4 \\
)\end{array}$ & $\begin{array}{c}- \\
0.0044(2)\end{array}$ & $0.0044(2)$ & $\begin{array}{c}- \\
0.0046(1)\end{array}$ & $0.0046(1)$ \\
\hline 13 & $\begin{array}{c}- \\
0.00424(9 \\
)\end{array}$ & $\begin{array}{c}- \\
0.00461(4)\end{array}$ & $\begin{array}{c}- \\
0.00460(4 \\
)\end{array}$ & $\begin{array}{c}- \\
0.00461(4 \\
)\end{array}$ & $0.0037(2)$ & $\begin{array}{c}- \\
0.0038(2)\end{array}$ & $\begin{array}{c}- \\
0.0039(1)\end{array}$ & $\begin{array}{c}- \\
0.0039(1)\end{array}$ \\
\hline 14 & $\begin{array}{c}- \\
0.00416(9 \\
)\end{array}$ & $\begin{array}{c}- \\
0.00472(5)\end{array}$ & $\begin{array}{c}- \\
0.00471(5 \\
)\end{array}$ & $\begin{array}{c}0.00472(5 \\
)^{-1}\end{array}$ & $\begin{array}{c}- \\
0.0042(2)\end{array}$ & $\begin{array}{c}- \\
0.0042(2)\end{array}$ & $\begin{array}{c}- \\
0.0042(1)\end{array}$ & $\begin{array}{c}- \\
0.0042(1)\end{array}$ \\
\hline 15 & $\begin{array}{c}- \\
0.00427(1 \\
0)\end{array}$ & $\begin{array}{c}- \\
0.00463(5)\end{array}$ & $\begin{array}{c}0.00463(5 \\
)\end{array}$ & $\begin{array}{c}- \\
0.00464(5 \\
)\end{array}$ & $\begin{array}{c}- \\
0.0042(2)\end{array}$ & $\begin{array}{c}- \\
0.0042(2)\end{array}$ & $\begin{array}{c}- \\
0.0042(1)\end{array}$ & $\begin{array}{c}- \\
0.0042(1)\end{array}$ \\
\hline 16 & $\begin{array}{c}- \\
0.00432(1 \\
1)\end{array}$ & $\begin{array}{c}- \\
0.00479(6)\end{array}$ & $\begin{array}{c}0.00479(6 \\
)\end{array}$ & $\begin{array}{c}- \\
0.00480(6 \\
)\end{array}$ & $\begin{array}{c}- \\
0.0047(3)\end{array}$ & $\begin{array}{c}- \\
0.0047(3)\end{array}$ & $\begin{array}{c}- \\
0.0052(2)\end{array}$ & $\begin{array}{c}- \\
0.0051(2)\end{array}$ \\
\hline 17 & $\begin{array}{c}- \\
0.00421(1 \\
2)\end{array}$ & $0.00469(7)$ & $\begin{array}{c}- \\
0.00468(7 \\
)\end{array}$ & $\begin{array}{c}- \\
0.00469(7 \\
)\end{array}$ & $\begin{array}{c}- \\
0.0043(3)\end{array}$ & $\begin{array}{c}- \\
0.0045(3)\end{array}$ & $\begin{array}{c}- \\
0.0045(2)\end{array}$ & $\begin{array}{c}- \\
0.0045(2)\end{array}$ \\
\hline 18 & $\begin{array}{c}- \\
0.00475(1 \\
4)\end{array}$ & - & $\begin{array}{c}- \\
0.00506(8 \\
)\end{array}$ & $\begin{array}{c}- \\
0.00506(8 \\
)\end{array}$ & $\begin{array}{c}- \\
0.0041(3)\end{array}$ & $\begin{array}{c}- \\
0.0043(3)\end{array}$ & $\begin{array}{c}- \\
0.0040(2)\end{array}$ & $\begin{array}{c}- \\
0.0040(2)\end{array}$ \\
\hline 19 & $\begin{array}{c}- \\
0.00438(1 \\
6)\end{array}$ & $\begin{array}{c}- \\
0.00491(1 \\
0)\end{array}$ & $\begin{array}{c}- \\
0.00491(1 \\
0)\end{array}$ & $\begin{array}{c}- \\
0.00492(1 \\
0)\end{array}$ & $0.0038(4)$ & $0.0040(4)$ & $\begin{array}{c}- \\
0.0040(3)\end{array}$ & $\begin{array}{c}- \\
0.0040(3)\end{array}$ \\
\hline 20 & $\begin{array}{c}- \\
0.00507(2 \\
0)\end{array}$ & $\begin{array}{c}- \\
0.00505(1 \\
2)\end{array}$ & $\begin{array}{c}- \\
0.00505(1 \\
2)\end{array}$ & $\begin{array}{c}- \\
0.00505(1 \\
2)\end{array}$ & $\begin{array}{c}- \\
0.0054(4)\end{array}$ & $\begin{array}{c}- \\
0.0057(5)\end{array}$ & $\begin{array}{c}- \\
0.0050(3)\end{array}$ & $\begin{array}{c}- \\
0.0050(3)\end{array}$ \\
\hline 21 & $\begin{array}{c}- \\
0.00456(2 \\
5)\end{array}$ & $\begin{array}{c}- \\
0.00488(1 \\
5)\end{array}$ & $\begin{array}{c}- \\
0.00488(1 \\
5)\end{array}$ & $\begin{array}{c}- \\
0.00488(1 \\
5)\end{array}$ & $\begin{array}{c}- \\
0.0041(6)\end{array}$ & $\begin{array}{c}- \\
0.0044(6)\end{array}$ & $\begin{array}{c}- \\
0.0052(4)\end{array}$ & $\begin{array}{c}- \\
0.0052(4)\end{array}$ \\
\hline 22 & - & - & - & - & - & - & - & - \\
\hline
\end{tabular}




\begin{tabular}{ccccccccc}
\hline \hline & $0.00509(2$ & $0.00529(2$ & $0.00529(2$ & $0.00529(2$ & $0.0037(8)$ & $0.0039(8)$ & $0.0041(5)$ & $0.0041(5)$ \\
& $6)$ & $0)$ & $0)$ & $0)$ & & & & \\
23 & $0.00497(3$ & $0.00500(2$ & $0.00500(2$ & $0.00500(2$ & $0.0056(1$ & - & - & - \\
& $6)$ & $8)$ & $8)$ & $8)$ & $1)$ & $0.006(11)$ & $0.0054(8)$ & $0.0054(8)$ \\
& & & & - & - & - & - \\
24 & & & & $0.0091(1$ & $0.0095(1$ & $0.0093(1$ & $0.0092(1$ \\
& & & & $5)$ & $6)$ & $1)$ & $1)$ \\
\hline \hline
\end{tabular}

Table 9. Line mixing coefficients $\left(\mathrm{atm}^{-1}\right.$ ) for $\mathrm{CO}-\mathrm{CO}$ and $\mathrm{CO}-\mathrm{H}_{2}$ for transitions in the first overtone band obtained using the Voigt, Speed-Dependent Voigt line shape models. Calculated values obtained using the EPG method are also included.

\begin{tabular}{|c|c|c|c|c|c|c|}
\hline \multirow{2}{*}{$\mathbf{m}$} & \multicolumn{3}{|c|}{$\mathrm{CO}-\mathrm{CO}$} & \multicolumn{3}{|c|}{$\mathrm{CO}-\mathrm{H}_{2}$} \\
\hline & Voigt & SD-Voigt & EPG & Voigt & SD-Voigt & EPG \\
\hline-24 & & & 0.0030 & & & 0.0054 \\
\hline-23 & & & 0.0020 & & & 0.0049 \\
\hline-22 & & & 0.0018 & & & 0.0047 \\
\hline-21 & & & 0.0017 & & & 0.0046 \\
\hline-20 & & & 0.0017 & & & 0.0045 \\
\hline-19 & & & 0.0016 & $0.0042(2)$ & $0.0040(1)$ & 0.0044 \\
\hline-18 & $-0.0030(22)$ & $-0.00291(10)$ & 0.0015 & $0.019(37)$ & $0.0194(19)$ & 0.0043 \\
\hline-17 & $-0.0004(17)$ & $-0.00159(11)$ & 0.0015 & $0.0044(2)$ & $0.0037(1)$ & 0.0042 \\
\hline-16 & $0.0000(14)$ & $-0.00026(8)$ & 0.0014 & $0.0038(1)$ & $0.0036(1)$ & 0.0041 \\
\hline-15 & $0.0018(11)$ & $0.00187(14)$ & 0.0013 & $0.0042(1)$ & $0.0040(1)$ & 0.0039 \\
\hline-14 & $0.0023(10)$ & $0.00167(7)$ & 0.0012 & $0.0071(1)$ & $0.0074(1)$ & 0.0037 \\
\hline-13 & $0.0048(8)$ & $0.00435(6)$ & 0.0011 & $0.0033(1)$ & $0.0031(0)$ & 0.0035 \\
\hline-12 & $0.0028(7)$ & $0.00224(7)$ & 0.0009 & $0.0026(1)$ & $0.0029(0)$ & 0.0032 \\
\hline-11 & $0.0015(7)$ & $0.00158(6)$ & 0.0007 & $0.0031(1)$ & $0.0029(0)$ & 0.0028 \\
\hline-10 & $0.0001(6)$ & $-0.00017(6)$ & 0.0005 & $0.0029(1)$ & $0.0027(0)$ & 0.0024 \\
\hline-9 & $0.0000(6)$ & $-0.00002(5)$ & 0.0002 & $0.0017(1)$ & $0.0018(0)$ & 0.0019 \\
\hline-8 & $-0.0003(6)$ & $-0.00061(6)$ & -0.0002 & $0.0011(1)$ & $0.0015(0)$ & 0.0013 \\
\hline-7 & $-0.0011(6)$ & $-0.00145(6)$ & -0.0007 & $0.0001(1)$ & $0.0006(0)$ & 0.0006 \\
\hline-6 & $-0.0011(0)$ & $-0.00113(6)$ & -0.0014 & $-0.0004(1)$ & $-0.0003(0)$ & -0.0003 \\
\hline-5 & $0.0016(6)$ & $0.00171(5)$ & -0.0024 & $-0.0004(1)$ & $-0.0007(0)$ & -0.0013 \\
\hline-4 & $-0.0012(7)$ & $-0.00167(6)$ & -0.0038 & $-0.0020(1)$ & $-0.0019(0)$ & -0.0025 \\
\hline-3 & $-0.0047(9)$ & $-0.00512(6)$ & -0.0059 & $-0.0029(1)$ & $-0.0031(0)$ & -0.0038 \\
\hline-2 & $-0.0045(12)$ & $-0.00469(8)$ & -0.0099 & $-0.0065(1)$ & $-0.0061(1)$ & -0.0064 \\
\hline-1 & $-0.0017(22)$ & $-0.00184(21)$ & -0.0194 & $-0.0162(2)$ & $-0.0163(1)$ & -0.0145 \\
\hline 1 & $0.0104(22)$ & $0.00952(11)$ & 0.0236 & $0.0101(1)$ & $0.0100(1)$ & 0.0093 \\
\hline
\end{tabular}




\begin{tabular}{ccccccc}
\hline \hline 2 & $0.0045(12)$ & $0.00476(6)$ & 0.0128 & $0.0110(1)$ & $0.0119(1)$ & 0.0121 \\
3 & $0.0033(8)$ & $0.00280(6)$ & 0.0076 & $0.0059(1)$ & $0.0062(1)$ & 0.0068 \\
4 & $0.0034(7)$ & $0.00325(5)$ & 0.0053 & $0.0041(1)$ & $0.0038(0)$ & 0.0044 \\
5 & $0.0023(6)$ & $0.00208(5)$ & 0.0037 & $0.0025(1)$ & $0.0023(0)$ & 0.0027 \\
6 & $0.0012(5)$ & $0.00085(5)$ & 0.0026 & $0.0007(1)$ & $0.0011(0)$ & 0.0014 \\
7 & $0.0011(5)$ & $0.00085(5)$ & 0.0018 & $0.0002(1)$ & $-0.0002(0)$ & 0.0002 \\
8 & $0.0003(5)$ & $0.00048(5)$ & 0.0011 & $-0.001(1)$ & $-0.0011(0)$ & -0.0008 \\
9 & $-0.0013(5)$ & $-0.00123(5)$ & 0.0006 & $-0.0019(1)$ & $-0.0018(0)$ & -0.0017 \\
10 & $-0.0009(6)$ & $-0.00110(6)$ & 0.0001 & $-0.0026(1)$ & $-0.0028(0)$ & -0.0026 \\
11 & $-0.0012(6)$ & $-0.00089(5)$ & -0.0003 & $-0.0035(1)$ & $-0.0032(0)$ & -0.0033 \\
12 & $-0.0026(7)$ & $-0.00288(6)$ & -0.0007 & $-0.0033(1)$ & $-0.0038(0)$ & -0.0040 \\
13 & $-0.0016(7)$ & $-0.00127(9)$ & -0.0010 & $-0.0048(1)$ & $-0.0041(0)$ & -0.0047 \\
14 & $-0.0019(9)$ & $-0.00287(7)$ & -0.0013 & $-0.0043(1)$ & $-0.0046(1)$ & -0.0053 \\
15 & $-0.0043(10)$ & $-0.00423(8)$ & -0.0016 & $-0.0055(1)$ & $-0.0052(1)$ & -0.0059 \\
16 & $-0.0034(12)$ & $-0.00450(7)$ & -0.0019 & $0.0005(15)$ & $0.0004(9)$ & -0.0065 \\
17 & $-0.0073(15)$ & $-0.00804(11)$ & -0.0021 & $-0.0060(1)$ & $-0.0061(1)$ & -0.0070 \\
18 & $-0.0023(18)$ & $-0.00256(11)$ & -0.0024 & $-0.0066(1)$ & $-0.0067(1)$ & -0.0076 \\
19 & $-0.0055(23)$ & $-0.00629(15)$ & -0.0026 & $-0.0068(1)$ & $-0.0066(1)$ & -0.0081 \\
20 & $-0.0012(31)$ & $-0.00054(15)$ & -0.0029 & $-0.0069(1)$ & $-0.0074(1)$ & -0.0087 \\
21 & $-0.0051(41)$ & $-0.00612(19)$ & -0.0032 & $-0.0084(2)$ & $-0.0073(1)$ & -0.0093 \\
22 & & & -0.0036 & & & -0.0101 \\
23 & & & -0.0045 & & & -0.0112 \\
24 & & & -0.0074 & & & -0.0132 \\
\hline \hline & & & & & & \\
& & & & & & \\
1
\end{tabular}

Table 10. Speed dependence parameter for pure CO (present study and Ref. [11]), and for CO$\mathrm{H}_{2}$ for transitions in the first overtone band obtained using the Speed-Dependent Voigt line shape model.

\begin{tabular}{cccc}
\hline \hline m & $\begin{array}{c}\text { CO-CO } \\
\text { Present study }\end{array}$ & $\begin{array}{c}\text { CO-CO } \\
\text { Devi } \text { et al., 2012 }\end{array}$ & $\begin{array}{c}\text { CO-H } \\
\text { Present study }\end{array}$ \\
\hline \hline-24 & & 0.083 & 0.00625 \\
-23 & & 0.071 & 0.00444 \\
-22 & & 0.066 & 0.00413 \\
-21 & & 0.070 & 0.00439 \\
-20 & & 0.064 & 0.00401 \\
-19 & 0.086 & 0.070 & 0.00438 \\
-18 & 0.140 & 0.070 & 0.00000 \\
-17 & 0.044 & 0.071 & 0.00444 \\
-16 & 0.056 & 0.068 & 0.00426 \\
-15 & 0.046 & 0.074 & 0.00463 \\
-14 & 0.077 & 0.070 & 0.00438 \\
-13 & 0.111 & 0.073 & 0.00456 \\
-12 & 0.103 & 0.074 & 0.00462 \\
\hline \hline
\end{tabular}




\begin{tabular}{cccc}
\hline \hline-11 & 0.110 & 0.077 & 0.00481 \\
-10 & 0.125 & 0.078 & 0.00487 \\
-9 & 0.106 & 0.085 & 0.00531 \\
-8 & 0.104 & 0.087 & 0.00544 \\
-7 & 0.118 & 0.096 & 0.00600 \\
-6 & 0.104 & 0.103 & 0.00644 \\
-5 & 0.119 & 0.107 & 0.00669 \\
-4 & 0.108 & 0.109 & 0.00681 \\
-3 & 0.114 & 0.107 & 0.00669 \\
-2 & 0.132 & 0.104 & 0.00650 \\
-1 & 0.088 & 0.107 & 0.00669 \\
1 & 0.113 & 0.106 & 0.00662 \\
2 & 0.110 & 0.105 & 0.00656 \\
3 & 0.109 & 0.111 & 0.00694 \\
4 & 0.122 & 0.117 & 0.00731 \\
5 & 0.123 & 0.116 & 0.00725 \\
6 & 0.118 & 0.112 & 0.00700 \\
7 & 0.106 & 0.106 & 0.00073 \\
8 & 0.114 & 0.098 & 0.00613 \\
9 & 0.108 & 0.093 & 0.00644 \\
10 & 0.107 & 0.088 & 0.00550 \\
11 & 0.100 & 0.084 & 0.00525 \\
12 & 0.096 & 0.080 & 0.00500 \\
13 & 0.099 & 0.077 & 0.00481 \\
14 & 0.092 & 0.076 & 0.00475 \\
15 & 0.088 & 0.077 & 0.00481 \\
16 & 0.074 & 0.077 & 0.00000 \\
17 & 0.084 & 0.075 & 0.00469 \\
18 & 0.097 & 0.076 & 0.00476 \\
19 & 0.098 & 0.073 & 0.00457 \\
20 & & 0.074 & 0.00463 \\
21 & 0.072 & 0.00451 \\
22 & & 0.069 & 0.00432 \\
23 & 0.069 & 0.00432 \\
24 & 0.065 & 0.01877 \\
\hline \hline & & & \\
\hline
\end{tabular}


Table 11. Thermally averaged theoretical line broadening coefficients convergence for different $b_{\max }$ values, as shown in Fig. 9. Note that all the values are calculated in $\mathrm{cm}^{-1} \mathrm{~atm}^{-1}$ at $296 \mathrm{~K}$.

\begin{tabular}{ccccccc}
\hline \hline & \multicolumn{3}{c}{ CO-CO } & & \multicolumn{3}{c}{$\mathbf{C O - H} \mathbf{2}$} \\
\hline \hline $\boldsymbol{J}$ & $\mathbf{b}_{\mathbf{m a x}}=\mathbf{1 4}$ & $\mathbf{b}_{\mathbf{m a x}}=\mathbf{1 9}$ & $\mathbf{b}_{\mathbf{m a x}}=\mathbf{2 5}$ & $\mathbf{b}_{\max }=\mathbf{1 2}$ & $\mathbf{b}_{\max }=\mathbf{1 3}$ & $\mathbf{b}_{\max }=\mathbf{1 5}$ \\
\hline 0 & 0.09974 & 0.10075 & 0.10202 & 0.07854 & 0.07792 & 0.07857 \\
2 & 0.08928 & 0.08974 & 0.08875 & 0.07572 & 0.07551 & 0.07578 \\
4 & 0.08136 & 0.08108 & 0.08088 & 0.07392 & 0.07453 & 0.07422 \\
6 & 0.07726 & 0.07667 & 0.07603 & 0.07331 & 0.07316 & 0.07311 \\
8 & 0.07320 & 0.07265 & 0.07338 & 0.07169 & 0.07159 & 0.07224 \\
10 & 0.06981 & 0.06899 & 0.06855 & 0.07018 & 0.06993 & 0.07008 \\
12 & 0.06463 & 0.06466 & 0.06492 & 0.06934 & 0.06916 & 0.06944 \\
14 & 0.06045 & 0.06091 & 0.06039 & 0.06810 & 0.06837 & 0.06853 \\
16 & 0.05616 & 0.05661 & 0.05568 & 0.06725 & 0.06742 & 0.06708 \\
18 & 0.05231 & 0.05255 & 0.05137 & 0.06713 & 0.06664 & 0.06635 \\
20 & 0.04867 & 0.04847 & 0.04743 & 0.06705 & 0.06662 & 0.06664 \\
22 & 0.04517 & 0.04522 & 0.04404 & 0.06584 & 0.06609 & 0.06643 \\
24 & 0.04222 & 0.04227 & 0.04130 & 0.06602 & 0.06603 & 0.06640 \\
\hline \hline
\end{tabular}

Table 12. Theoretical line broadening coefficients in $\mathrm{cm}^{-1} \mathrm{~atm}^{-1}$ at $296 \mathrm{~K}$ obtained applying the Maxwell-Boltzmann speed averaging and Mean Thermal Velocity (MThV) approximation shown in Fig. 10.

\begin{tabular}{ccccc}
\hline \hline & \multicolumn{2}{c}{ CO-CO } & \multicolumn{2}{c}{ CO-H $_{\mathbf{2}}$} \\
\cline { 2 - 5 } $\boldsymbol{J}$ & $\begin{array}{c}\text { Maxwell-Boltzmann } \\
\text { Average }\end{array}$ & MThV & $\begin{array}{c}\text { Maxwell-Boltzmann } \\
\text { Average }\end{array}$ & MThV \\
\hline \hline 0 & 0.10075 & 0.10109 & 0.07792 & 0.07346 \\
2 & 0.08974 & 0.09041 & 0.07551 & 0.07191 \\
4 & 0.08108 & 0.08076 & 0.07453 & 0.07229 \\
6 & 0.07667 & 0.07543 & 0.07316 & 0.07258 \\
8 & 0.07265 & 0.07183 & 0.07159 & 0.07190 \\
10 & 0.06899 & 0.06762 & 0.06993 & 0.07065 \\
12 & 0.06466 & 0.06403 & 0.06916 & 0.06889 \\
14 & 0.06091 & 0.05945 & 0.06837 & 0.06689 \\
16 & 0.05661 & 0.05537 & 0.06742 & 0.06566 \\
18 & 0.05255 & 0.05042 & 0.06664 & 0.06513 \\
20 & 0.04847 & 0.04662 & 0.06662 & 0.06443 \\
22 & 0.04522 & 0.04345 & 0.06609 & 0.06449 \\
24 & 0.04227 & 0.04075 & 0.06603 & 0.06462 \\
\hline \hline
\end{tabular}


Table 13. Thermally averaged theoretical line broadening coefficients $\left(\mathrm{cm}^{-1} \mathrm{~atm}^{-1}\right)$ at $296 \mathrm{~K}$ shown in Figs. 10 and 11.

\begin{tabular}{cccccc}
\hline \hline \multicolumn{3}{c}{ CO-CO } & & \multicolumn{2}{c}{ CO-H $_{\mathbf{2}}$} \\
\hline \hline $\boldsymbol{J}$ & $\mathbf{1}$ & $\mathbf{2}$ & $\mathbf{3}$ & $\mathbf{1}$ & $\mathbf{2}$ \\
\hline \hline 0 & 0.10075 & 0.10012 & 0.10079 & 0.07792 & 0.07947 \\
2 & 0.08974 & 0.08847 & 0.08901 & 0.07551 & 0.07724 \\
4 & 0.08108 & 0.08020 & 0.08023 & 0.07453 & 0.07641 \\
6 & 0.07667 & 0.07547 & 0.07579 & 0.07316 & 0.07563 \\
8 & 0.07265 & 0.07154 & 0.07142 & 0.07159 & 0.07450 \\
10 & 0.06899 & 0.06796 & 0.06800 & 0.06993 & 0.07321 \\
12 & 0.06466 & 0.06363 & 0.06356 & 0.06916 & 0.07282 \\
14 & 0.06091 & 0.05998 & 0.05968 & 0.06837 & 0.07180 \\
16 & 0.05661 & 0.05523 & 0.05504 & 0.06742 & 0.07075 \\
18 & 0.05255 & 0.05106 & 0.05086 & 0.06664 & 0.07037 \\
20 & 0.04847 & 0.04685 & 0.04658 & 0.06662 & 0.06997 \\
22 & 0.04522 & 0.04335 & 0.04314 & 0.06609 & 0.06986 \\
24 & 0.04227 & 0.04029 & 0.04020 & 0.06603 & 0.06960 \\
\hline \hline
\end{tabular}

CO-CO: $R_{\max }=20 \AA, b_{\max }=19 \AA$. Parameters of interaction PES are given as follows: $1 . \varepsilon=110 \mathrm{~K}, \sigma=3.59 \AA$, $\gamma$ $=0.089 ; 2 . \varepsilon=91.7 \mathrm{~K}, \sigma=3.690 \AA, \gamma=0.089 ; 3 . \varepsilon=91.7 \mathrm{~K}, \sigma=3.690 \AA ⿻, \gamma=0.089$.

CO- $\mathbf{H}_{2}: R_{\max }=15 \AA, b_{\max }=13 \AA$. Parameters of interaction PES are given as follows: $1 . \varepsilon=48.8787 \mathrm{~K}, \sigma=3.3872 \AA$, $\gamma=0.16667 ; 2 . \varepsilon=91.7 \mathrm{~K}, \sigma=3.690 \AA, \gamma=0.089$.

Table 14. Thermally averaged line broadening coefficients $\left(\mathrm{cm}^{-1} \mathrm{~atm}^{-1}\right)$ at $296 \mathrm{~K}$ resulting from contribution of different parts of the interaction PES in the case of CO-CO and $\mathrm{CO}-\mathrm{H}_{2}$ shown in Fig. 13 and Fig. 14.

\begin{tabular}{cccccccc}
\hline \hline \multirow{2}{*}{$\boldsymbol{J}$} & \multicolumn{3}{c}{ CO-CO } & \multicolumn{3}{c}{ CO-H } \\
\cline { 2 - 8 } & TH & TH+dd & TH+dd+QQ & TH+dd+dQ+QQ & TH & TH+QQ & TH+dQ+QQ \\
\hline \hline 0 & 0.06548 & 0.06559 & 0.09969 & 0.10075 & 0.06236 & 0.07845 & 0.07792 \\
2 & 0.05720 & 0.05741 & 0.08811 & 0.08974 & 0.05954 & 0.07593 & 0.07551 \\
\hline \hline
\end{tabular}




\begin{tabular}{cccccccc}
\hline \hline 4 & 0.05205 & 0.05211 & 0.07924 & 0.08108 & 0.05846 & 0.07497 & 0.07453 \\
6 & 0.04886 & 0.04873 & 0.07491 & 0.07667 & 0.05727 & 0.0735 & 0.07316 \\
8 & 0.04745 & 0.04754 & 0.07162 & 0.07265 & 0.05724 & 0.07196 & 0.07159 \\
10 & 0.04719 & 0.04730 & 0.06795 & 0.06899 & 0.05764 & 0.07033 & 0.06993 \\
12 & 0.04677 & 0.04678 & 0.06407 & 0.06466 & 0.05803 & 0.06910 & 0.06916 \\
14 & 0.04599 & 0.04602 & 0.06017 & 0.06091 & 0.05900 & 0.06837 & 0.06837 \\
16 & 0.04534 & 0.04527 & 0.05610 & 0.05661 & 0.05926 & 0.06762 & 0.06742 \\
18 & 0.04357 & 0.04352 & 0.05196 & 0.05255 & 0.05938 & 0.06689 & 0.06664 \\
20 & 0.04232 & 0.04228 & 0.04787 & 0.04847 & 0.05957 & 0.06666 & 0.06662 \\
22 & 0.04087 & 0.04088 & 0.04457 & 0.04522 & 0.05989 & 0.06622 & 0.06609 \\
24 & 0.03925 & 0.03922 & 0.04166 & 0.04227 & 0.05985 & 0.06643 & 0.06603 \\
\hline \hline
\end{tabular}

Highlights

- Self- and $\mathrm{H}_{2}$-broadened line parameters for transitions in the $2 \leftarrow 0$ band of $\mathrm{CO}$ at $298 \mathrm{~K}$ are reported

- Line intensities, pressure shifts, line mixing and speed dependence parameters are presented.

- Calculations of self- and $\mathrm{H}_{2}$-broadening coefficients of $\mathrm{CO}$ using classical impact theory are included. 
Multispectrum fits of 10 spectra of $\mathrm{CO}$ using the Voigt model and weak line mixing (A)
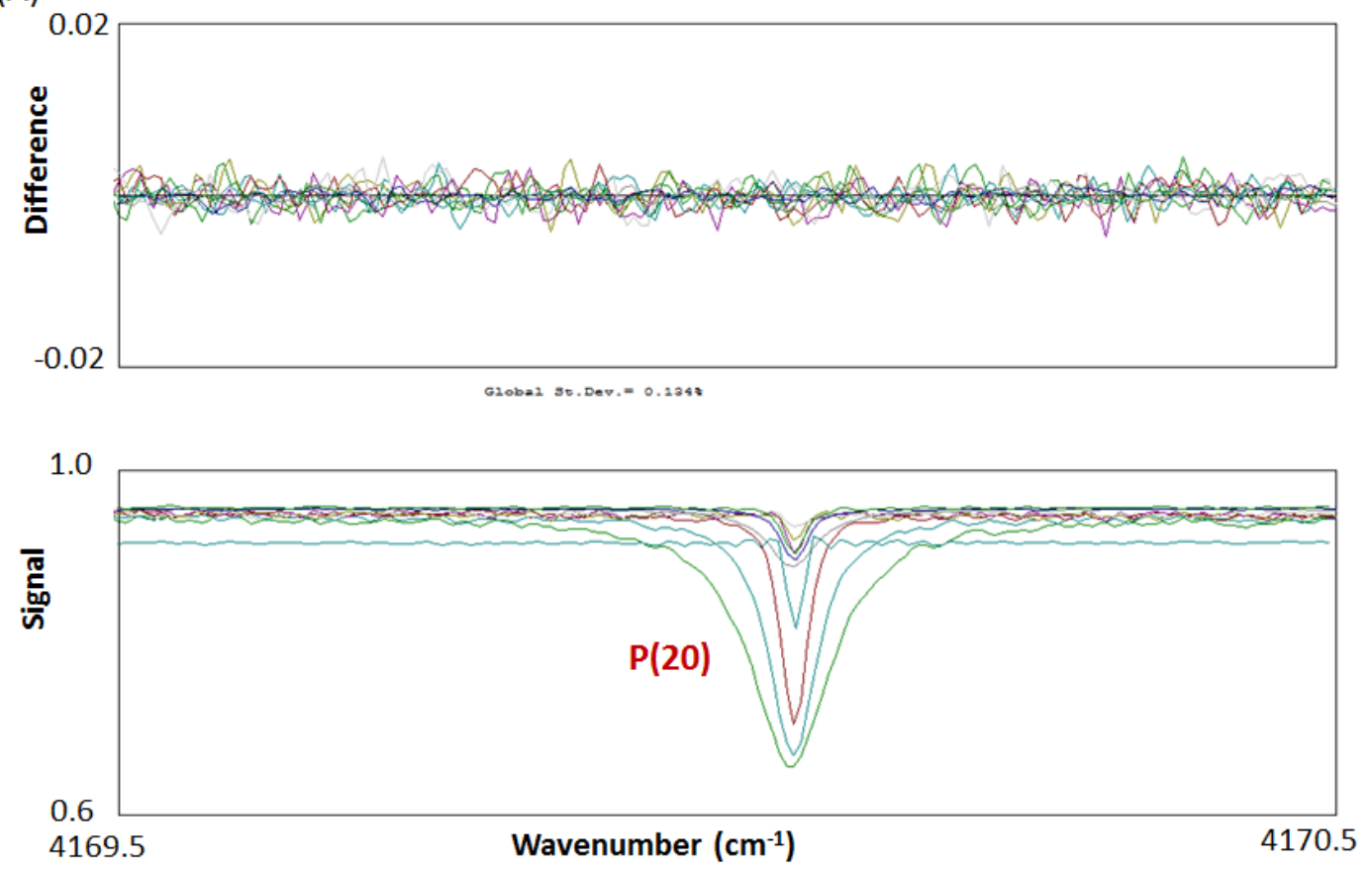

Multispectrum fits of 10 spectra of $\mathrm{CO}$ using the SD-Voigt model and weak line mixing (B)
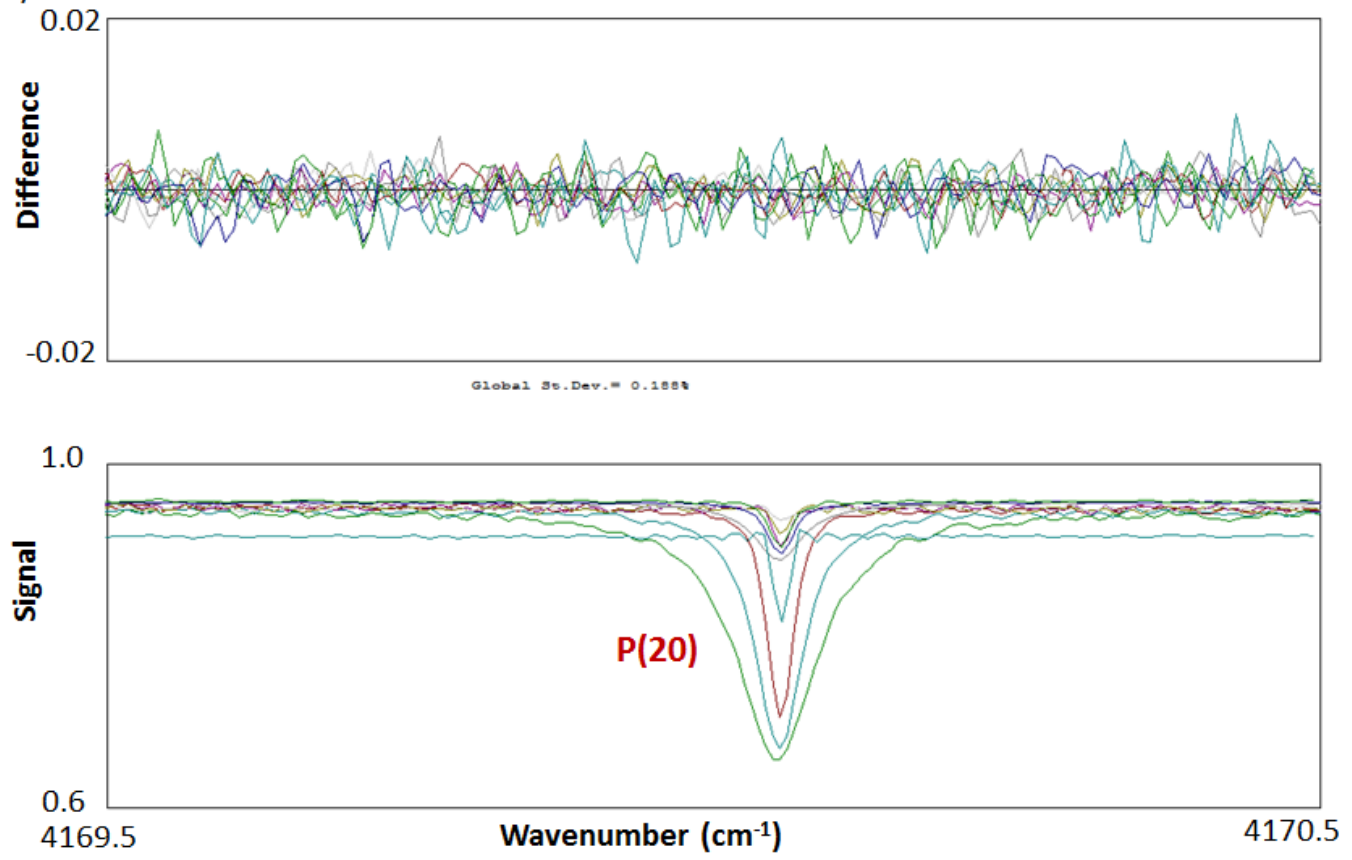
Multispectrum fits of 10 spectra of $\mathrm{CO}$ using the Rautian model and weak line mixing

(C)
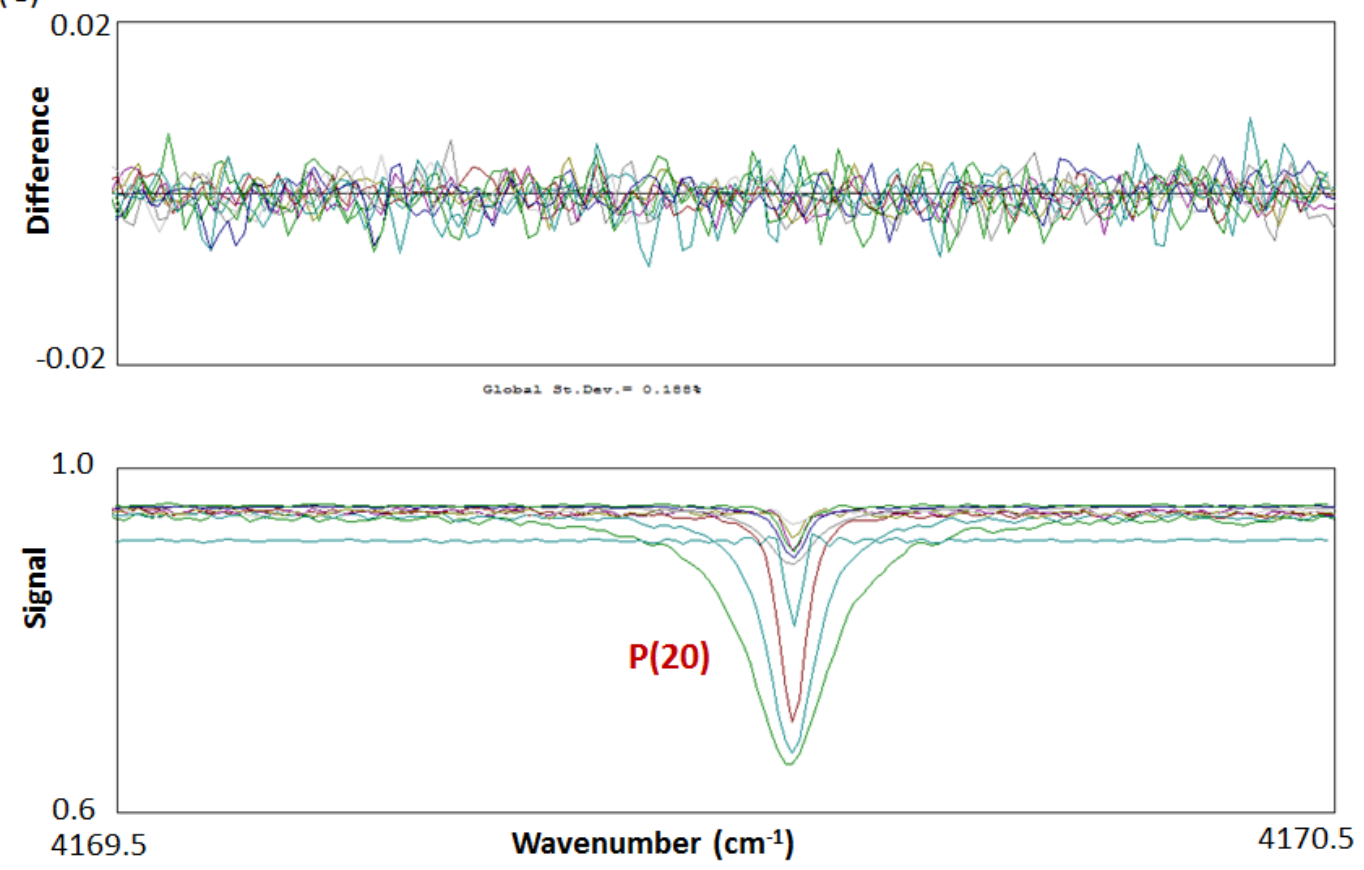

Multispectrum fits of 10 spectra of $\mathrm{CO}$ using the SD-Rautian model and weak line mixing (D)
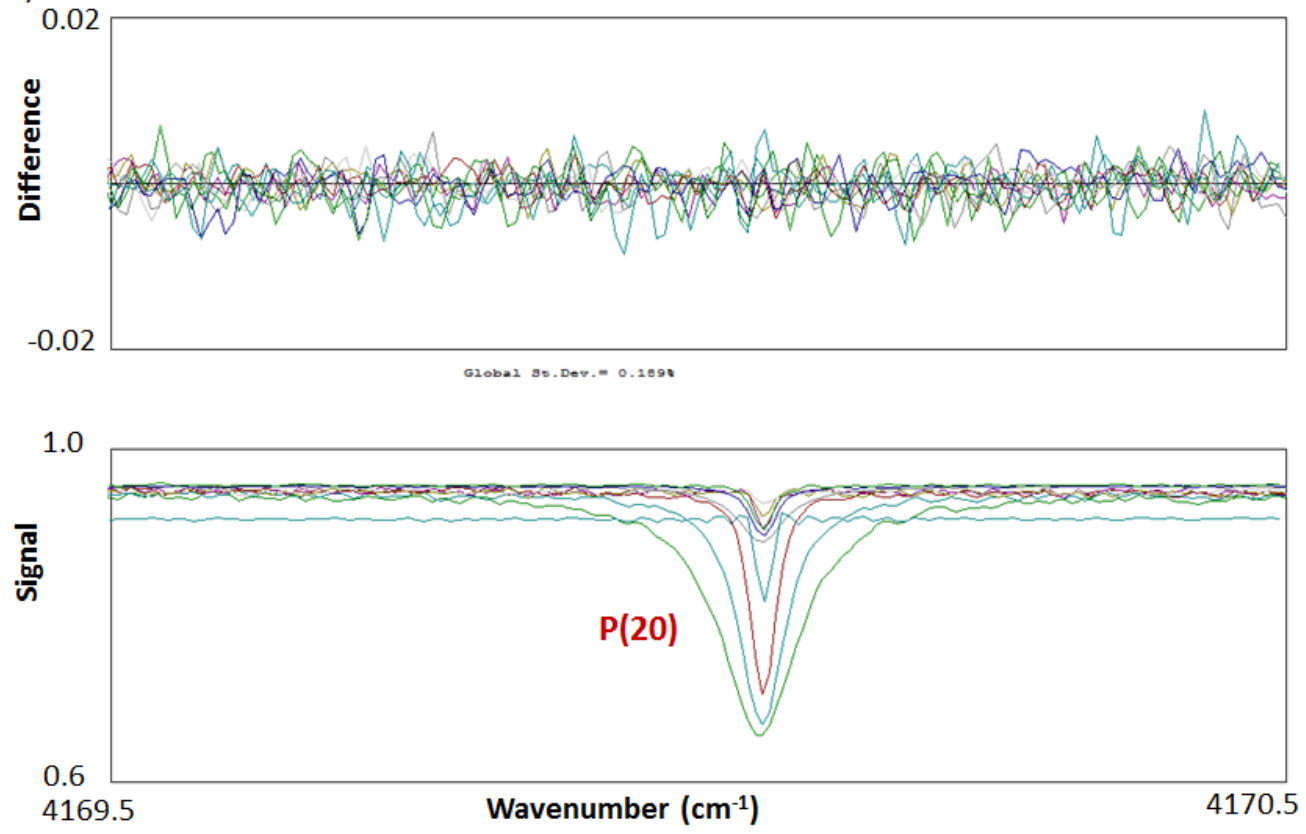


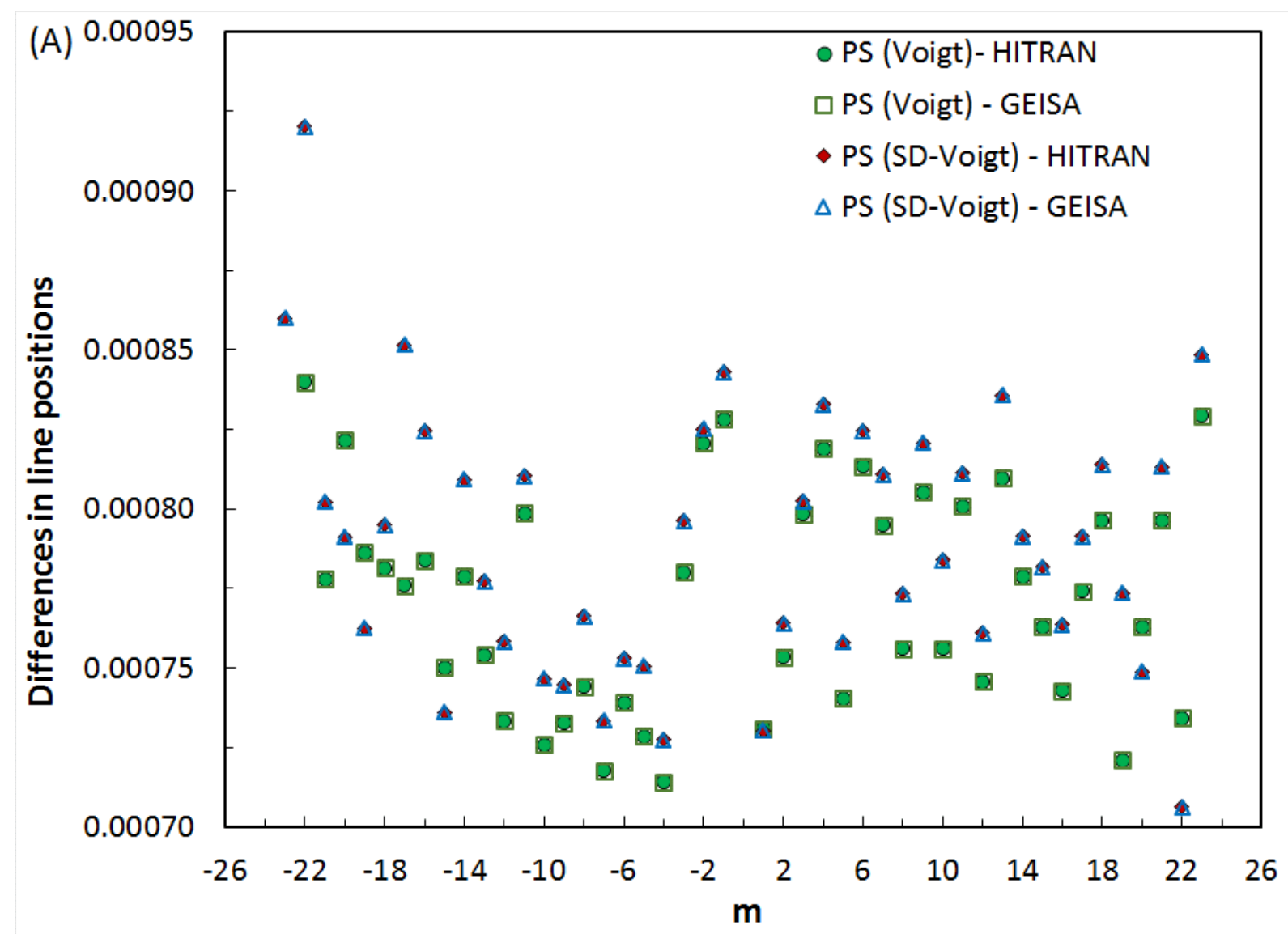



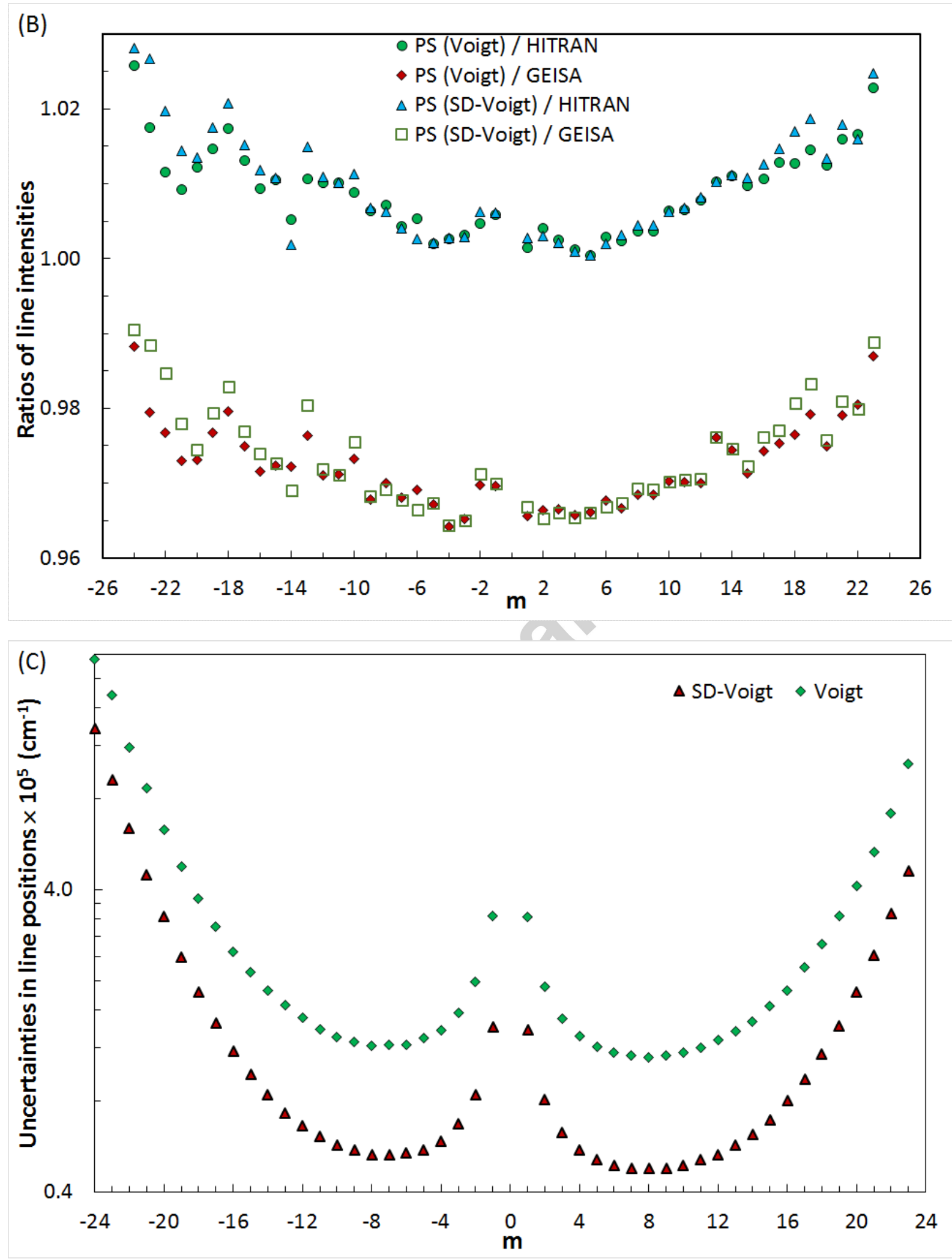


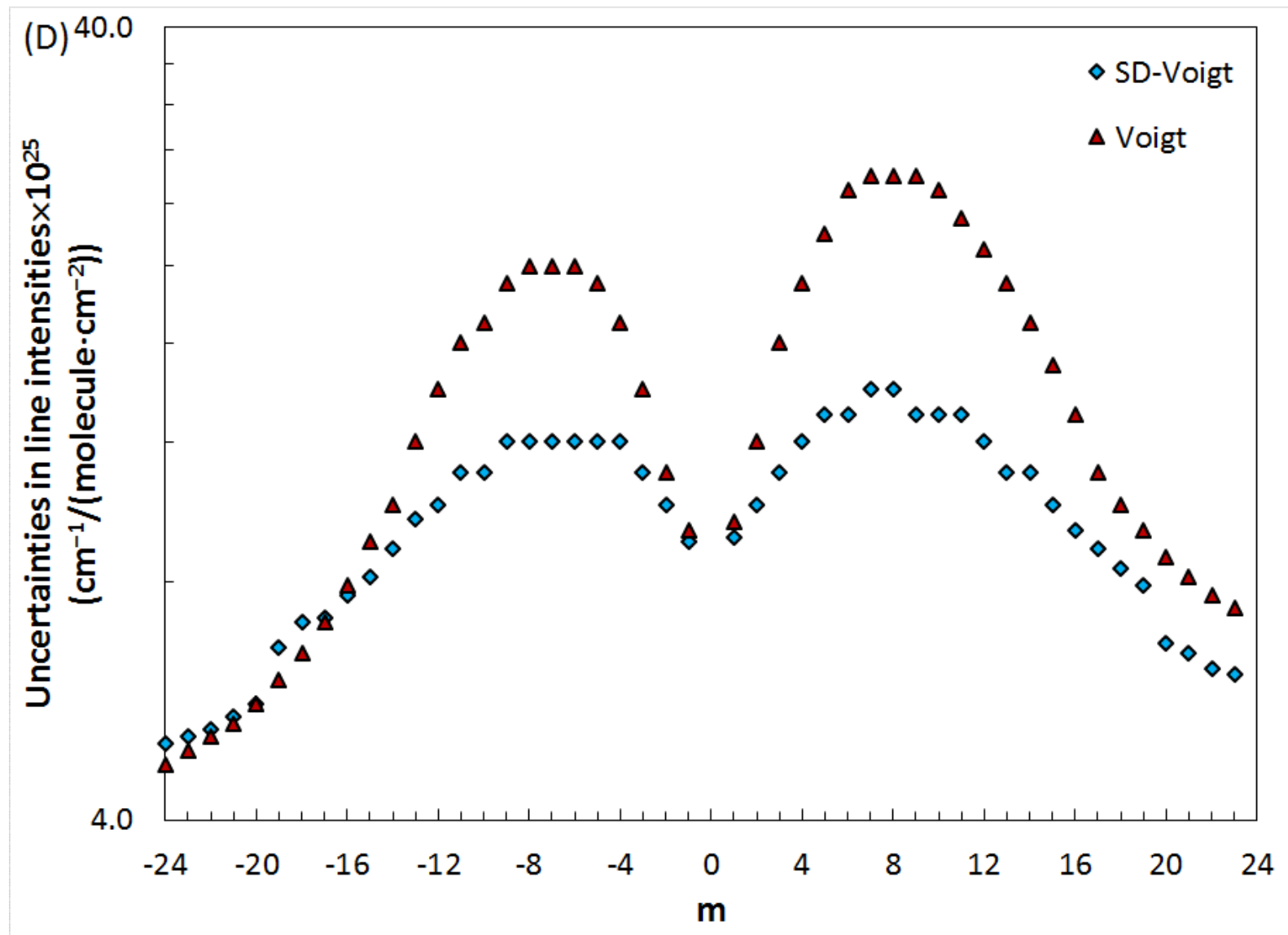



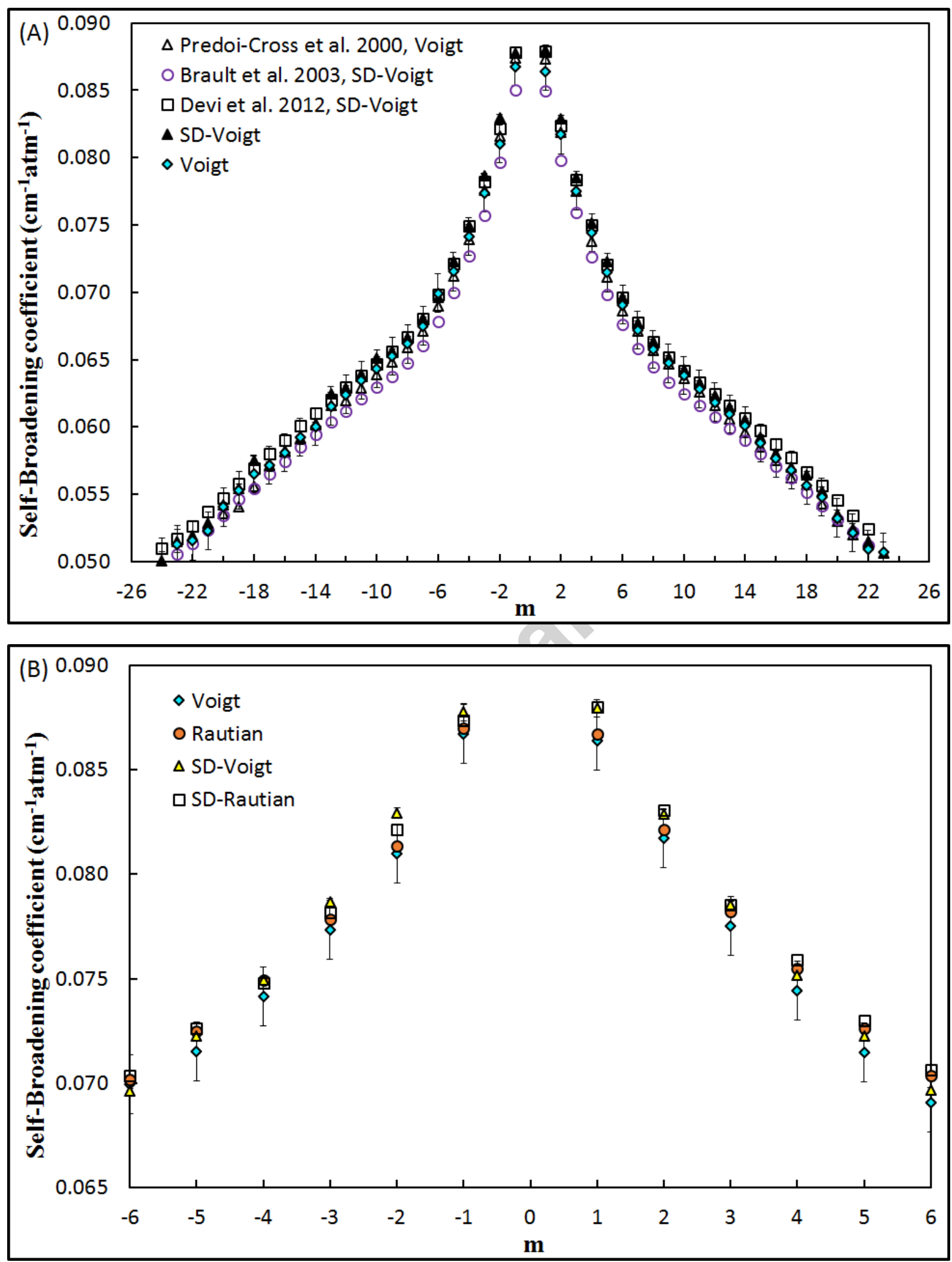


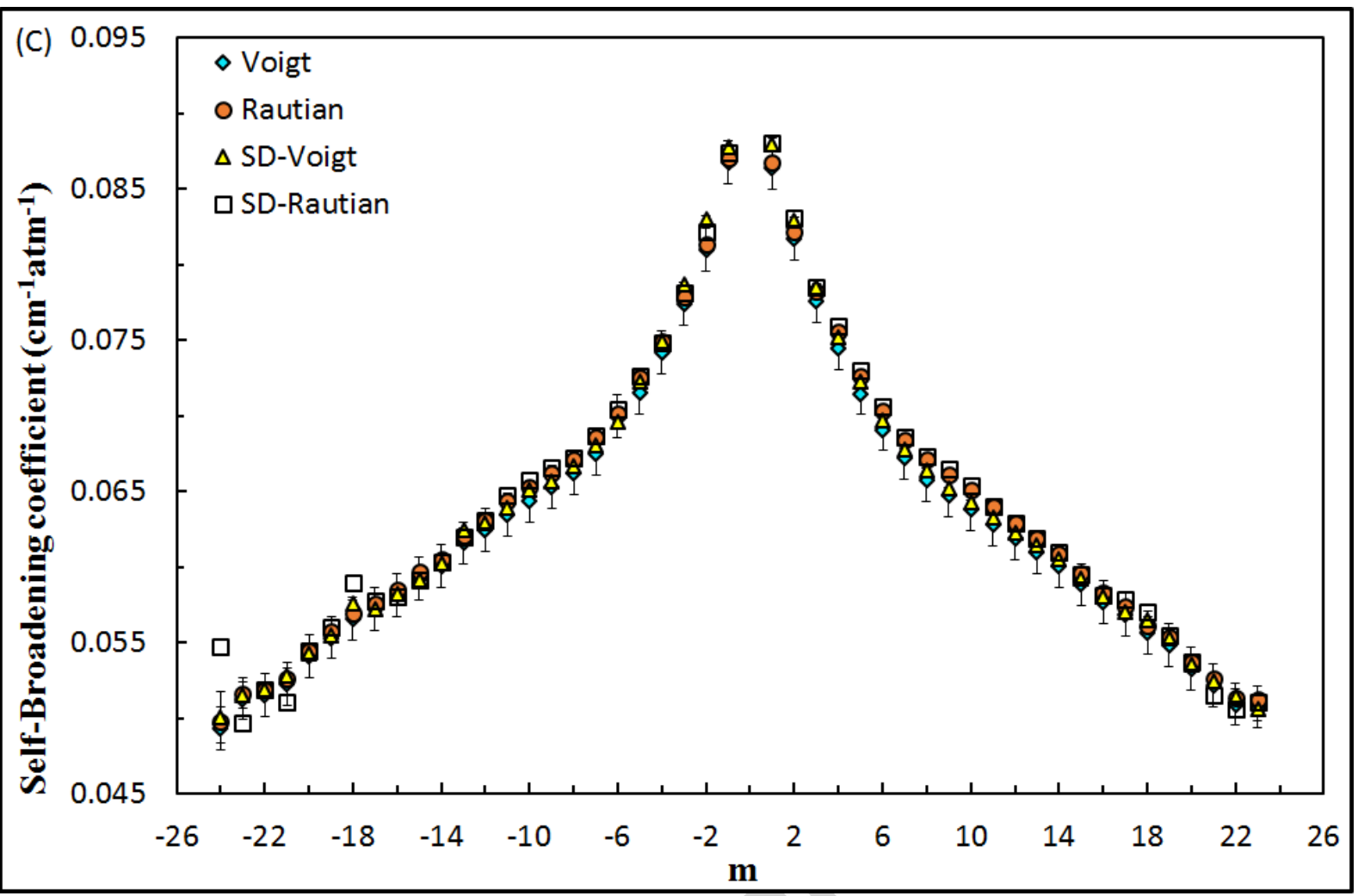



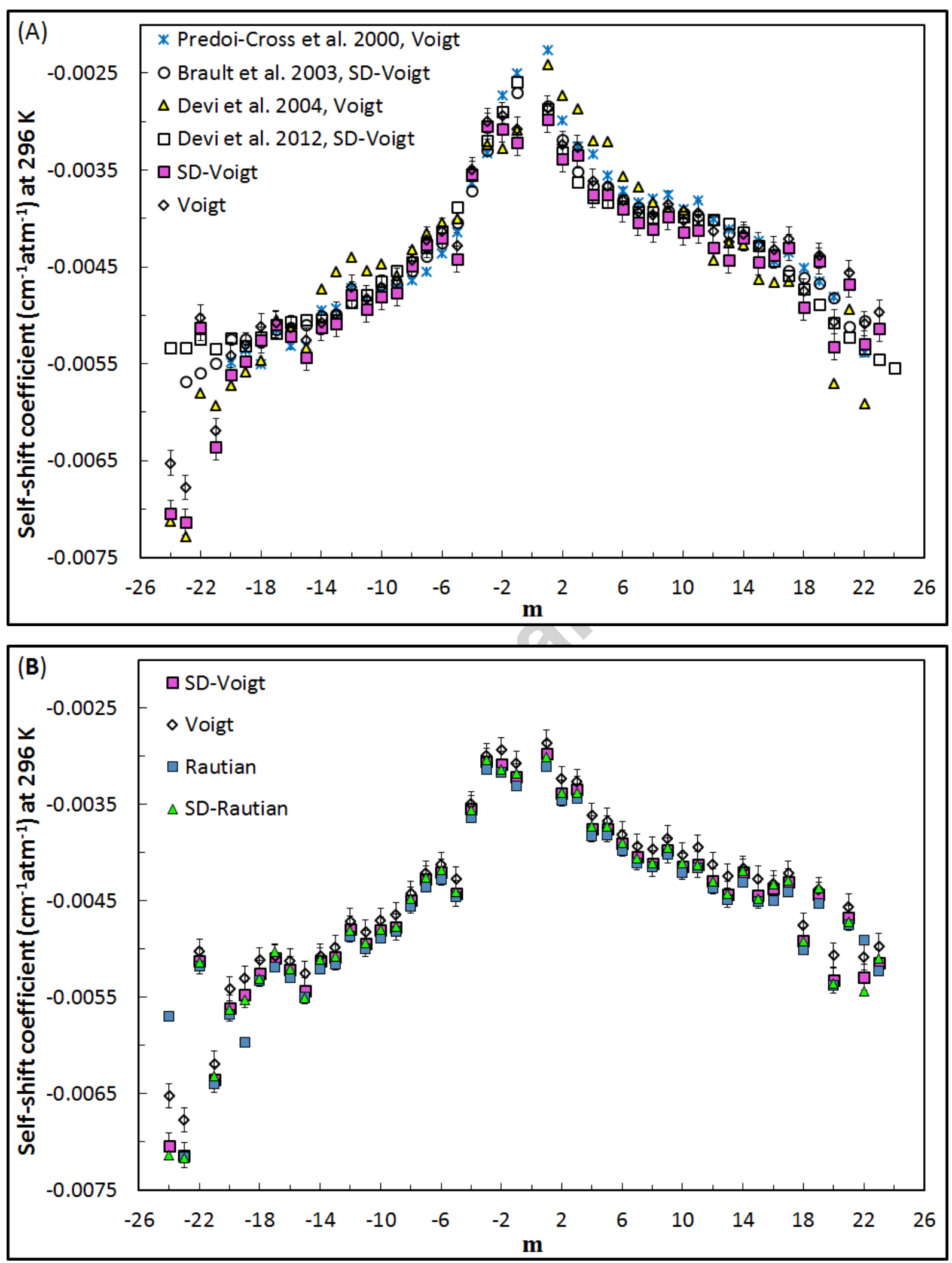


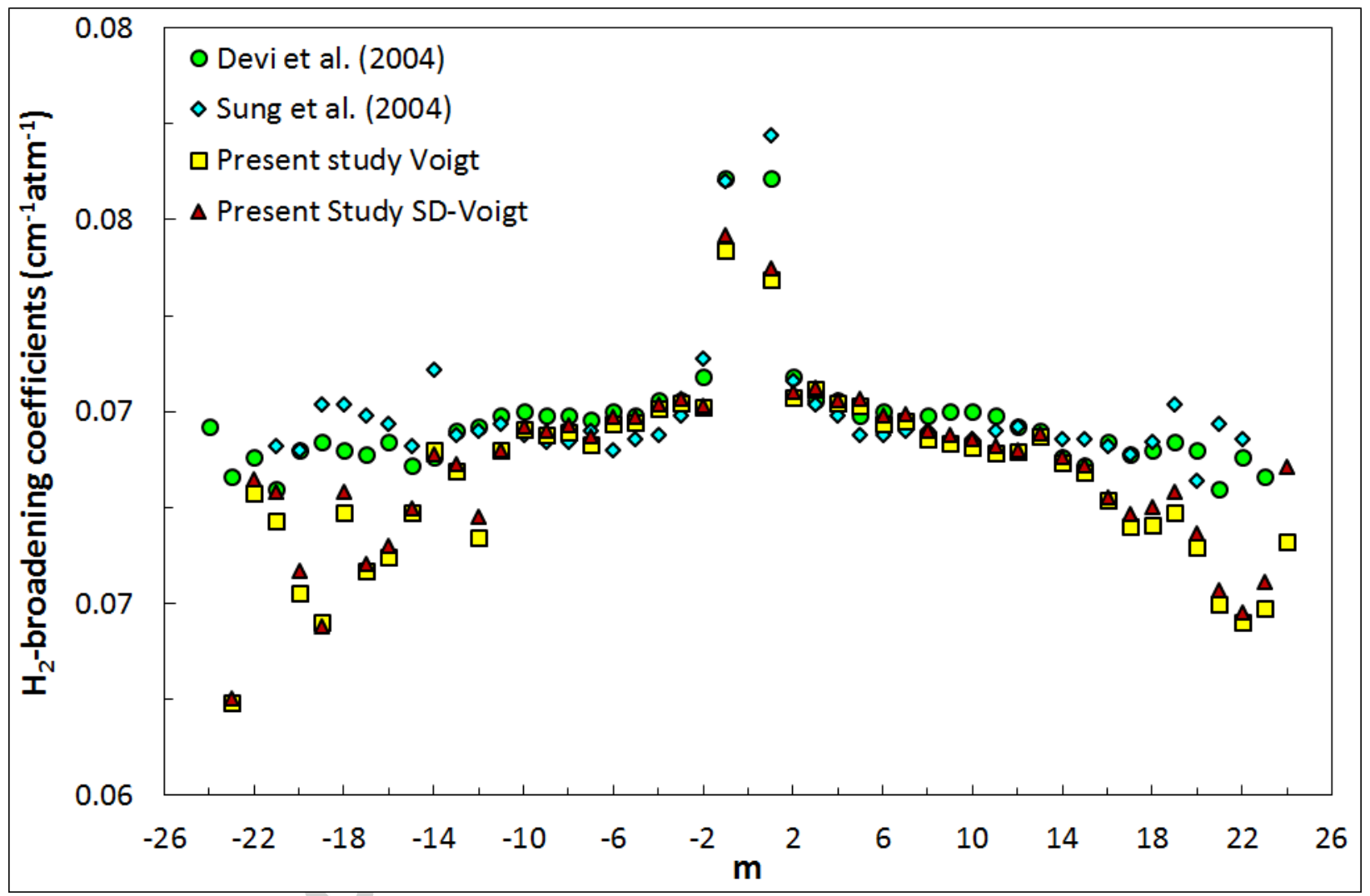




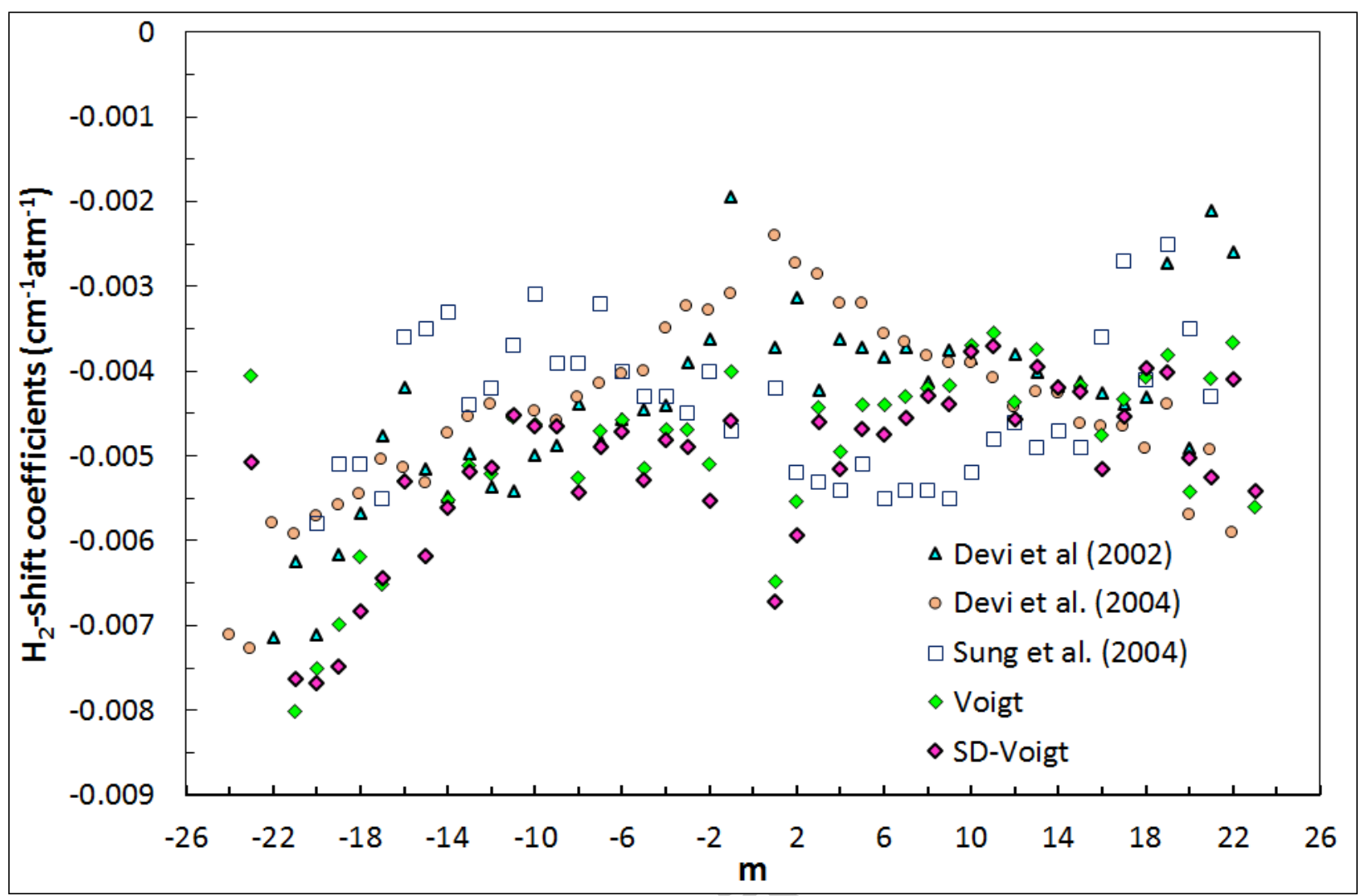



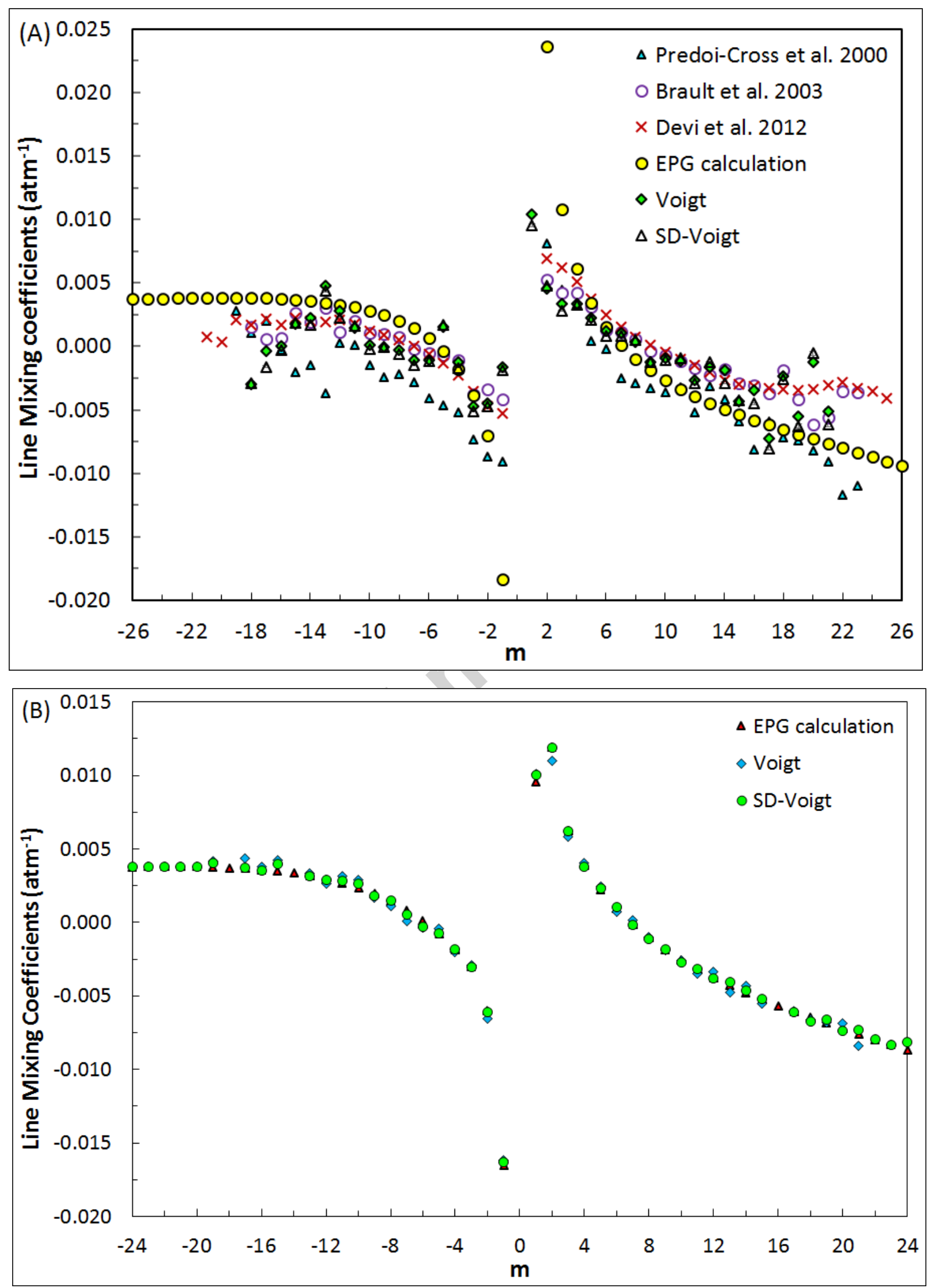


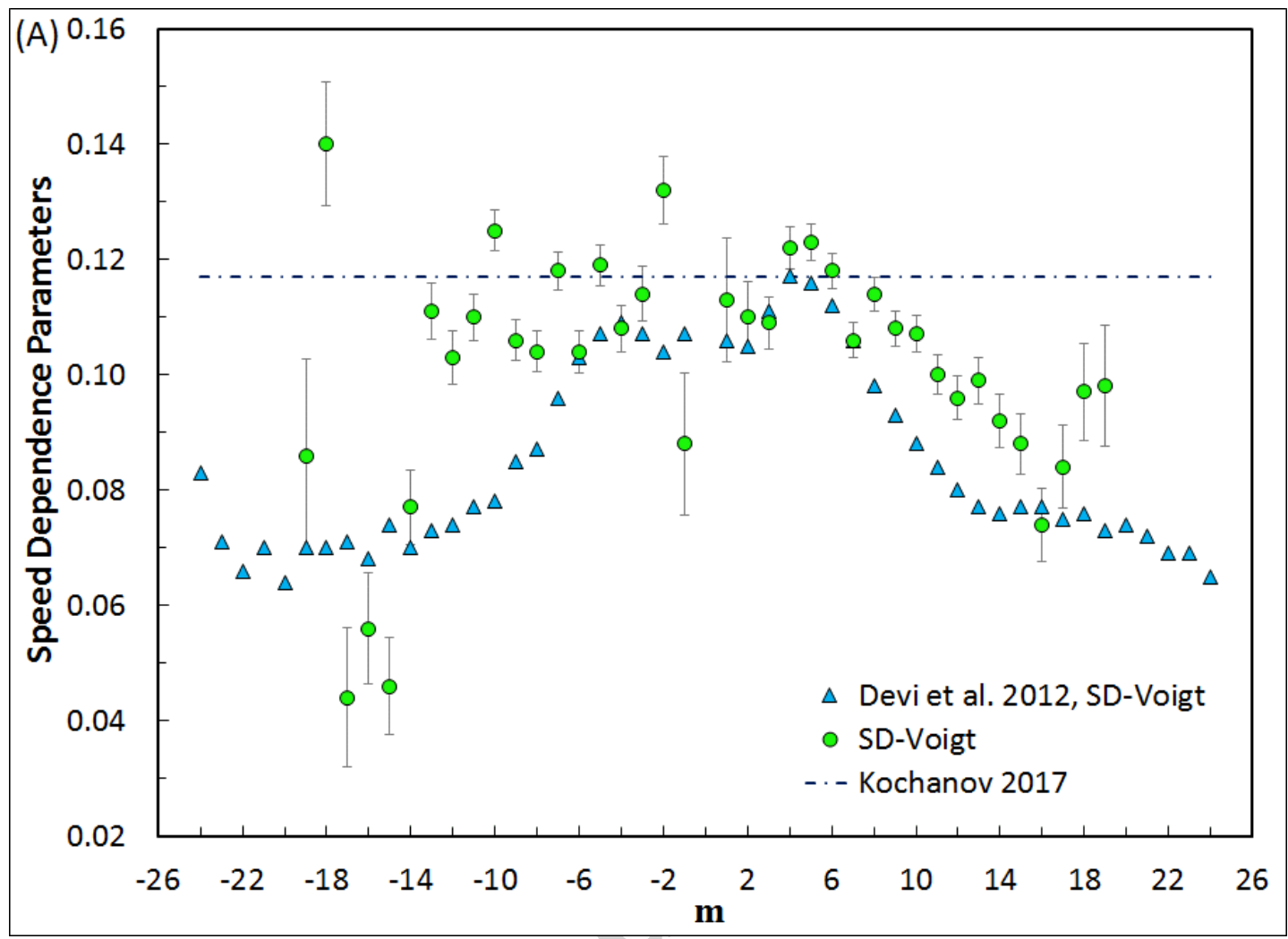




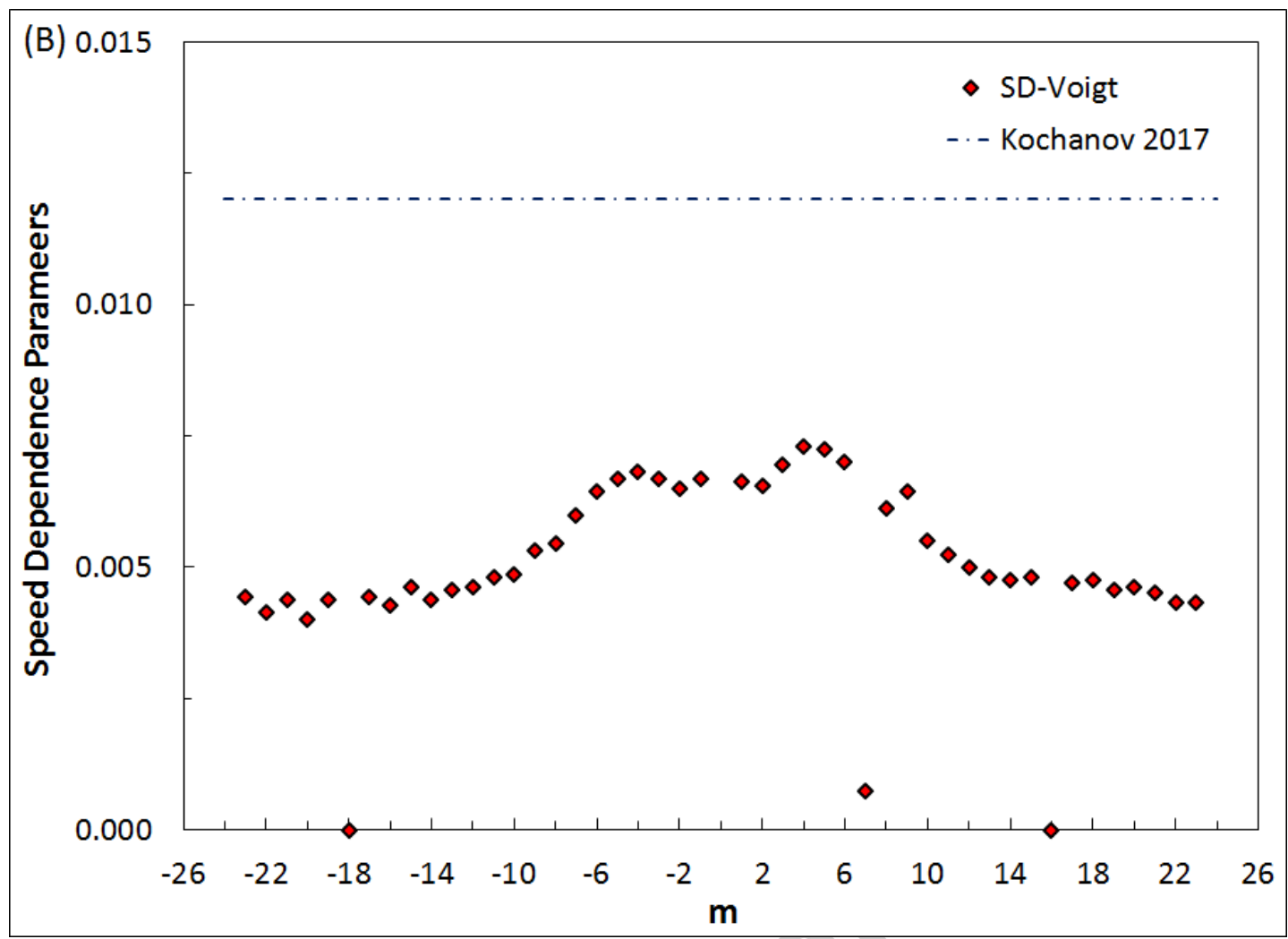



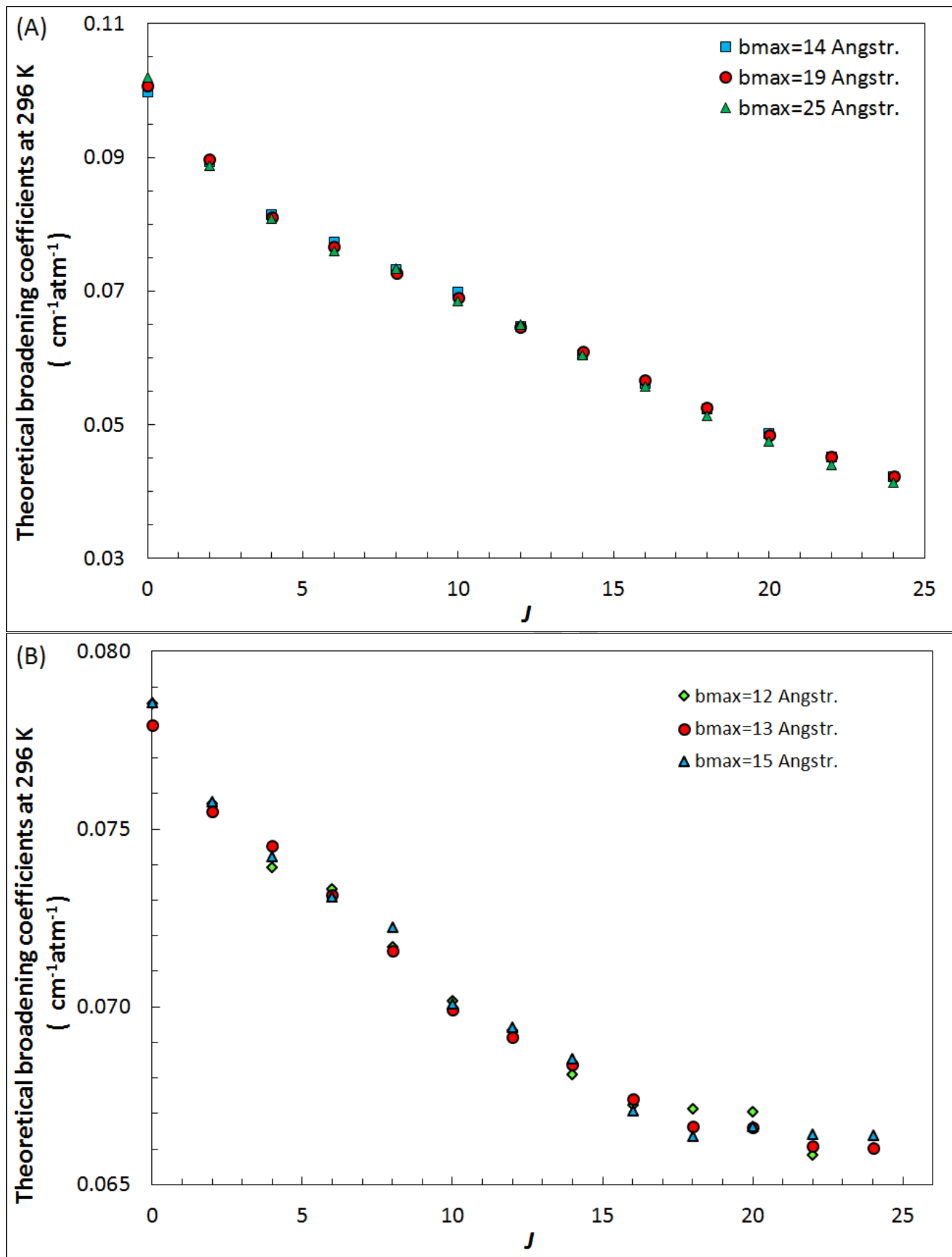


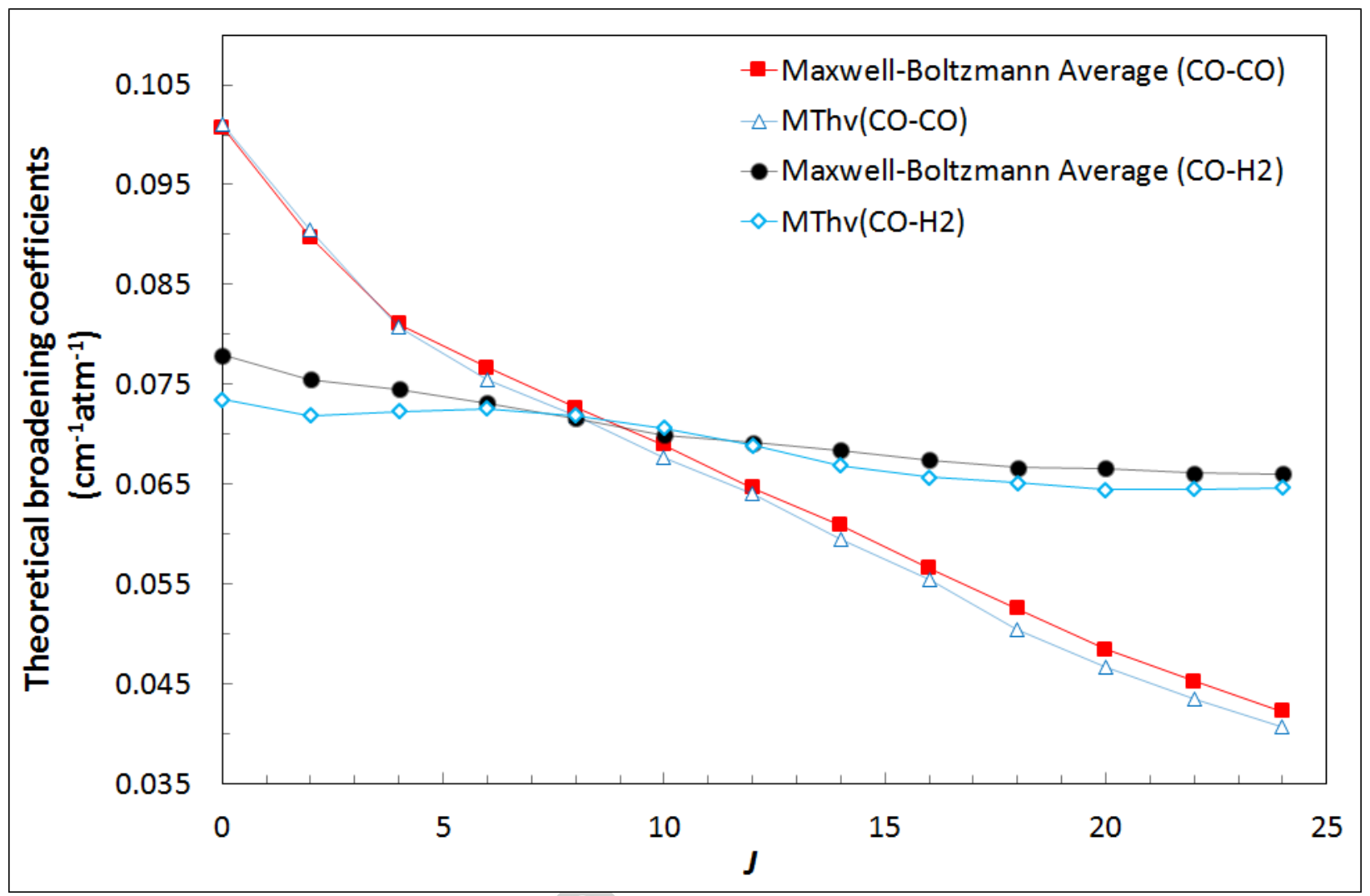




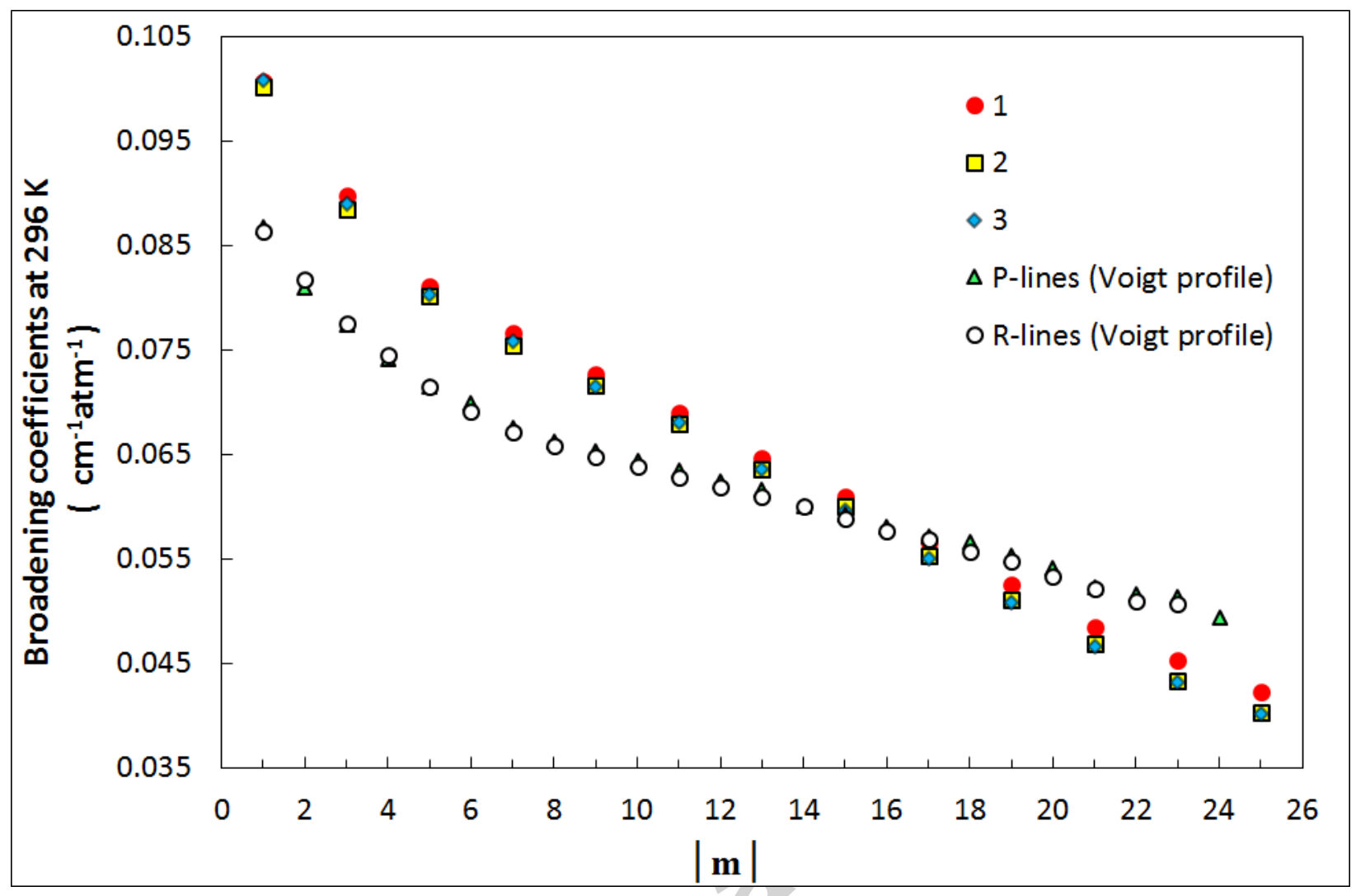




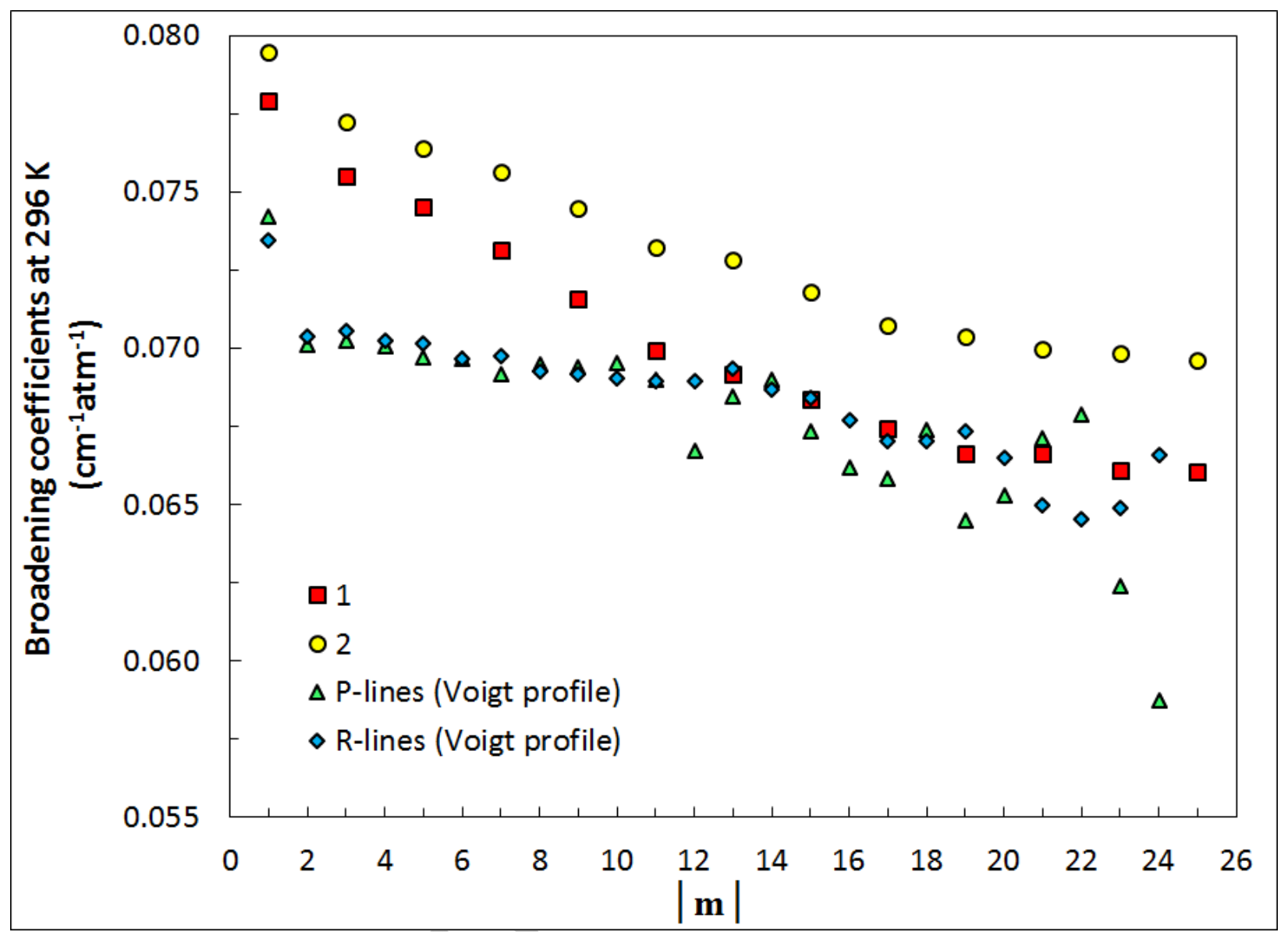




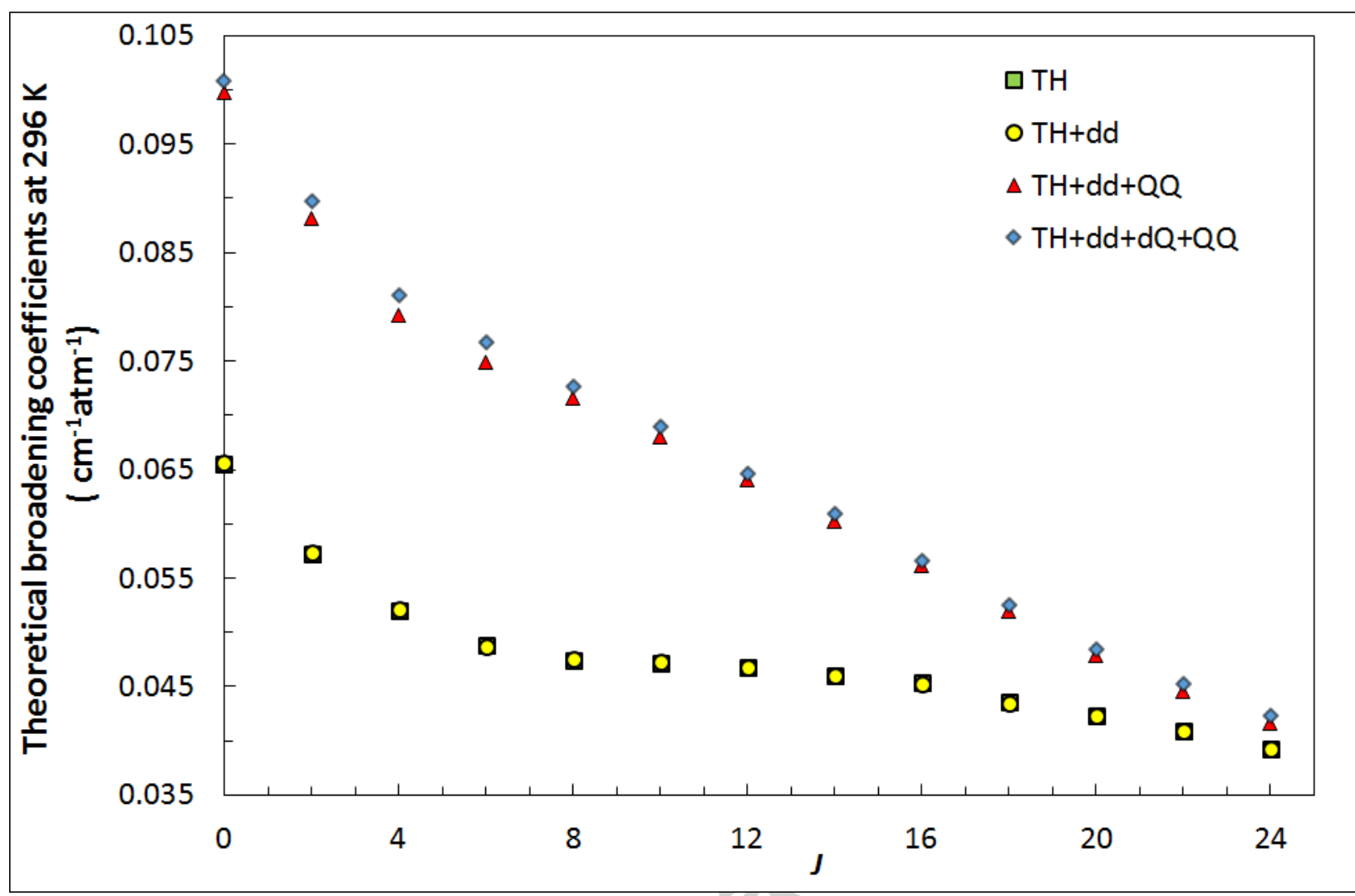




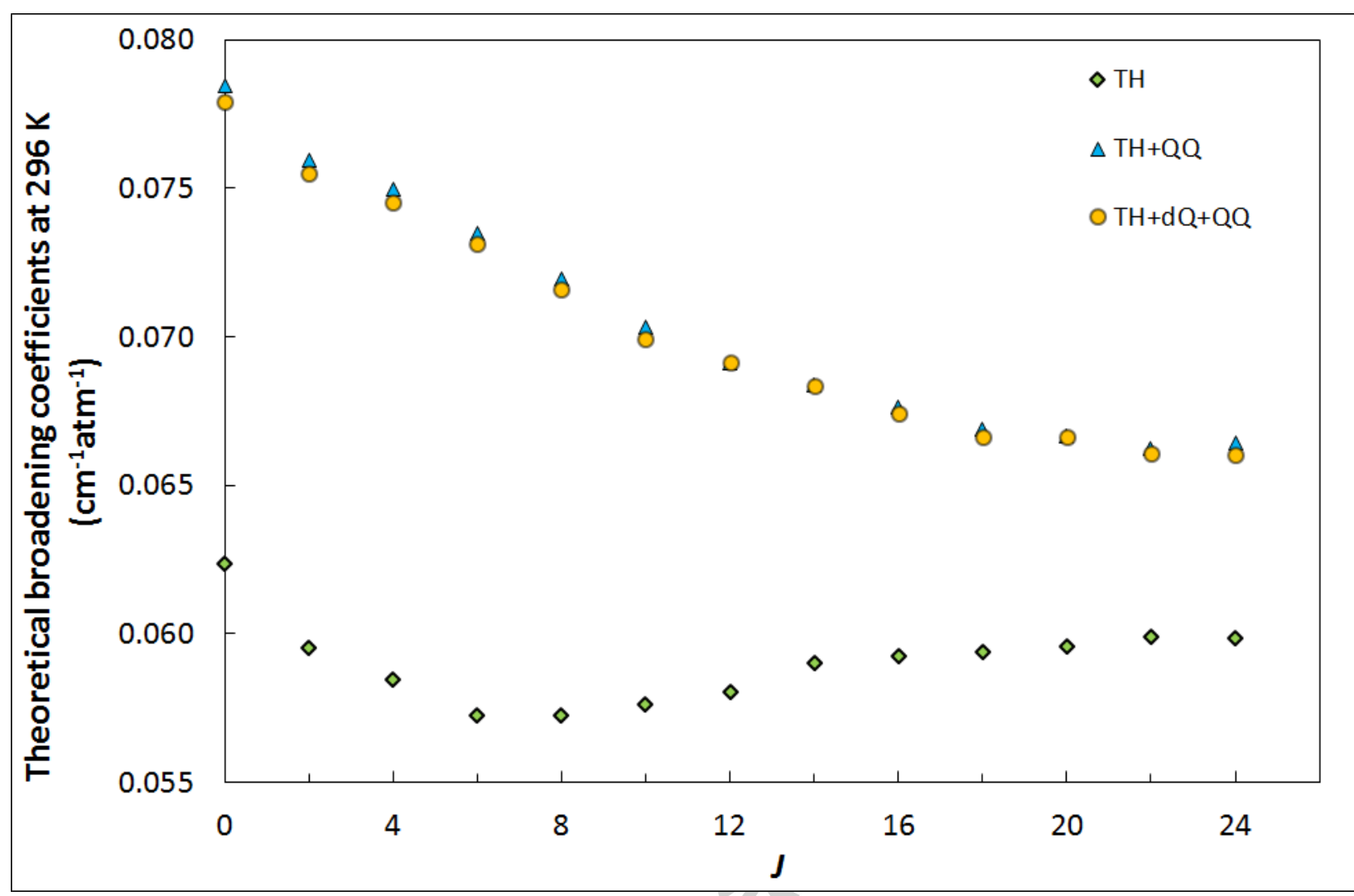

